\title{
Performance of primary healthcare centres in Bengaluru urban district
}

Citation for published version (APA):

Bangalore Sathyananda, R. (2020). Performance of primary healthcare centres in Bengaluru urban district: an evaluation. [Doctoral Thesis, Maastricht University]. Maastricht University. https://doi.org/10.26481/dis.20200901rs

Document status and date:

Published: 01/01/2020

DOI:

10.26481/dis.20200901rs

Document Version:

Publisher's PDF, also known as Version of record

\section{Please check the document version of this publication:}

- A submitted manuscript is the version of the article upon submission and before peer-review. There can be important differences between the submitted version and the official published version of record.

People interested in the research are advised to contact the author for the final version of the publication, or visit the DOI to the publisher's website.

- The final author version and the galley proof are versions of the publication after peer review.

- The final published version features the final layout of the paper including the volume, issue and page numbers.

Link to publication

\footnotetext{
General rights rights.

- You may freely distribute the URL identifying the publication in the public portal. please follow below link for the End User Agreement:

www.umlib.nl/taverne-license

Take down policy

If you believe that this document breaches copyright please contact us at:

repository@maastrichtuniversity.nl

providing details and we will investigate your claim.
}

Copyright and moral rights for the publications made accessible in the public portal are retained by the authors and/or other copyright owners and it is a condition of accessing publications that users recognise and abide by the legal requirements associated with these

- Users may download and print one copy of any publication from the public portal for the purpose of private study or research.

- You may not further distribute the material or use it for any profit-making activity or commercial gain

If the publication is distributed under the terms of Article $25 \mathrm{fa}$ of the Dutch Copyright Act, indicated by the "Taverne" license above, 


\section{(9) CAPHRI Das Mastricht University $\mid(q)$ Maastricht uMc+ Nuffic}

\section{PERFORMANCE OF PRIMARY HEALTHCARE CENTRES IN BENGALURU URBAN DISTRICT AN EVALUATION}

Rajeshwari Bangalore Sathyananda

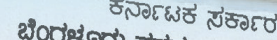

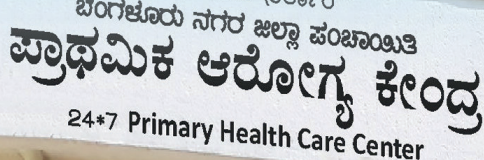
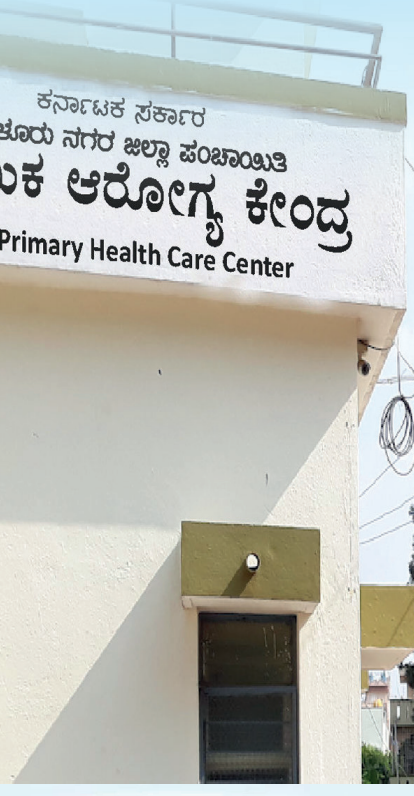



\section{PERFORMANCE OF PRIMARY HEALTHCARE CENTRES IN BENGALURU URBAN DISTRICT: AN EVALUATION}

Rajeshwari Bangalore Sathyananda 


\title{
PERFORMANCE OF PRIMARY HEALTHCARE CENTRES IN BENGALURU URBAN DISTRICT: AN EVALUATION
}

\author{
To obtain the degree of Doctor at Maastricht University, \\ on the authority of the Rector Magnificus Prof.dr. Rianne M. Letschert \\ in accordance with the decision of the Board of Deans, \\ to be defended in public on \\ Tuesday $1^{\text {st }}$ September 2020 at 13:00 hours, CET
}

by

Rajeshwari Bangalore Sathyananda 


\section{Supervisors}

Prof. Dr. C.P. van Schayck

Prof. Dr. A. Krumeich

Prof. Dr. A. de Rijk

Prof. Dr. U. Manjunath (Institute of Health Management Research, Bengaluru, India)

\section{Assessment Committee}

Prof. Dr. J.W.M. Muris (Chair)

Prof. Dr. G. R. Babu (Indian Institute of Public Health, Bengaluru, India)

Prof. Dr. R. Batenburg (Radboud University/ Nivel Utrecht)

Prof. Dr. G.J.A. Hummels 
@ Copyright Rajeshwari Bangalore Sathyananda, Maastricht 2020

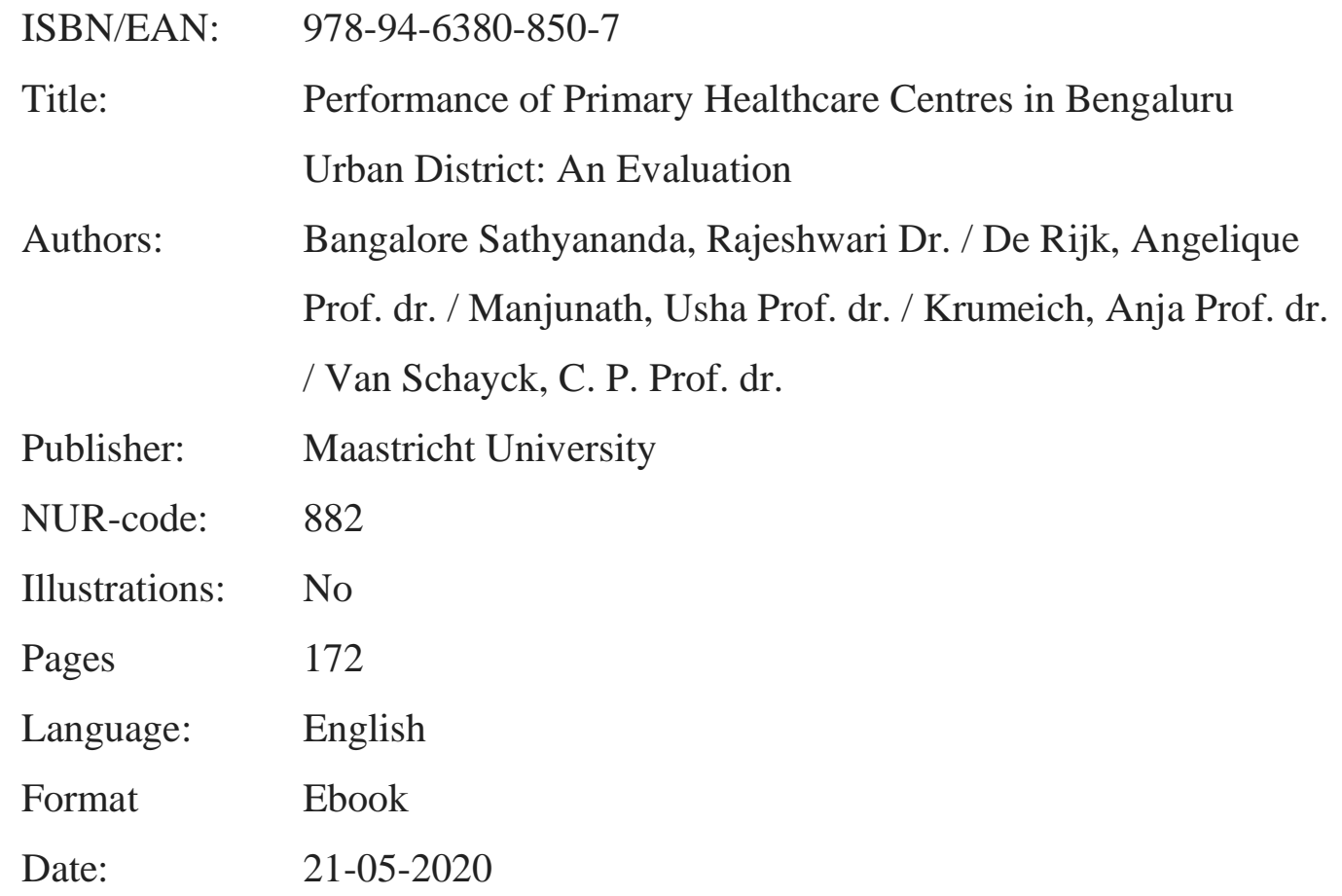

The research presented in this thesis was conducted at CAPHRI Care and Public Health Research Institute, Department- PRIMARY CARE, of Maastricht University. CAPHRI participates in the Netherlands School of Public Health and Care Research CaRe

This research described in this dissertation presents was funded by NUFFIC: CF11830.

All rights are reserved. No part of this book may be reproduced or transmitted in any form or by any means, without the written permission from the author or, where appropriate, the publisher of the article. 


\title{
This Thesis is dedicated to
}

\author{
All the healthcare providers in the public health sector, \\ especially in primary healthcare, who serve the \\ patient community against all odds, contributing towards \\ consistent health improvement
}


Contents

Chapter 1

General Introduction

Chapter 2

Primary Health Centres' Performance Assessment Measures

in Developing Countries: Review of the Empirical

Literature

Chapter 3 Primary Healthcare Centres Performance Assessment:

Perspectives of Patients in India

Chapter 4 Providers' Perspectives on the Performance of Primary

Healthcare Centres in India-The Missing Link

Chapter 5 The Performance of Primary Healthcare Centres from the Manager's Perspective: A Qualitative Analysis

Chapter 6 Performance of PHC and Provider wellbeing: A quantitative analysis of centre, patient and provider related measures

Chapter 7

General Discussion \& Conclusion

Summary

Valorisation

Acknowledgement

About the Author

173 


\section{Chapter 1}

General Introduction 


\section{General Introduction}

This thesis is about performance assessment in Primary Health Care Centres in India. As in most countries, in India, the health of the population as reflected in the life expectancy at birth has been steadily advancing for the last few decades. ${ }^{1}$ However, one of the reasons for this are the multipronged approach in implementing healthcare promotion and preventive healthcare programmes, along with the curative services provided through specified centres known as Primary Healthcare Centres (PHC) ${ }^{2}$, different from some high income countries (HIC) ${ }^{1}$ which address healthcare through different centres. Though India has been committed to primary care since the pre-independence era (1920s), like other low and middle-income countries (LMIC) ${ }^{2}$, it fell short of achieving the Millennium Development Goals ${ }^{3-8}$ until the end of twentieth century. Now, with its commitment to Sustainable Development Goals, India is working on furthering its achievements. ${ }^{9,10}$ One of the requirements for achieving better health is a well-performing health system, thus the performance assessment of PHCs is vital - because if it can be measured, it can probably be controlled and improved. In this introduction, first we look at the global initiative of health system performance assessment. Second, we explore what the patients have to contribute; third we aim to know how providers and performance are related, followed by the contribution of managers. Fifth we explain the context of Indian healthcare and the need for measures to assess PHC performance. Finally we present the aims, research questions, the methodology adopted and the structure of the thesis in this chapter.

\section{Health System Performance Assessment - a Global Initiative}

The specific indicators of PHC performance assessment that are being used in LMIC (developing countries) had been long unknown, with no clear distinction being made between LMICs and HICs. ${ }^{11}$ Literature on the performance assessment of primary healthcare is mostly clustered around the health outcomes. $^{12}$ The World Health Organization (WHO) has developed aspects for universal health system performance assessment. It broadly distinguishes six aspects that must be considered for performance assessment: overall levels of health; the distribution of health in the population; the overall level of responsiveness of the health system; the distribution of responsiveness; the distribution of resources; and the distribution of financial contributions. ${ }^{13,14}$ The indicators enlisted in the WHO framework are extensive and its implementation in the field would need extensive data which would financially burden LMICs that are struggling with resource constraints. ${ }^{15,16}$ Therefore, very often only a limited set of centre characteristics such as number of deliveries, immunization and

\footnotetext{
${ }^{1} \mathrm{HIC}$ are countries with gross national income per capita more than $\$ 12,376$.

2 LMIC are countries with gross national income per capita between $\$ 1,026$ and $\$ 3,995$.
} 
other output indicators is used. The overall health system performance has been assessed by some researchers using econometric methods, which required intensive expert training and would hardly be applicable for the PHC setting. ${ }^{17}$ The applicability of WHO aspects to a PHC setup in India is questionable because of the limited scope of service provision at the centres and the diverse work environments that are influenced by local challenges. The Primary Health Care Performance Initiative (PHCPI), a group consisting of the World Bank Group, the World Health Organization, the University of Toronto, John Hopkins University and other organisations - has developed a framework with performance indicators to assess primary healthcare in developing countries, including LMICs. ${ }^{18}$ The initiative has identified five domains, consisting of system level determinants, inputs, service delivery, outputs, and outcomes. These five domains prescribed by the initiative consist of 10 subdomains and 36 vital indicators focused on assessing the performance of primary care. The details of this framework and the indicators are presented in table 1 .

However, these indicators are mainly intended to monitor health systems which could be considered as distant from the cornerstone of primary healthcare providing organisations. The PHCPI framework does not reflect the local environment and the conditions in which the services are being delivered nor does it reflect the insights from local service providers. The PHCPI indicators are not developed based on the insights from all the stakeholders of primary healthcare that could influence the functioning of the centres. It is unfortunate that the perspective of the providers is largely ignored, as involving providers would enhance the accuracy of performance measurement. ${ }^{19}$ For a deeper understanding, the PHC performance including the perspectives of various stakeholders would lead to a more accurate construction of reality during assessment. ${ }^{20}$

As such, there is need for a study to explore PHC performance indicators that are simple to administer but not limited to only centre characteristics, and that are grounded in the day-to-day functioning of the PHCs in India. Only then, the PHC performance indicators can be expected to enable regular monitoring, and thus enhancing the functioning of these centres. To ground the PHC performance indicators, it is first necessary that the indicators are based on the perspectives of stakeholders. Three stakeholder groups can be distinguished: the patients, the providers of care and the managers. Second, it is necessary to contextualize the PHC performance and thus the specific context of the Indian context needs to be taken into account. The existing knowledge that constitute the basis of this thesis about these three stakeholder perspectives and about the Indian context will be addressed in more detail. 
Table1. Primary Health Care Performance Initiative's Framework of vital performance indicators

\begin{tabular}{|c|c|c|c|}
\hline Sl No & Domain & Sub-domain & Indicator \\
\hline 1 & $\begin{array}{l}\text { System level } \\
\text { Determinants }\end{array}$ & Health Financing & Per capita primary healthcare expenditure \\
\hline \multirow[t]{3}{*}{2} & \multirow[t]{3}{*}{ Inputs } & Drugs and supplies & $\begin{array}{l}\text { Availability of basic equipment } \\
\text { Availability of essential drugs } \\
\text { Availability of vaccines } \\
\text { Facilities with clean water, electricity, sanitation }\end{array}$ \\
\hline & & Facility infrastructure & Health center and health post density \\
\hline & & Workforce & $\begin{array}{l}\text { Community health workers, nurses and midwife } \\
\text { density }\end{array}$ \\
\hline \multirow[t]{3}{*}{3} & \multirow[t]{3}{*}{$\begin{array}{l}\text { Service } \\
\text { delivery }\end{array}$} & Access & $\begin{array}{l}\text { Access barriers due to treatment costs } \\
\text { Access barriers due to distance }\end{array}$ \\
\hline & & $\begin{array}{l}\text { Availability of } \\
\text { effective primary } \\
\text { healthcare services }\end{array}$ & $\begin{array}{l}\text { Provider absence rate } \\
\text { Diagnostic accuracy } \\
\text { Adherence to clinical guidelines } \\
\text { Daily caseload per provider }\end{array}$ \\
\hline & & $\begin{array}{l}\text { High Quality primary } \\
\text { healthcare }\end{array}$ & $\begin{array}{l}\text { Dropout rate } 1^{\text {st }} \text { to } 3^{\text {rd }} \text { DPT } 3 \text { vaccination } \\
\text { Dropout rate } 1^{\text {st }} \text { to } 4^{\text {th }} \text { antenatal visit } \\
\text { Treatment success rate for new TB cases } \\
\text { Care-seeking for symptoms of pneumonia }\end{array}$ \\
\hline 4 & Outputs & $\begin{array}{l}\text { Effective service } \\
\text { coverage }\end{array}$ & $\begin{array}{l}\text { Demand for family planning satisfied with modern } \\
\text { methods } \\
\text { Antenatal care coverage } \\
\text { Skilled birth attendance } \\
\text { DTP3 immunization coverage } \\
\text { Children with diarrhea receiving appropriate } \\
\text { treatment } \\
\text { TB cases detected and cured } \\
\text { People living with HIV receiving ART } \\
\text { ITN coverage for malaria prevention } \\
\text { Cervical cancer screening rate } \\
\text { Hypertension control } \\
\text { Diabetes mellitus control }\end{array}$ \\
\hline \multirow[t]{2}{*}{5} & \multirow[t]{2}{*}{ Outcomes } & Health status & $\begin{array}{l}\text { Maternal mortality ratio } \\
\text { Adult mortality from NCDs } \\
\text { Under-5 mortality rate } \\
\text { Neonatal mortality rate }\end{array}$ \\
\hline & & Equity & $\begin{array}{l}\text { Difference between } 1^{\text {st }} \text { and } 5^{\text {th }} \text { wealth quintiles for } \\
\text { under- } 5 \text { mortality }\end{array}$ \\
\hline
\end{tabular}

\section{Patient's assessment of PHC Performance}

The patients assessment of the PHC has been limited to the evaluation of service utilisation and general patient satisfaction using a standard established questionnaire from HIC. ${ }^{21-23}$ The dimension of satisfaction mostly captures the patient's perceived quality of care delivery, ignoring the local context of patient expectations. ${ }^{21,22}$ However the PHCs in the LMIC could have different structure and functional capabilities ${ }^{24}$ that would need localization and contextualisation of the tools used in data collection to capture the reality. Patient satisfaction in LMIC consisted of satisfaction on clinical and non-clinical services. ${ }^{23}$ Though primary healthcare performance assessment tool is available ${ }^{25}$, it 
is more focussed on the system in a HIC with managed care, thus there is need for a new tool that is context specific and locally applicable.

\section{Contribution of Providers in PHC Performance}

There is considerable literature about the determinants of performance of health care providers in general, mostly from HICs. ${ }^{26,} 27$ Literature on PHC performance from provider perspective is very limited, with provider's in LMIC, identifying the establishment of bonds, patient's experiences and delivery of the programs implemented at the centres as performance. ${ }^{28-30}$

Providers who are engaged with their work, perform better. ${ }^{31}$ Performance in primary health care may be distinguished as both process performance and outcome performance. ${ }^{32}$ Individual health care professional performance can be studied from three perspectives: individual perspective, situational perspective and performance regulation perspective and all three perspectives can contribute to understanding their performance. The individual perspective adds to the understanding of how individual factors relate to performance. The situational focuses on environmental factors that affect worker well-being, which in turn influences worker performance. ${ }^{32}$ There is considerable evidence for the link between provider well-being, engagement, and performance in HIC among healthcare professionals. ${ }^{32,33}$ Promoting performance through provider well-being, however, is not an easy feat. ${ }^{32}$

\section{Performance from provider's perspective}

Research in LMIC and HMIC on performance in general healthcare is also being influenced by the leadership of providers who are able to improve the local circumstances at the centres. ${ }^{34-47}$ There is debate on which styles are most effective. ${ }^{34}$ Further, the explanatory mechanism is not clear. The literature indicates that leadership showing the right attitude, good behaviour and communication, facilitated collaboration between various providers, whereas efficient nursing depended on strong, consistent and knowledgeable leadership. ${ }^{34-36}$ Empirical research has shown that motivated leaders inspire their followers to perform their best and enrich the work environment, which would in turn enhance employee job satisfaction and thus augment provider well-being and patient satisfaction. ${ }^{37-47}$ Also, though there is evidence that the provider's Quality of life is linked to their productiveness and quality of care ${ }^{48-49}$, there is no established link in the PHC in an LMIC and the probability that it can depict the performance. 
Healthcare managers and performance

The opinion of managers who are responsible for the functioning of these PHCs are important as they deal with the operations of the centre and interact with the higher system gaining the most valuable insight. In the literature managers from LMIC have assessed the performance as the health indicators, provision of facility in delivering services, performance of the individual staff in care delivery and their own practices of supervision. ${ }^{50}$ If the managers demonstrate better leadership it would lead to enhanced healthcare delivery in-turn improving the health of the population. ${ }^{38}$ Thus capturing their opinion on the performance of the centre plays an important role.

\section{Context of Indian Primary Healthcare}

India, being committed to achieving Sustainable Development Goals, is faced with regional disparities regarding health indicators for such as mortality, infant mortality and immunisation rate. ${ }^{2,51}$ This disparity is further complicated by the burden of out-of-pocket expenditure in healthcare that is contributing to the impoverishment of the population. ${ }^{52-54}$ The challenges in the system are the disparity in the density of the health workforce, and the lack of supportive supervision within the health system, as well as the tendency to blame the weakest link. To overcome these challenges, India has committed to Sustainable Development Goal 3.C to strengthen health system by substantially increasing recruitment, development, training and retention of the health workforce. ${ }^{10}$ The recommended strategy to strengthen the health system is to recruit health workers, re-shift tasks by creating midlevel service providers, and promoting a culture of problem solving, accountability, responsiveness and team functioning. ${ }^{10}$ Though these strategies have been identified by the government, the contribution of the existing providers and their wellbeing to sustained care, the voices of the patients, providers and managers, and local circumstances during service delivery have been long ignored.

The healthcare sector in India is diverse and vast, with both private and public players using alternative healthcare methods to cater to the health of the population. ${ }^{55}$ This public health system which is government owned and operated forms a small component of the healthcare system in India, but significantly contributes to the health of the population with its focus on disease prevention and health promotion in the general public. As per the norms of the Indian Public Health Standards, the PHCs cater to the health of around 30,000 people, meaning they are critical to grassroots care.

In India, there are two kinds of PHCs based on the working hours and service provision, such as the availability of 24-hour baby delivery services for pregnant women. The PHCs that work round the clock are called 24/7 PHCs and have doctors, nurses, pharmacists, a laboratory technician, 
optometrists, health assistants and other non-care provider staff (clerks and cleaning staff), who are managed by an Administrative Medical Officer.

The non-24/7 PHCs operate only during the day and have only one doctor along with few nurses/other staff. Organisationally, each PHC has five to eight subcentres for a group of villages, and each subcentre is served by Junior Health Assistants (JHAs, both male and female) who handle a population of 5,000, primarily providing the community with health education and preventive healthcare. ${ }^{24}$ The functioning of the PHC is being evaluated by the achievement of the set targets (services delivery and national health program implementation) by the centres. Considering the importance of well-functioning PHCs in ensuring the health of the population, the monitoring and performance evaluation of these centres is significant.

The Indian government is working on universal health coverage to enhance the health of the population through the Ayushman Bharat Scheme, which includes the establishment of Health and Wellness Centres for rendering comprehensive primary healthcare, and the National Health Protection Scheme to cover hospitalisation costs. ${ }^{56}$ The National Health Protection Scheme is an effort to provide health coverage to poor and vulnerable population for secondary and tertiary care. Though these are called wellness centres, they are different from what it means in a HIC, in being a centre for healthcare and wellbeing of people. The wellness centres are upgraded sub-centres and rural PHCs that help bring comprehensive primary healthcare, including aid for non-communicable diseases and maternal and child health services, closer to the general public. ${ }^{57}$ These wellness centres would have a multipurpose health worker and Accredited Social Health Activists reporting to a mid-level health provider - a person with nursing background. A cluster of these wellness centres will be associated with a PHC to serve as a first point of referral for treating diseases, and the Medical Officer of the PHC would be responsible for the services and administration of these centres.

In India, monitoring the public health system is an ongoing process as part of managing the health department and various implemented government health programmes. The government of Karnataka had been utilising data from the Health Management Information System to monitor the health systems, which consisted of evaluations for six components in the centres: human resources, infrastructure, drugs and supplies, service availability, patient-orientation and service utilisation. ${ }^{58}$ The Indian Ministry of Health and Family Welfare has been emphasising quality improvement of healthcare centres at various levels. This is based on a long list of measures which would need extensive data collection from the care centres. ${ }^{59}$ The Ministry also set out the Indian Public Health Standards (IPHS) as a set of guidelines for establishing public healthcare centres. ${ }^{24}$ The IPHS 
guidelines for PHCs include the availability of infrastructure, human resources and service at these centres, but they do not cover the process of care delivery. ${ }^{24}$

\section{Current necessity for PHC performance measure in India}

While more centres are being established and new providers are recruited in India, the necessity of a measurement instrument for PHC performance that is easy to administer, fitting with stakeholder perspectives and with the Indian context in enhanced, even though different perspectives may vary without any overlap. To keep the measurement instrument easy to administer, utilising the primary and secondary data in optimum proportion would take advantage of the available resources. ${ }^{15}$ Therefore, research on measurement instrument and the interdependence between different measures of PHC is needed.

\section{Aims of the Research}

With this research we intend to fill the gap in the understanding of how to assess the performance of PHCs. The research questions addressed in this thesis are:

1. How are PHCs being evaluated in developing countries? What measures/indicators of PHC performance have been utilised in empirical literature in developing countries? (Chapter 2)

2. What are PHC performance indicators from the perspectives of various stakeholders of the PHCs? The stakeholders considered are:

- $\quad$ The patients (Chapter 3)

- The providers (Chapter 4)

- The mid-level healthcare managers in India (Chapter 5)

3. How can we assess PHC performance from multiple perspectives? What are the relationships between various perspectives of PHC performance assessment? (Chapter 6)

4. What criteria contribute to the existing health system performance frameworks? (Chapters 7)

\section{Methodological consideration and Data analysis}

\section{Study Design}

A mixed (qualitative and quantitative) research methodology was employed in this study to explore the opinions of patients, providers, and managers and to assess the performance of the PHCs from multiple perspectives. The qualitative research was conducted based on the principles of the Responsive Evaluation methodology (also called Fourth Generation evaluation) with aim to explore the concerns, claims and beliefs of patients, providers, and managers with regards to the performance of PHCs. ${ }^{20}$ The quantitative research consisted of an evaluation of the centres from various 
perspectives. The centre performance was assessed based on the traditional centre characteristics' indicators (the availability of the infrastructure and the quantity of the services delivered), whereas the providers were assessed based on their quality of life and their work engagement. The performance of the centre was further assessed by the patients using a questionnaire newly developed for the current research. This quantitative research was conducted to explore various patterns between the perspectives within the centres.

\section{Study sites}

This research was conducted in three PHCs located in the urban district of Bengaluru, Karnataka State, India. The Bengaluru urban district is administratively divided into four talukas or blocks, and there are 20 PHCs that operate 24 hours a day, seven days per week. The number of pregnant women who delivered babies at these centres are related to the number of patients utilising the services and their perceived quality of care at the PHC, thus reflecting the general performance of the PHC concerned; this information is reflected in the reports on performance assessment. ${ }^{52,}{ }^{60}$ Hence, the PHCs were selected based on the basis of the number of pregnant women who delivered babies in the centre for the population covered in the financial year 2016-2017. The high, medium and low delivery loads in relation to the population served per PHC was considered to include centres with diverse service provision in the study.

Ethics

The study was approved by the Manipal University Ethics Committee, Manipal University, Manipal, Karnataka. Ethics in research procedures were followed in the study by obtaining written consent from the participants. Participation in the study was voluntary and the confidentiality of participants was ensured. Participants could refrain from giving input where they so desired and were free to exit the study at any point.

Data analysis

The personal details of the interviewees were removed from the recorded interviews to ensure confidentiality. The recorded interviews were translated into English by professionals, transcribed and analysed thematically using ATLAS-TI software to develop primary and secondary codes, and to identify various themes. ${ }^{60}$ The quantitative data was entered, cleaned and analysed using SPSS 25. All data is analysed statistically by ANOVA and Scheffé tests to compare between PHCs and distinguish patterns in order to identify the most suitable performance indicators.

The results of this analysis are presented in the following chapters. 


\section{Outline of the Thesis}

In chapter 2, we present the systematic review of empirical literature on performance assessment measures for Primary Health Centres in developing countries. This review expands and enriches the more general WHO aspects in order to better attune them to the specific performance measurement of PHC centres.

In chapter 3, we explore the performance of PHCs from the perspective of the patients in India, to provide an overview of the kind of assessment criteria that patients brought forward during their visits to the PHC.

In chapter 4, we explore what criteria health care providers would use to assess PHC performance. During interviews with providers in selected PHCs, they gave us insight into their perspectives in relation to the WHO aspects for performance assessment and the PHCPI framework. These indicators not only signal whether a PHC is performing well or not, but also form a 'missing link' connecting demands from external and internal customers to improve delivery of care and hence the health of the population.

In chapter 5, we explore various indicators of PHC performance from the perspectives of the midlevel managers of the PHCs.

In chapter 6, we describe how we developed and used a holistic model to assess PHCs. This included the perspectives of the healthcare centres, the providers and the patients using the new 'Questionnaire for Patient's Perspective on Performance of Primary Healthcare Centres', which was developed using the views of the patients from chapter 3.

In Chapter 7, we discuss the results of all the studies in order to gain insight into how PHC performance in India can best be measured, and we discuss implications on public health policy. This chapter also presents recommendations for future research into PHC performance assessment aimed at improving the functioning and sustainability of the centres. 


\section{References}

1. https://data.worldbank.org/indicator/SP.DYN.LE00.IN?locations=IN\&view=chart Accessed on $20^{\text {th }}$ December 2019.

2. National Health Policy 2017. Ministry of Health and Family Welfare, Government of India. https://mohfw.gov.in/sites/default/files/9147562941489753121.pdf Accessed on 25th November 2019.

3. Bhore committee 1946. https://www.nhp.gov.in/bhore-committee-1946_pg Accessed on 1st December 2018.

4. UN Press release 2015. Maternal death ratio has fallen 44 percent since 1990-UN. https://www.unfpa.org/press/maternal-death-ratio-has-fallen-44-cent-1990-\%E2\%80\%93-un. Accessed on 7 Oct 2016.

5. The Global strategy for women's children's and adolescent's health 2016-2030: survive thrive transform 2015. http://www.who.int/life-course/partners/globalstrategy/globalstrategyreport2016-2030-lowres.pdf?ua=1. Accessed on 7 October 2016.

6. Donnay F. Maternal survival in Developing countries: what has been done, what can be achieved in the next decade. International Journal of Gynaecology and Obstetrics. 2000;70:89-97.

7. Urban health report.2016. http://apps.who.int/iris/handle/10665/204715.Accessed on 7 Oct 2016.

8. Global status report on non-communicable diseases 2014. https://apps.who.int/iris/bitstream/10665/148114/1/978941564854_eng.pdf?ua=1. Accessed on 7 Oct 2016.

9. The Sustainable Development Goals 2016. http://www.un.org/sustainabledevelopment/development-agenda/2016. Accessed on 4 Jan 2016.

10. Sustainable Development Goals: Agenda 2030, India 2017 A Civil Society Report https://gcap.global/wp-content/uploads/2018/07/Sustainable-Development-Goals-2018.pdf Accessed on 21st November 2019.

11. Kurk M E, Freedman L P. Assessing health system performance in developing countries: A review of literature. Health Policy. 2008;85:263-276. 
12. Munar W, Snilstveit B, Aranda L E, Biswas N, Baffour T, Stevenson J. Evidence gap map of performance measurement and management in primary healthcare systems in low-income and middle-income countries. BMJ Global Health.2019;4:e001451. Doi:10.1136/bmjgh-2019001451.

13. The World Health Report 2000. Health Systems: Improving Performance. https://www.who.int.en. Accessed 1 Nov 2014.

14. Health Systems Performance Assessment: Debates, Methods and Empiricism. WHO Publication. 2003. http://www.who.int/health_financing/documents/cov-hspa/en/. Accessed on 10 Sept 2015.

15. Groene O, Skau J K H, Frolich A. An international review of projects on hospital performance assessment. International Journal of Quality in Health care. 2008;20(3):162-171.

16. Albuquerque I F, Cunha R C. Martins S D, Brito A Sa. Primary health care services: workplace spirituality and organizational performance. Journal of Organizational change management. 2014;27(1): 59-82. https://doi.org/10.1108/JOCM-11-2012-0186.

17. Tandon A, Murray C J L, Lauer J A, Evans D B. Measuring Overall Health System Performance for 191 Countries. GPE Discussion Paper Series: No.30. EIP/GPE/EQC. World Health Organization. https://www.who.int/healthinfo/paper30.pdf (Accessed on 13 Aug 2014).

18. Veillard J, Cowling K, Bitton A, Ratcliffe H, Kimball M, Barkley S, Mercereau L, Wong E, Taylor C, Hirschhorn L R, Wang H. Better Measurement for Performance Improvement in Lowand Middle-Income Countries: The Primary Health Care Performance Initiative (PHCPI) Experience of Conceptual Framework Development and Indicator Selection. The Milbank Quarterly. 2017;95(4):836-883.

19. Thier S O, Gelijns A C. Improving Health: The reason performance measurement matters. Health Affairs. 1998;17(4):26-28. www.healthaffairs.org. Accessed on $9^{\text {th }}$ Dec 2019.

20. Guba E G, Lincol Y S. Fourth Generation Evaluation 1989;21-49, Sage Publication.

21. Varatharajan D, Thankappan R, Jayapalan S. Assessing the Performance of Primary Health Centres Under Decentralized Government of Kerala, India. Health Policy and Planning. 2004;19(1):41-51.

22. Awadalla H I, Kamel E G, Mahfouz E M, Refaat T M. Evaluation of Maternal and Child Health Services in El-Minia City, Egypt. Journal of Public Health. 2009;17(5):321-329. 
23. Lannes L. Improving health worker performance: The patient-perspective from a PBF program in Rwanda. Social Science and Medicine. 2015;138:1-11.

24. Indian Public Health Standards 2016. http://nhm.gov.in/nhm/nrhm/guidelines/indian-publichealth-standards.html (Accessed on 12th November 2018). 47

25. Primary Care Assessment Tools. http://www.jhsph.edu/research/centers-and-institutes/johnshopkins-primary-care-policy-center/pca_tools.html. Accessed on 12 Oct 2016.

26. Fort A L, Voltero L. Factors affecting the performance of maternal health care providers in Armenia. Human Resources for Health. 2004;2-8. https://doi.org/10.1186/1478-4491-2-8.

27. Kalinichenko O, Carla A F, Santos S P. Performance Assessment in Primary Health Care: A systematic Literature Review. CEFAGE-UE Working Paper 2013/03. www.cefage.uevora.pt/en/content/download/3466/45683/version/1/.../2013_03.pdf. (2013). Accessed 10 Oct 2015.

28. Shreedevi D. Gap analysis and the performance of primary health centres in the implementation of the school health programme of NRHM. International journal of Research in Business Management. 2014;2(2):1-8.

29. Macinko J, Almeida C, KlingelhoeferdeSa P. A Rapid Assessment Methodology for the Evaluation of Primary Care Organization and Performance in Brazil. Health Policy and Planning. 2007;22(3):167-177.

30. Ponce M A Z, Vendramini S H F, Santos M R dos, Santos M L S G, Santena L M, Villa T C S. The Establishment of Bonds between Professional and Patient in TB treatment: The Performance of Primary Health care Services in a city in the Interior of Sao Paulo. Rev Lat Am Enfermagem. 2011;19(5):1222-9.

31. Kartal N. Evaluation the relationship between work engagement, work alienation and work performance of healthcare professionals. International journal of healthcare management. 2018;11(3):251-259.

32. Taris T W, Schaufeli W B. Individual Well-being and performance at work A conceptual and theoretical overview.2015. https://www.wilmarschaufeli.nl/publications/Schaufeli/434.pdf. Accessed $9^{\text {th }}$ Dec 2019. 
33. Shimazu A, Schaufeli W B, Kubota K, Kawakami N. Do workaholism and work engagement predict employee well-being and performance in opposite directions? Industrial Health.2012;50:316-321.

34. Kumar R DC, Khiljee N. Leadership in healthcare. Anaesthesia and Intensive Care Medicine. 2015;17(1):63-65.

35. Rolfe P. Transformational Leadership Theory: What Every Leader Needs to Know. Nurse Leader. 2011;54-57. Doi:10.1016/j.mnl/2011.01.014.

36. Kramer M W, Crespy DA. Communicating collaborative leadership. The Leadership Quarterly. 2011;22:1024-1037. Doi:10.1016/j.leaqua.2011.07.021.

37. Boamah S A, Spence Laschinger H K, Wong C, Clarke S. Effect of transformational leadership on job satisfaction and patient safety outcomes. Nursing Outlook. 2017;66(2):180-189. https://doi.org/10.1016/j.outlook.2007.10.004.

38. Alilyyani B, Wond C A, Cummings G. Antecedents, mediators, and outcomes of authentic leadership in healthcare: A systematic review. International Journal of Nursing Studies. 2018; 83:34-64. https://doi.org/10.1016/j.ijnurstu.2018.04.001.

39. Xu J H. Leadership theory in clinical practice. Chinese Nursing Research. 2017;4:155-157. https://doi.org/10.1016/j.cnre.2017.10.001.

40. Cummings G G, Tate K, Lee S, Wong C A, Paananen T, Micaroni S PM, Chatterjee G E. Leadership styles and outcome patters for the nursing workforce and work environment: A systematic review. International Journal of Nursing Studies. 2018;85:19-60. https://doi.org/10.1016/j.ijnurstu.2018.04.016.

41. Kark R, Dijk van D. Motivation to lead, motivation to follow: The role of the self-regulatory focus in leadership process. Academy of Management Review. 2007;32(2):500-28.

42. Rad A M M, Yarmohammadian M H. A study of leadership between managers' leadership style and employees's job satisfaction. Leadership in Health Services. 2006;19(2):11-28. Doi.10.1108/13660750610665008.

43. McCutcheon AS, Doran D, Evans M, Hall LM, Pringle D. Effects of leadership and span of control on nurses' job satisfaction and patient satisfaction. Nursing Leadership. 2009;23(3):4867. 
44. Carol A, Wong R N, P Elliott-Miller R N, Laschinger H, Cuddihy M, Meyer R M, Keatings RN, Burnett C, Szudy N. Examining the relationships between span of control and manager job and unit performance outcomes. Journal of Nursing Management. 2013;23(2). https://doiorg.ezprozy.ub.unimaas.nl/10.1111/jonm.12107.

45. Shuck, Reio. The Employee Engagement Landscape and HRD: How do we link theory and scholarship to current practice? Advances in developing human resources 2011.13(4)419-428.

46. Kahn, W.A. 'Psychological conditions of personal engagement and disengagement at work', Academy of Management Journal. 1990;33:692-724.

47. Rowe A. K., de Savigny D, Lanata C. F., Victora C. G., How can we achieve and maintain high-quality performance of health workers in low-resource settings? Lancer.2005;366:1026-35. Doi:10.1016/S0140-6736(05)67028-6.

48. Stc Hamilton K E, Coates V, Kelly B, Boore J R P, Cundell J H, Gracey J, Mcfetridge B, McGonigle M, Sinclair M. Performance assessment in health care providers: a critical review of evidence and current practice. Journal of Nursing Management. 2007;15:773-91.

49. Taris T W, Schaufeli W B. Individual Well-being and performance at work A conceptual and theoretical overview. 2015. https://www.wilmarschaufeli.nl/publications/Schaufeli/434.pdf

50. Bradley S, Kamwendo F, Masanja H, Pinho H, Waxman R, Boostrom C, McAuliffe E. District health managers' perceptions of supervision in Malawi and Tanzania. Human Resource for Health. 2013;11:43.

51. Pandve HT, Pandve TK. (2013). Primary Healthcare system in India: Evolution and Challenges. International Journal of Health Systems and Disaster Management. 2013;1(30):123-128.

52. Roy K, Howard D H. Equity in out-of-pocket payments for hospital care: Evidence from India. Health Policy. 2007;80:297-307.

53. Modugu H R, Kumar M, Kumar A, Millett C. State and socio-demographic group variation in out-of-pocket expenditure, borrowings and Janani Suraksha Yojana (JSY) programme use for birth deliveries in India. BMC Public Health. 2012;12:1048.

54. Garg C, Karan A K. Reducing out-of-pocket expenditure to reduce poverty: a disaggregated analysis at rural-urban and state level in India. Health Policy and Planning. 2009;24:116-128. Doi:10.1093/healpol/czn046. 
55. K Park. Parks Textbook of Preventive And Social Medicine. Health Programs in India: Edi 20, pp378-79. Bhanot publication Jabalpur India.

56. https://pib.gov.in/PressReleaseIframePage.aspx?PRID=1518544 Accessed on $25^{\text {th }}$ November 2019.

57. Ayushman Bharat Comprehensive Primary Health Care Through Health and Wellness Centres, Operational Guidelines. NHSRC. http://nhsrcindia.org/ (Accessed on 25 ${ }^{\text {th }}$ November 2019).

58. https://nrhm-mis.nic.in/hmisreports/frmstandard_reports.aspx. (Accessed on 10 Jan 2019).

59. Ministry of Health and Family Welfare, Government of India. Quality Standards for Urban Primary Health Centre- 2015.

60. Castleberry A, Nolen A. Thematic analysis of qualitative research data: Is it as easy as it sounds? Currents in pharmacy teaching and learning. 2018;10(6):807-15. Doi:10.1016/j.cptl.2018.03.019. 


\section{Chapter 2}

\section{Primary Health Centres' Performance Assessment Measures in Developing Countries: Review of the Empirical Literature}

Bangalore Sathyananda, R., de Rijk,A., Manjunath, U., Krumeich, A., van Schayck,C.P. Published in:

BMC Health Services Research 18, 627 (2018) 
Title: Primary Health Centres' Performance Assessment Measures in Developing Countries: Review of the Empirical Literature

\begin{abstract}
Background: It is universally accepted that primary healthcare is essential for achieving public health and that assessment of its performance is critical for continuous improvement. The World Health Organization's (WHO's) framework for performance assessment is a comprehensive global standard, but difficult to apply in developing countries because of financial and data constraints. This study aims to review the empirical literature on measures for PHC performance assessment in developing countries and compare them for comprehensiveness with the aspects described by the WHO Framework.
\end{abstract}

Methods: Research articles published in English scientific journals between January 1979 and October 2016 in five databases were selected in a systematic way. The reporting quality of the article and the quality of the measures were assessed with instruments adapted for the purpose of this study. Data was categorized and described.

Results: Out of the 4,359 articles, fifteen articles met the specified inclusion criteria. Nine articles used quantitative methods, one article used qualitative methods exclusively and five used mixed methods. Fourteen articles had a good description of the measurement properties. None of the articles presented validity tests of the measures but eleven articles presented measures that were well established. Mostly studies included components of personnel competencies (skilled / non-skilled) and centre performance (patient satisfaction /cost /efficiency).

Conclusions: In comparison to the WHO framework, the measures in the articles were limited in scope as they did not represent all service components of PHCs. Hence, PHC performance assessment should include system components along with relevant measures of personnel performance beyond knowledge of protocols. Existing measures for PHC performance assessment in developing countries need to be validated and concise measures for neglected aspects need to be developed.

\title{
Background
}

During the last three decades, significant achievements have been made in improving the health of the world population. ${ }^{1,2}$ This can be attributed in part to the Millennium Development Goals and is further augmented by the launch of the Sustainable Development Goals in September 2015. 1, 2 In developing countries, however, still more progress needs to be made. In these countries, still far too 
many women die during childbirth, ${ }^{1-3,4,5}$ too many children die from preventable causes ${ }^{1,2,4,6}$ and too many adults die from treatable infectious and non-communicable diseases ${ }^{7,6}$. Reducing mortality and morbidity is the main focus of primary healthcare. ${ }^{1,2}$ While progress has been made in communicable diseases, the burden of non-communicable diseases is straining developing countries' healthcare resources. ${ }^{6,7}$

Primary healthcare has been recognised as the most essential and critical type of healthcare delivery that addresses the health needs of the people through Primary Health Centres (PHC). ${ }^{8}$ The performance of healthcare in general, not in particular PHC, reflects the achievement of a health system and has gained significant attention in the last decade. ${ }^{9-14}$ In order to monitor their health system, countries carry out performance assessment. In business terminology, performance is fulfilling one's obligation, in a way that releases from liabilities. ${ }^{15}$ Performance assessment can be defined as a 'coherent evaluation system which assesses the whole occupational functioning including its constituent parts'. ${ }^{16}$ A comprehensive assessment of the system in developing countries is vital for determining the gap between demand for services and the ability of the healthcare systems to reciprocate.

In this regard, the World Health Organization's (WHO) health systems performance assessment framework serves as the global benchmark. According to the framework, health systems performance objectives are good health, responsiveness and fair financial contribution. ${ }^{17}$ The framework describes six aspects of performance assessment: overall level of health considering the general health of population; distribution of health in population (healthcare services coverage); overall level of responsiveness indicated by the quality of care, satisfaction of care and availability of services; distribution of responsiveness; distribution of resources such as human resources and care facilities; distribution of financial contribution from various agents and their optimal use. ${ }^{17}$ Even though it would be ideal, many developing countries might lack adequate resources and data to assess PHC performance according to this framework, and hence, may have reservations about applying the framework. ${ }^{10,18}$

The specific measures of PHC performance assessment which are used in developing countries are not well known. In the most recent review of health care performance measurements, no distinction was made between developed and developing countries. ${ }^{19}$ The Primary Healthcare Systems are evolving at a faster pace in developing countries than before. The Primary Health Care Performance Initiative calls this a "Black Box" and identifies an urgent need to build on the existing knowledge. ${ }^{20}$

The aim of this study is to review the scientific literature on measures of PHC performance assessment used in developing countries and to compare them with the WHO framework for health 
care performance assessment for comprehensiveness. Based on the literature, four aspects of healthcare performance measurement ${ }^{9,11,21}$ are emphasized in this review:

- The methods for assessing performance in health care ${ }^{22}$

- The quality of measurement (validity and reliability) 16

- The professional actions, that is, the performance of the provider $23,24,25$

- The levels covered by the measurement: the level of the patient, that of the community, district/state level and/or country level. Concurrently, measures could capture different perspectives such as that of the health care provider or that of the patient. ${ }^{26}$

\section{Methods}

This paper employs a review of the literature on PHC performance assessment in developing countries. The flow diagram of the selection and search process is depicted in Figure 1.

\section{Search strategy}

An initial search for articles from the following databases was carried out: Hospital/Health care (Pubmed, Embase), Psychology (JSTOR, PsycINFO) and Business (Emerald Insight). Endnote7 software was utilised to download and select articles. As the aim of the review was to include articles on PHC performance assessment in developing countries that are published in English, the search terms included 'primary health centre' or 'health centre' and 'performance assessment' or 'performance and developing country' \{(primary health centre or health centre) and (performance assessment or performance) and developing country\}. The period of publication for the search was from the year 1979, a year after Alma Ata up to December 2014. Further, an additional search was done from January 2015 to October 2016 to include recent articles. Mesh terms were employed when available in the database. The search results from the databases identified were combined to eliminate duplicates. The details of the search strategy are given in Appendices 1 and 2. A similar search was conducted in Google scholar and the articles fulfilling inclusion criteria were included for full review (Figure 1).

The inclusion criteria employed were:

- Empirical articles with measurement of PHC or professional performance (from professional or health centre perspectives);

- The measurements were conducted in a developing country; and

- Papers were published in English

Review articles and discussion papers were excluded. The authenticity of this review was ensured by including only published empirical articles, avoiding grey literature and reviews. The articles were 
screened first by title and then by the abstract to select the relevant articles for full paper review, on the basis of the set inclusion and exclusion criteria.

\section{Quality assessment}

The selected full articles were assessed for quality. The complete evaluation of methodological characteristics as suggested by COSMIN and Noben and colleagues could not be applied, as methodologies of the articles selected were not advanced enough. ${ }^{27},{ }^{28}$ Hence, a simpler instrument was developed, based on the quality of the description and the quality of the measurement property (the reliability and validity) itself. It is theoretically possible that the measurement property is weak although the description is good. ${ }^{28}$ With our instrument for assessing the quality of description, the articles were scored as: 0 , if there was no description of the measurement property; 1 , if only a few points of the measurement property were described (little information); and 2, if there was a detailed description of the measure in the article (good information).

The quality of the measurement property was assessed based on four criteria:

- The standardization: method of data collection was noted and the standardization by pretesting of the tool and/or the training of researchers was reported.

- The triangulation of the data collection method and/or data source with significantly similar results.

- The measure used was well established/widely published; this was done by verifying references and other cited publications.

- The reliability and validity of the measures was tested using statistical methods and compared with a global standard (WHO performance assessment framework). ${ }^{29}$

The quality was scored as follows:

0 - If none of the above criteria was fulfilled

1- If only standardization of the measure and/or researchers by training was done

2- If triangulation of methods/data sources was done

3- If the methods used for analysis were well established/published

4- If validity of the measure was tested with good results

The results were relegated to a lower number if the higher criteria were not fully met or exclusively mentioned in the article. The qualitative article was scored between 0-2 as its measures would be unique, based on the theoretical framework used (scores 3 and 4 were irrelevant). The papers were analysed for quality by the first two authors independently, the differences were discussed and agreed upon. 
The selected full articles were analysed and reviewed to understand and describe how the performance of PHCs had been assessed in developing countries. All selected articles were studied to understand how they had defined performance and the perspectives of the performance assessment (provider or patient). The topographical and content analysis of measures was done and these were compared with the measures of WHO performance assessment framework for comprehensiveness. ${ }^{29}$

\section{Ethics}

No ethical approval was needed for this narrative review.

\section{Results}

\section{Literature search results}

After downloading the articles (4,359 articles) using the search strategy described above, duplicates were removed, inclusion and exclusion criteria were applied systematically, which resulted in the selection of eight articles from the initial search and three articles from the additional search for the review. Further, searches from the reference tracking and in Google Scholar resulted in another four articles (Figure 1). Thus, in total fifteen articles were included for quality assessment and content analysis (Table 1). Table 1 provides an overview of these fifteen articles. 


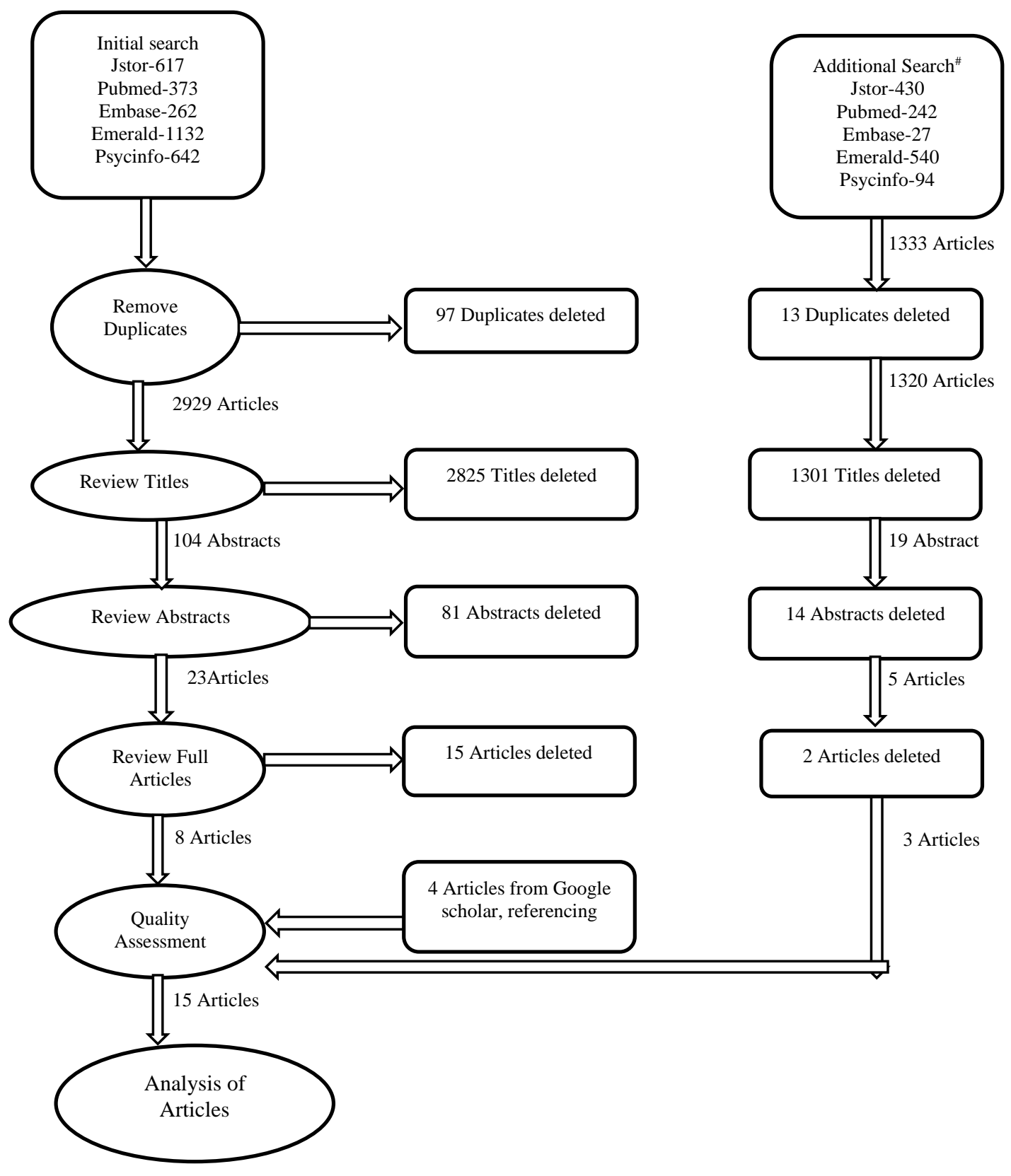

\# To include recent publications

Figure 1 Methodology of review 
Table 1: Description of articles

\begin{tabular}{|c|c|c|c|c|c|c|c|c|c|c|c|c|}
\hline $\begin{array}{l}\text { Sl } \\
\text { No }\end{array}$ & Title & Authors & Publication & Country & $\begin{array}{l}\text { Study } \\
\text { type }\end{array}$ & $\begin{array}{l}\text { Study } \\
\text { population }\end{array}$ & $\begin{array}{l}\text { Size of } \\
\text { Popula } \\
\text { tion }\end{array}$ & $\begin{array}{l}\text { Definition of } \\
\text { Performance }\end{array}$ & Measures identified & $\begin{array}{l}\text { Performance } \\
\text { distinguished as } \\
\text { centre(system)/ } \\
\text { personnel }\end{array}$ & $\begin{array}{l}\text { Degree of } \\
\text { description of } \\
\text { measurement } \\
\text { property } \\
\end{array}$ & $\begin{array}{l}\text { Quality of } \\
\text { measurem } \\
\text { ent } \\
\text { property }\end{array}$ \\
\hline 1 & $\begin{array}{l}\text { Investing in } \\
\text { Improved } \\
\text { Performance } \\
\text { of National } \\
\text { Tuberculosis } \\
\text { Programs } \\
\text { Reduces the } \\
\text { Tuberculosis } \\
\text { Burden: } \\
\text { Analysis of } 22 \\
\text { High-Burden } \\
\text { Countries }\end{array}$ & $\begin{array}{l}\text { Akachi, } \\
\text { Y., A. } \\
\text { Zumla, } \\
\text { and R. } \\
\text { Atun }{ }^{28}\end{array}$ & $\begin{array}{l}\text { The Journal } \\
\text { of Infectious } \\
\text { Diseases, } \\
\text { 2012. 205: } \\
\text { p. S284- } \\
\text { S292 }\end{array}$ & $\begin{array}{l}\text { High TB } \\
\text { burden } \\
\text { countries }\end{array}$ & $\begin{array}{l}\text { Quantit } \\
\text { ative }\end{array}$ & $\begin{array}{l}\text { Developing } \\
\text { Countries }\end{array}$ & $\begin{array}{l}\text { Not } \\
\text { Applica } \\
\text { ble }\end{array}$ & $\begin{array}{l}\text { 1.Secondary } \\
\text { analysis of } \\
\text { WHO, OECD } \\
\text { data } \\
\text { 2.Indicators of } \\
\text { National } \\
\text { Tubercular } \\
\text { Program } \\
\text { (NTP) and its } \\
\text { effect on } \\
\text { burden of } \\
\text { disease }\end{array}$ & $\begin{array}{l}\text { 1. Tuberculosis Burden: } \\
\text { a. Incidence } \\
\text { b. Prevalence } \\
\text { c. Mortality } \\
\text { 2. Tuberculosis control program: } \\
\text { a. Case detection rate } \\
\text { b. Treatment success rate } \\
\text { c. NTP expenditure }\end{array}$ & $\begin{array}{l}\text { System } \\
\text { (Country) }\end{array}$ & 2 & 3 \\
\hline 2 & $\begin{array}{l}\text { Performance } \\
\text { of female } \\
\text { volunteer } \\
\text { community } \\
\text { health workers } \\
\text { in Dhaka urban } \\
\text { slums }\end{array}$ & $\begin{array}{l}\text { Alam, K., } \\
\text { S. } \\
\text { Tasneem, } \\
\text { and E. } \\
\text { Oliveras } \\
29\end{array}$ & $\begin{array}{l}\text { Social } \\
\text { Science \& } \\
\text { Medicine, } \\
\text { 2012. 75(3): } \\
\text { p. 511-515. }\end{array}$ & $\begin{array}{l}\text { Dhaka, } \\
\text { Banglades } \\
\text { h }\end{array}$ & $\begin{array}{l}\text { Mixed } \\
\text { Method } \\
\text { [Quanti } \\
\text { tative } \\
\text { and } \\
\text { Qualitat } \\
\text { ive } \\
\text { (Focus } \\
\text { group } \\
\text { discussi } \\
\text { on)] }\end{array}$ & $\begin{array}{l}\text { Community } \\
\text { Health } \\
\text { Workers } \\
\text { (CHW) }\end{array}$ & $\begin{array}{l}542 \\
(50 \% \text { of } \\
\text { CHW }) \\
+3\end{array}$ & $\begin{array}{l}\text { 1. Active } \\
\text { participation }\end{array}$ & $\begin{array}{l}\text { 1. Activities, tasks and services: } \\
\text { a. Home visits } \\
\text { b. Identifying pregnancies } \\
\text { c. Bringing pregnant women to delivery centres } \\
\text { d. Accompanying pregnant women to delivery and } \\
\text { providing essential new born care }\end{array}$ & Personnel & 2 & 1 \\
\hline 3 & $\begin{array}{l}\text { Accessibility } \\
\text { to tuberculosis } \\
\text { treatment: } \\
\text { assessment of } \\
\text { health service } \\
\text { performance. }\end{array}$ & $\begin{array}{l}\text { Arakawa, } \\
\text { T., et al. }{ }^{30}\end{array}$ & $\begin{array}{l}\text { Rev Lat Am } \\
\text { Enfermagem } \\
\text {, 2011. } \\
\text { 19(4): p. } \\
\text { 994-1002 }\end{array}$ & $\begin{array}{l}\text { Ribeirao } \\
\text { Preto, Sao } \\
\text { Paulo } \\
\text { State, } \\
\text { Brazil }\end{array}$ & $\begin{array}{l}\text { Quantit } \\
\text { ative }\end{array}$ & $\begin{array}{l}\text { Persons with } \\
\text { TB and } \\
\text { undergoing } \\
\text { treatment at } \\
\text { referral } \\
\text { services }\end{array}$ & 100 & $\begin{array}{l}\text { Accessibility } \\
\text { of services }\end{array}$ & $\begin{array}{l}\text { 1. Organization accessibility } \\
\text { 2. Economic accessibility } \\
\text { 3. Geographical accessibility }\end{array}$ & Centre & 2 & 3 \\
\hline 4 & $\begin{array}{l}\text { Problems } \\
\text { measuring } \\
\text { community } \\
\text { health status at } \\
\text { a local level: } \\
\text { Papua New } \\
\text { Guinea's health } \\
\text { information } \\
\text { system. }\end{array}$ & $\begin{array}{l}\text { Ashwell, } \\
\text { H.E. and } \\
\text { L. } \\
\text { Barclay }^{31}\end{array}$ & $\begin{array}{l}\text { Rural } \\
\text { Remote } \\
\text { Health, } \\
\text { 2010. 10(4): } \\
\text { p. } 1539 .\end{array}$ & $\begin{array}{l}\text { Papua } \\
\text { New } \\
\text { Guinea' }\end{array}$ & $\begin{array}{l}\text { Mixed } \\
\text { Method } \\
\text { [Qualita } \\
\text { tive } \\
\text { (intervi } \\
\text { ews) } \\
\text { Quantit } \\
\text { ative } \\
\text { data } \\
\text { from } \\
\text { census] }\end{array}$ & $\begin{array}{l}\text { Health } \\
\text { persons } \\
\text { rendering } \\
\text { services at } \\
\text { national, } \\
\text { provincial } \\
\text { and district } \\
\text { health } \\
\text { facilities }\end{array}$ & $\begin{array}{l}175 \\
+77\end{array}$ & $\begin{array}{l}\text { 1. Community } \\
\text { Health and } \\
\text { Wellbeing } \\
\text { 2. Community } \\
\text { use of services }\end{array}$ & $\begin{array}{l}\text { 1. Community Health } \\
\text { a. Physical health } \\
\text { b. Social and Economic well being } \\
\text { c. Healthy lifestyle } \\
\text { d. Hygienic living environment } \\
\text { e. Maternal and Child Health } \\
\text { 2. Use of services } \\
\text { a. Use of Antenatal, childbirth, immunization services } \\
\text { b. Use of Environmentally induced diseases like } \\
\text { malaria, pneumonia diarrhoea }\end{array}$ & Centre & 1 & 2 \\
\hline
\end{tabular}




\begin{tabular}{|c|c|c|c|c|c|c|c|c|c|c|c|c|}
\hline $\begin{array}{l}\text { SI } \\
\text { No }\end{array}$ & Title & Authors & Publication & Country & $\begin{array}{l}\text { Study } \\
\text { type }\end{array}$ & $\begin{array}{l}\text { Study } \\
\text { population }\end{array}$ & $\begin{array}{l}\text { Size of } \\
\text { Popula } \\
\text { tion }\end{array}$ & $\begin{array}{l}\text { Definition of } \\
\text { Performance }\end{array}$ & Measures identified & $\begin{array}{l}\text { Performance } \\
\text { distinguished } \\
\text { as centre/ } \\
\text { personnel }\end{array}$ & $\begin{array}{l}\text { Degree of } \\
\text { description of } \\
\text { measurement } \\
\text { property }\end{array}$ & $\begin{array}{l}\text { Quality of } \\
\text { measureme } \\
\text { nt property }\end{array}$ \\
\hline 5 & $\begin{array}{l}\text { Evaluation of } \\
\text { maternal and } \\
\text { child health } \\
\text { services in El- } \\
\text { Minia City, } \\
\text { Egypt. }\end{array}$ & $\begin{array}{l}\text { Awadalla, } \\
\text { H.I., et } \\
\text { al }^{32}\end{array}$ & $\begin{array}{l}\text { Journal of } \\
\text { Public } \\
\text { Health, } \\
\text { 2009. 17(5): } \\
\text { p. 321-329. }\end{array}$ & $\begin{array}{l}\text { El-Minia } \\
\text { City, } \\
\text { Egypt }\end{array}$ & $\begin{array}{l}\text { Quantit } \\
\text { ative }\end{array}$ & $\begin{array}{l}\text { Female } \\
\text { clients using } \\
\text { health } \\
\text { services at } \\
\text { maternal } \\
\text { and child } \\
\text { health } \\
\text { centres }\end{array}$ & 400 & $\begin{array}{l}\text { 1. Utilization } \\
\text { 2. Client } \\
\text { Satisfaction }\end{array}$ & $\begin{array}{l}\text { 1.Utilization of various components of Maternal \&Child } \\
\text { Health (MCH) services } \\
\text { a. Abortion } \\
\text { b. Under } 5 \text { year mortality } \\
\text { c. Curative MCH services } \\
\text { d. Antenatal care } \\
\text { e. Delivery services } \\
\text { f. Family planning services } \\
\text { g. Preventive and curative MCH services } \\
\text { 2.Satisfaction } \\
\text { a. Waiting time } \\
\text { b. Environment } \\
\text { c. Doctor client interaction } \\
\text { d. Nurse client interaction } \\
\text { e. Economic feasibility }\end{array}$ & Centre & 2 & 1 \\
\hline 6 & $\begin{array}{l}\text { District health } \\
\text { managers' } \\
\text { perceptions of } \\
\text { supervision in } \\
\text { Malawi and } \\
\text { Tanzania. }\end{array}$ & $\begin{array}{l}\text { Bradley, } \\
\text { S., et al. }{ }^{33}\end{array}$ & $\begin{array}{l}\text { Hum Resour } \\
\text { Health, } \\
\text { 2013. 11: p. } \\
\text { 43. }\end{array}$ & $\begin{array}{l}\text { Malawi } \\
\text { and } \\
\text { Tanzania }\end{array}$ & $\begin{array}{l}\text { Qualitat } \\
\text { ive }\end{array}$ & $\begin{array}{l}\text { District } \\
\text { health } \\
\text { management } \\
\text { team }\end{array}$ & 57 & $\begin{array}{l}\text { 1. Health } \\
\text { indicators } \\
\text { 2. Facility } \\
\text { Provision } \\
\text { 3. Individual } \\
\text { Staff } \\
\text { performance } \\
\text { 4. Supervisory } \\
\text { practices }\end{array}$ & $\begin{array}{l}\text { 1. Health indicators } \\
\text { a. Number of Deliveries } \\
\text { b. Maternal mortality figures } \\
\text { 2. Facility Provision } \\
\text { a. Availability of supplies } \\
\text { b. Registers filled } \\
\text { c. Cleanliness of wards } \\
\text { 3. Individual Staff performance } \\
\text { a. Punctuality } \\
\text { b. Response time for on call staff } \\
\text { c. Absenteeism } \\
\text { d. Staff reporting to work at recommended time } \\
\text { 4. Supervisory practices }\end{array}$ & Personnel & 2 & $2 *$ \\
\hline 7 & $\begin{array}{l}\text { A Rapid } \\
\text { assessment } \\
\text { methodology for } \\
\text { the evaluation of } \\
\text { primary care } \\
\text { organization and } \\
\text { performance in } \\
\text { Brazil }\end{array}$ & $\begin{array}{l}\text { Macinko, } \\
\text { J., C. } \\
\text { Almeida, } \\
\text { and P.K. } \\
\text { de Sá }^{34}\end{array}$ & $\begin{array}{l}\text { Health } \\
\text { Policy and } \\
\text { Planning, } \\
\text { 2007. 22(3): } \\
\text { p. 167-177. }\end{array}$ & Brazil & $\begin{array}{l}\text { Quantit } \\
\text { ative }\end{array}$ & $\begin{array}{l}\text { Client and } \\
\text { provider }\end{array}$ & 936 & $\begin{array}{l}\text { Assessment of } \\
\text { primary care } \\
\text { experiences }\end{array}$ & $\begin{array}{l}\text { 1.Accessibility of Facility and Services } \\
\text { 2.Gate keeping/ First contact care } \\
\text { 3.Longitudinality } \\
\text { 4.Comprehensiveness } \\
\text { 5.Coordination } \\
\text { 6.Family focus } \\
\text { 7.Community orientation } \\
\text { 8.Provider characteristics }\end{array}$ & Centre & 2 & 3 \\
\hline 8 & $\begin{array}{l}\text { The } \\
\text { establishment of } \\
\text { bonds between } \\
\text { professional and } \\
\text { patient in TB } \\
\text { treatment: the } \\
\text { performance of } \\
\text { primary health } \\
\text { care services in a } \\
\text { city in the } \\
\text { interior of Sao } \\
\text { Paulo }\end{array}$ & $\begin{array}{l}\text { Ponce, } \\
\text { M.A., et } \\
\text { al. } .^{35}\end{array}$ & $\begin{array}{l}\text { Rev Lat Am } \\
\text { Enfermagem } \\
\text {, 2011. } \\
\text { 19(5): p. } \\
1222-9\end{array}$ & $\begin{array}{l}\text { Sao Paul, } \\
\text { Brazil }\end{array}$ & $\begin{array}{l}\text { Quantit } \\
\text { ative }\end{array}$ & $\begin{array}{l}\text { Patient } \\
\text { Health } \\
\text { professional } \\
\text { Managers }\end{array}$ & $\begin{array}{l}108+37 \\
+15\end{array}$ & $\begin{array}{l}\text { Establishment } \\
\text { of bonds } \\
\text { (Patient } \\
\text { experience } \\
\text { Health } \\
\text { professional } \\
\text { experience } \\
\text { Managers } \\
\text { experience) }\end{array}$ & Bonding Identified by 11 items & Centre & 2 & 3 \\
\hline
\end{tabular}




\begin{tabular}{|c|c|c|c|c|c|c|c|c|c|c|c|c|}
\hline $\begin{array}{l}\text { Sl } \\
\text { No }\end{array}$ & Title & Authors & Publication & Country & $\begin{array}{l}\text { Study } \\
\text { type }\end{array}$ & $\begin{array}{l}\text { Study } \\
\text { populatio } \\
\text { n }\end{array}$ & $\begin{array}{l}\text { Size of } \\
\text { Popula } \\
\text { tion } \\
\end{array}$ & $\begin{array}{l}\text { Definition of } \\
\text { Performance }\end{array}$ & Measures identified & $\begin{array}{l}\text { Performance } \\
\text { distinguished } \\
\text { as centre/ } \\
\text { personnel }\end{array}$ & $\begin{array}{l}\text { Degree of } \\
\text { description of } \\
\text { measurement } \\
\text { property }\end{array}$ & $\begin{array}{l}\text { Quality of } \\
\text { measureme } \\
\text { nt property }\end{array}$ \\
\hline 9 & $\begin{array}{l}\text { Assessing the } \\
\text { performance } \\
\text { of primary } \\
\text { health centres } \\
\text { under } \\
\text { decentralized } \\
\text { government in } \\
\text { Kerala, India }\end{array}$ & $\begin{array}{l}\text { Varathraja } \\
\text { n D, } \\
\text { Thankapp } \\
\text { an R, } \\
\text { Jayapalan } \\
\mathrm{S}^{36}\end{array}$ & $\begin{array}{l}\text { Health } \\
\text { Policy and } \\
\text { Planning, } \\
2004.19(1) 4 \\
1-51\end{array}$ & $\begin{array}{l}\text { Kerala, } \\
\text { India }\end{array}$ & $\begin{array}{l}\text { Mixed } \\
\text { Method } \\
\text { [Qualitati } \\
\text { ve (key } \\
\text { informant/ } \\
\text { client } \\
\text { interviews } \\
\text { ) } \\
\text { Quantitati } \\
\text { ve data } \\
\text { from } \\
\text { PHCs] }\end{array}$ & $\begin{array}{l}\text { Primary } \\
\text { Health } \\
\text { Centre }\end{array}$ & 10 & $\begin{array}{l}\text { Cost } \\
\text { effectiveness }\end{array}$ & $\begin{array}{l}\text { 1. Infrastructure: Building structure, Toilet, Clean } \\
\text { running water, Electricity, Communication, Wash } \\
\text { basin, equipment and instruments, furniture, drugs and } \\
\text { other supplies } \\
\text { 2. Access: Size of building to patient load, home } \\
\text { visits by PHC staff, facility hours, patient records } \\
\text { waiting area, patient privacy, distribution/display of } \\
\text { health education materials, display of community } \\
\text { statistics } \\
\text { 3. Costs: salary, investment, maintenance, patient } \\
\text { care, building, furniture, equipment } \\
\text { 4. Number of patient contacts served } \\
\text { 5. Client experience: focus on illness, service } \\
\text { received, access frequency, staff behaviour, diagnosis } \\
\text { 6. Key informant experience: budget, cost, financial } \\
\text { sources, PHC and local government characteristics } \\
\text { and linkages }\end{array}$ & Centre & 2 & 3 \\
\hline 10 & $\begin{array}{l}\text { Gap analysis } \\
\text { and the } \\
\text { performance } \\
\text { of primary } \\
\text { health centres } \\
\text { in the } \\
\text { implementatio } \\
\mathrm{n} \text { of the school } \\
\text { health } \\
\text { programme of } \\
\text { NRHM }\end{array}$ & $\begin{array}{l}\text { Shreedevi } \\
\mathrm{D}^{37}\end{array}$ & $\begin{array}{l}\text { International } \\
\text { journal of } \\
\text { Research in } \\
\text { Business } \\
\text { Managemen } \\
\mathrm{t}, \\
2014.2(2) 1- \\
8\end{array}$ & $\begin{array}{l}\text { Andhra } \\
\text { Pradesh, } \\
\text { India }\end{array}$ & $\begin{array}{l}\text { Quantitati } \\
\text { ve }\end{array}$ & $\begin{array}{l}\text { Primary } \\
\text { Health } \\
\text { Centre }\end{array}$ & 159 & Program delivery & $\begin{array}{l}\text { Program Specific } \\
\text { 1. Services } \\
\text { a. Screening, Health care and Referral } \\
\text { b. Immunization } \\
\text { c. Micronutrient management } \\
\text { d. De-worming } \\
\text { 2. Promotion } \\
\text { 3. Capacity building } \\
\text { 4. Monitoring \& Evaluation } \\
\text { 5. Midday Meal }\end{array}$ & $\begin{array}{l}\text { System(Distric } \\
\text { t) }\end{array}$ & 2 & 3 \\
\hline 11 & $\begin{array}{l}\text { Factors } \\
\text { affecting the } \\
\text { performance } \\
\text { of maternal } \\
\text { health care } \\
\text { providers in } \\
\text { Armenia }\end{array}$ & $\begin{array}{l}\text { Fort AL, } \\
\text { Voltero } \\
\mathrm{L}^{38}\end{array}$ & $\begin{array}{l}\text { Human } \\
\text { Resources } \\
\text { for Health } \\
2004, \text { p 2-8 }\end{array}$ & Armenia & $\begin{array}{l}\text { Mixed } \\
\text { Method } \\
\text { [Qualitati } \\
\text { ve } \\
\text { (personnel } \\
\text { interviews } \\
\text { ) } \\
\text { Quantitati } \\
\text { ve data } \\
\text { (skill } \\
\text { items)] }\end{array}$ & $\begin{array}{l}\text { Nurses } \\
\text { and } \\
\text { Midwifes }\end{array}$ & 285 & $\begin{array}{l}\text { Completion of } \\
\text { clinical and non- } \\
\text { clinical tasks }\end{array}$ & $\begin{array}{l}\text { Skill Items of } \\
\text { 1. Prenatal care ( } 42 \text { items) } \\
\text { 2. Post-natal care (3 items) }\end{array}$ & Personnel & 2 & 3 \\
\hline
\end{tabular}




\begin{tabular}{|c|c|c|c|c|c|c|c|c|c|c|c|c|}
\hline $\begin{array}{l}\text { Sl } \\
\text { No }\end{array}$ & Title & Authors & Publication & Country & $\begin{array}{l}\text { Study } \\
\text { type }\end{array}$ & $\begin{array}{l}\text { Study } \\
\text { population }\end{array}$ & $\begin{array}{l}\text { Size of } \\
\text { Populat } \\
\text { ion }\end{array}$ & $\begin{array}{l}\text { Definition of } \\
\text { Performance }\end{array}$ & Measures identified & $\begin{array}{l}\text { Performance } \\
\text { distinguished as } \\
\text { centre/ } \\
\text { personnel }\end{array}$ & $\begin{array}{l}\text { Degree of } \\
\text { description of } \\
\text { measurement } \\
\text { property }\end{array}$ & $\begin{array}{l}\text { Quality of } \\
\text { measure } \\
\text { ment } \\
\text { property }\end{array}$ \\
\hline 12 & $\begin{array}{l}\text { Improving health } \\
\text { worker } \\
\text { performance: } \\
\text { The patient- } \\
\text { perspective from } \\
\text { a PBF program } \\
\text { in Rwanda }\end{array}$ & $\begin{array}{l}\text { Lannes } \\
. \mathrm{L}^{39}\end{array}$ & $\begin{array}{l}\text { Social } \\
\text { science and } \\
\text { Medicine } \\
(2015) \\
138: 1-11\end{array}$ & Rwanda & $\begin{array}{l}\text { Quantitati } \\
\text { ve }\end{array}$ & $\begin{array}{l}\text { Health } \\
\text { workers of } \\
\text { Primary level } \\
\text { facilities }\end{array}$ & 157 & $\begin{array}{l}\text { Patient } \\
\text { satisfaction }\end{array}$ & $\begin{array}{l}\text { 1. Clinical services } \\
\text { a. Privacy during examination } \\
\text { b. Staff attitude } \\
\text { c. Explanation } \\
\text { d. Cost of drugs } \\
\text { e. Cost of services } \\
\text { f. Availability of drugs } \\
\text { g. Overall satisfaction } \\
\text { 2. Non-clinical services } \\
\text { a. Waiting time } \\
\text { b. Time with provider } \\
\text { c. Cleanliness }\end{array}$ & Personnel & 2 & 3 \\
\hline 13 & $\begin{array}{l}\text { Assessment of } \\
\text { the role of } \\
\text { primary health } \\
\text { care in } \\
\text { tuberculosis } \\
\text { control in Serbia }\end{array}$ & $\begin{array}{l}\text { Stosic M, } \\
\text { Lazarevic } \\
\text { N, Kuruc } \\
\text { V, Ristic } \\
\text { L }^{40}\end{array}$ & $\begin{array}{l}\text { MedicinskiP } \\
\text { regled (Novi } \\
\text { Sad) } \\
\text { 2015. } 68(9- \\
\text { 10):331-335 }\end{array}$ & Serbia & $\begin{array}{l}\text { Quantitati } \\
\text { ve }\end{array}$ & $\begin{array}{l}\text { Primary } \\
\text { Health } \\
\text { Centre }\end{array}$ & 19 & $\begin{array}{l}\text { Organization of } \\
\text { care }\end{array}$ & $\begin{array}{l}\text { 1. Availability and coverage of general practice and } \\
\text { TB services } \\
\text { 2. Health activities performed } \\
\text { 3. Collaboration with health services } \\
\text { Compliance to health needs }\end{array}$ & Centre & 2 & 3 \\
\hline 14 & $\begin{array}{l}\text { Skilled Birth } \\
\text { Attendants in } \\
\text { Tanzania: A } \\
\text { descriptive study } \\
\text { of cadres and } \\
\text { emergency } \\
\text { obstetric care } \\
\text { signal functions } \\
\text { performed }\end{array}$ & $\begin{array}{l}\text { Uneo E, } \\
\text { Adegoke } \\
\text { A. A, } \\
\text { Masenga } \\
\text { G, Fimbo } \\
\text { J, Msuya } \\
\text { S E }\end{array}$ & $\begin{array}{l}\text { Maternal } \\
\text { and child } \\
\text { health } \\
\text { journal, } \\
2015.19: 155 \\
-169\end{array}$ & Tanzania & $\begin{array}{l}\text { Mixed } \\
\text { Method[Q } \\
\text { uantitative } \\
\text { (facility } \\
\text { survey } \\
\text { and task } \\
\text { items) } \\
\text { Qualitativ } \\
\text { e(challeng } \\
\text { es in care } \\
\text { delivery)] }\end{array}$ & $\begin{array}{l}\text { Healthcare } \\
\text { workers in } \\
\text { Primary } \\
\text { Health } \\
\text { Centre }\end{array}$ & 158 & $\begin{array}{l}\text { Knowledge and } \\
\text { Skill of } \\
\text { Emergency } \\
\text { Obstetric Care } \\
\text { signal } \\
\text { functions }\end{array}$ & $\begin{array}{l}\text { 1. BEmOC signal functions } \\
\text { a. Administers parenteral antibiotics } \\
\text { b. Administers uterotonics drug } \\
\text { c. Administers parenteral anti-convulsants } \\
\text { d. Manually remove the placenta } \\
\text { e. Remove retained products } \\
\text { f. Perform assisted vaginal delivery } \\
\text { g. Perform basic neonatal resuscitation } \\
\text { 2. CEmOC signal functions } \\
\text { a. Perform surgery } \\
\text { Perform blood transfusion }\end{array}$ & Personnel & 2 & 3 \\
\hline 15 & $\begin{array}{l}\text { Organization and } \\
\text { delivery of } \\
\text { primary } \\
\text { healthcare } \\
\text { services in } \\
\text { Petropolis, Brazil }\end{array}$ & $\begin{array}{l}\text { Macinko } \\
\text { J, } \\
\text { Almeida } \\
\text { C, } \\
\text { Oliveria } \\
\text { ES, Sa P } \\
\mathrm{K}^{42}\end{array}$ & $\begin{array}{l}\text { International } \\
\text { Journal of } \\
\text { Health } \\
\text { Planning } \\
\text { and } \\
\text { Managemen } \\
\mathrm{t}\end{array}$ & Brazil & $\begin{array}{l}\text { Mixed } \\
\text { Method } \\
\text { [Quantitat } \\
\text { ive } \\
\text { (facility } \\
\text { survey) } \\
\text { Qualitativ } \\
\text { e(validate } \\
\mathrm{d} \\
\text { participan } \\
\mathrm{t} \\
\text { selection)] }\end{array}$ & $\begin{array}{l}\text { Primary care } \\
\text { facility and } \\
\text { Family care } \\
\text { centres }\end{array}$ & $\begin{array}{l}33 \text { care } \\
\text { facilitie } \\
\mathrm{s}\end{array}$ & $\begin{array}{l}\text { Attributes of } \\
\text { Primary care } \\
\text { systems }\end{array}$ & $\begin{array}{l}\text { 1. Accessibility } \\
\text { 2. First contact } \\
\text { 3. Longitudinality } \\
\text { 4. Comprehensiveness } \\
\text { 5. Coordination } \\
\text { 6. Family-focused } \\
\text { 7. Community orientation } \\
\text { 8. Provider characteristics }\end{array}$ & Centre & 2 & 3 \\
\hline
\end{tabular}




\section{Quality of measures}

Fourteen articles had a good description of the measurement properties. The quality of the measures varied. Measures in eleven articles scored 3, two articles scored 2 and two articles scored 1 (Table 1). None of the measures was tested for validity with good results.

\section{Description of the PHC performance measures}

Empirical research on PHC performance measures was published from Brazil, India, Papua New Guinea, Egypt, Bangladesh, Armenia, Malawi, Tanzania, Rwanda, Serbia and other developing countries. A descriptive analysis revealed that PHC performance was distinguished as individual staff/personnel performance and that of the centre/health system performance with a focus on consumer's and/or provider's perspectives. Figure 2 depicts the perspective and level of assessment.

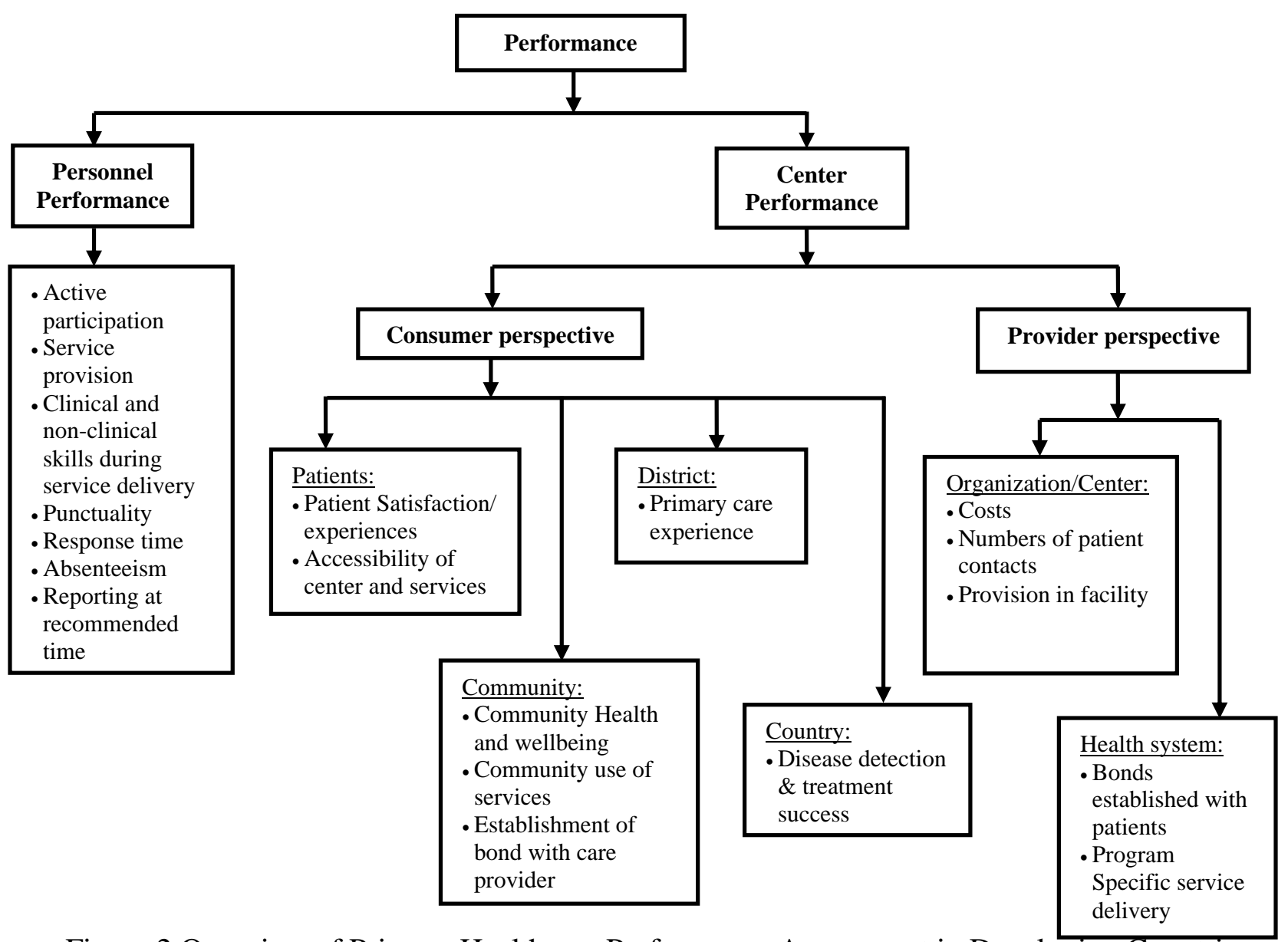

Figure 2 Overview of Primary Healthcare Performance Assessment in Developing Countries assessed in our review

\section{Method of performance assessment}

Of the fifteen articles included in the review, nine articles had utilized quantitative data, one article had exclusively employed qualitative methods and five had employed mixed methods. The methods of data collection included were interviews with clients, health workers, key informants and/or 
stakeholders ${ }^{30-38}$, focus group discussions ${ }^{30}$, direct observation ${ }^{35,39}$, facility-based survey ${ }^{34,35,40,41}$, and secondary data analysis (records on costs, infrastructure, service provision, health indicators, number of patients served and other patient details). ${ }^{30,31,34,39,42}$

\section{Performance of the professionals}

Five studies evaluated the personnel performance assessment (nurses, midwives, management team, community health workers and medical professionals). The assessment considered competency/clinical services and non-competency/non-clinical service-based components. The personnel performance was assessed using the Quick Investigation of Quality tool. ${ }^{34}$ Adherence to the protocol was the most common method in competency-based personnel performance assessment. $^{30}, 33,35,36,38$ For the non-competency-based personnel performance assessment, the measures used were punctuality, response time, absenteeism, time of reporting to work, time spent with patients, waiting time and cleanliness. ${ }^{33,36}$ Reproductive healthcare delivery was evaluated in all the papers. ${ }^{30,33,35,36,38}$

It was found that autonomy of the team, availability of manpower, clarity in the job description, roles and responsibilities, working conditions, workload and environment, the level of motivation, their education and training along with good supervisory practices contributed to the performance of healthcare personnel. ${ }^{33,} 38$

\section{Performance of the Health system/Centre}

Of the 15 articles selected, 9 studies assessed the performance of the centre or the health system. ${ }^{31,32 \text {, }}$ 34, 36, 37, 39-44 Satisfaction of patients, community, care providers and other stakeholders were the most common measures utilized for centre/health system performance assessment. The performance of the health system was assessed from the provider's perspective ( 4 articles), ${ }^{31,34,37,39}$ the consumer's perspective (4 articles) ${ }^{32,40,42,43}$ and both perspectives ( 2 article) ${ }^{41,44}$ at various levels.

\section{Perspective and structural levels of performance}

The target groups in the studies were individual patients, local community, district or country level. Health care personnel such as nurses, doctors and health managers along with other key stakeholders like local governing bodies were included. From the respondent's perspective, performance was defined as satisfaction, accessibility of the centre, case detection and success of the treatment provided in the country, care experiences, establishment of patient's bonds for treatment success and organizational care. Centre performance assessment was assessed as provider and patient bonding leading to therapy compliance and treatment success. This was also assessed in terms of costs and 
effectiveness of the services provided, the satisfaction of the providers and other stakeholders on the availability of resources and functioning of the centre. The scope of the centre performance assessment was at the structural levels of centre, community, district or country.

\section{Comparison with the WHO aspects of health systems performance assessment}

The measures described in the articles were compared with the six aspects of the WHO health systems performance assessment framework (Table 2) ${ }^{29}$ In the articles included, measures for three aspects (overall level of responsiveness, distribution of responsiveness and distribution of resources) were considered in relation to specific diseases/services, though the WHO framework uses systemspecific measures. Measures for disease/service specific WHO aspects (overall level of health, distribution of health in population and distribution of financial contribution) were less well represented in the fifteen articles. 
Table 2: Measures categorized as per WHO aspects of health systems performance assessment

\begin{tabular}{|c|c|c|c|c|c|c|}
\hline Measures & Overall Level of Health & $\begin{array}{l}\text { Distribution of Health } \\
\text { in Population }\end{array}$ & Overall Level of Responsiveness & $\begin{array}{l}\text { Distribution of } \\
\text { Responsiveness }\end{array}$ & Distribution of Resources & $\begin{array}{l}\text { Distribution of Financial } \\
\text { Contribution }\end{array}$ \\
\hline $\begin{array}{l}\text { Global standard: } \\
\text { Measures from } \\
\text { WHO aspects of } \\
\text { performance } \\
\text { assessment }^{15}\end{array}$ & $\begin{array}{l}\text { 1. Mortality rate: age and specific } \\
\text { 2. Morbidity rate: age and disease } \\
\text { specific } \\
\text { 3. Maternal Mortality Ratio } \\
\text { 4. Infant Mortality rate and } \\
\text { Neonatal Mortality rate } \\
\text { 5. DALE/DALY/HALE } \\
\text { 6. Life expectancy } \\
\text { 7. Disease and disability } \\
\text { prevalence }\end{array}$ & $\begin{array}{l}\text { 1. Immunization } \\
\text { coverage } \\
\text { 2. Antenatal care } \\
\text { 3. Natal care: } \\
\text { percentage of } \\
\text { deliveries attended by } \\
\text { trained personnel } \\
\text { 4. Growth monitoring } \\
\text { 5. Contraceptive } \\
\text { prevalence rate } \\
\text { 6. Emergence of } \\
\text { communicable } \\
\text { disease }\end{array}$ & $\begin{array}{l}\text { 1. Quality of care } \\
\text { 2. Client satisfaction }\end{array}$ & $\begin{array}{l}\text { 1. Availability and use of } \\
\text { facilities } \\
\text { 2. Human resources for } \\
\text { health }\end{array}$ & $\begin{array}{l}\text { 1. Human resources } \\
\text { 2. Healthcare facilities }\end{array}$ & $\begin{array}{l}\text { 1. Government health budget } \\
\text { 2. Contribution of } \\
\text { NGOs/donors on health } \\
\text { services } \\
\text { 3. Contribution for insurance } \\
\text { 4. Individual out-of-pocket } \\
\text { expenditure } \\
\text { 5. Measurement of health } \\
\text { system efficiency: Per } \\
\text { capita expenditure } \\
\text { 6. Education/ average years } \\
\text { of schooling }\end{array}$ \\
\hline $\begin{array}{l}\text { Measures from } \\
\text { review of } \\
\text { articles }\end{array}$ & $\begin{array}{l}\text { - Case detection and Treatment } \\
\text { Success Rate }{ }^{42} \\
\text { - Incidence, prevalence and } \\
\text { mortality by disease }{ }^{42} \\
\text { - Community health }{ }^{31} \\
\text { - Number of deliveries and } \\
\text { maternal mortality figures }\end{array}$ & $\begin{array}{l}\text { - Coverage of general / } \\
\text { program specific } \\
\text { services }^{37,39,42} \\
\text { - } \text { Community health }^{31}\end{array}$ & $\begin{array}{l}\text { - Client experience and satisfaction with quality of } \\
\text { care: privacy, doctor client interaction, nurse } \\
\text { client interaction, staff attitude, explanation, } \\
\text { economic feasibility, availability of drugs, cost of } \\
\text { service/drugs } 32,34,36,42 \\
\text { - waiting time, time with provider, cleanliness, } \\
\text { environment }{ }^{22,36} \\
\text { - Facility hours, privacy, patient records, health } \\
\text { education }{ }^{34} \\
\text { - Provider and key informant satisfaction with } \\
\text { budget, costs, financial resources, facility and } \\
\text { local management characteristics and linkages }{ }^{34} \\
\text { - Number of patients served }{ }^{30,34} \\
\text { - Provider client bonding } \\
\text { - Program implementation }{ }^{39} \\
\text { - Services / skill item performance: quality, } \\
\text { quantity, efficiency, problem solving capacity, } \\
\text { adaptability } 30 \\
\text { - Primary health care experiences with respect to: } \\
\text { access, gate keeping/ first contact, } \\
\text { comprehensiveness, coordination, family focus }{ }^{40,} \\
41 \\
\text { - Community orientation, Provider characteristics } \\
36,40 \\
\text { - Attributes of primary care- Longitudinality, } \\
\text { comprehensiveness, coordination }\end{array}$ & $\begin{array}{l}\text { - Use of antenatal, } \\
\text { childbirth, immunization } \\
\text { services, } \\
\text { environmentally induced } \\
\text { disease like malaria, } \\
\text { pneumonia, diarrhoea }{ }^{31,} \\
32,39 \\
\text { - Utilization of maternal } \\
\text { and child health services } \\
\text { like abortion, under } \\
\text { 5year mortality, } \\
\text { preventive \& curative } \\
\text { services, antenatal care, } \\
\text { delivery services, family } \\
\text { planning services }{ }^{32} \\
\text { - Availability and } \\
\text { coverage of care }{ }^{37,40} \\
\text { - Attributes of primary } \\
\text { care- first contact, } \\
\text { community orientation, } \\
\text { provider characteristics } \\
41\end{array}$ & $\begin{array}{l}\text { Human resources: } \\
\text { - Skill sets: prenatal, intra natal and } \\
\text { post-natal care protocol } 35,38 \\
\text { - Active participation in core } \\
\text { activities } 30,38 \\
\text { Attitude and characteristics of } \\
\text { provider- punctuality, response time, } \\
\text { absenteeism, supervisory practices, } \\
\text { collaboration, co-ordination, } \\
\text { community orientation, compliance } \\
\text { to health needs, health activities } \\
\text { performed }{ }^{33,36,37,39,40,41} \text { and } \\
\text { collaboration } \\
\text { Facility provision: Availability of } \\
\text { supplies, maintained registers, } \\
\text { cleanliness } 33,34,36,37 \\
\text { Accessibility } 34,40,41,43 \\
\text { - Organization accessibility (building } \\
\text { size to patient load) } \\
\text { - Economic accessibility } \\
\text { - Geographic accessibility } \\
\text { Basic Infrastructure: building } \\
\text { structure, toilet, clean running water, } \\
\text { electricity, communication, } \\
\text { equipment and instrument, furniture, } \\
\text { drugs and supplies } 34\end{array}$ & $\begin{array}{l}\text { - Funding received } \\
\text { /expenditure } \text { ext,42 }^{34} \text { Cost effectiveness }{ }^{34}\end{array}$ \\
\hline
\end{tabular}




\section{Discussion}

The aim of this review was to analyse the measures of PHC performance assessment used in developing countries as published in the empirical literature and to compare them with the WHO framework for health systems performance assessment. The fifteen articles that were considered provided scarce information on measurement quality and covered limited aspects of PHC performance when compared to the WHO health systems performance assessment framework.

\section{Performance of professionals}

Personnel performance was based on observation methods, assessed competency and noncompetency-based tasks. This correlated highly with patient satisfaction, an indicator of centre performance, as well as that of availability of resources, support and culture of the organization. ${ }^{45}$ The investigators used the 'Quick Investigation of Quality' tool that had been validated earlier. ${ }^{45,46}$ Such validated tools for observation of professional performance provide a quick and effective method for assessment of PHC personnel performance in a developing country. As reproductive and child health is one of the main focus areas of primary healthcare and an important health indicator, it is hence appropriate to use this in the evaluation of PHC performance as well.

\section{Performance of the centre}

The performance of the centre was assessed using the Primary Care Assessment Tool. ${ }^{40,41,43}$ This tool was validated in a developing country for family healthcare. ${ }^{41,47}$ It is interesting to note that this instrument could be used to assess the performance from the consumer's as well as from the provider's perspective. This tool provides an extensive list of surveys on different attributes of PHC. Based on the requirement of the evaluation, one could consider specific components. In other studies, measures such as costs, patients served and effectiveness along with the client satisfaction were identified. Cost effectiveness is an appropriate measure that can be used across all $\mathrm{PHCs}^{48}$ and thus, helps in making right choices by identifying the most effective service or intervention or centre. $^{48}$

\section{Perspective of performance}

Satisfaction of various stakeholders including patients and providers is an accepted standard in performance assessment as they are interrelated. Community participation in the functioning of the PHC highly influences the performance of PHC and its personnel, so it could be included as a component in the PHC performance assessment. ${ }^{34}$ 
The current practices of PHC performance assessment in developing countries were analysed with the WHO framework for performance assessment. ${ }^{17,} 29$ The WHO framework is completely focused on output and outcome, with the structure and process considered intrinsic to the system. However, for ease and clarity, many authors have used the Donabedian model for assessing performance in primary health care. ${ }^{9}, 23,26,49$ The current review highlights the limited representation of the performance measures in relation to aspects of the WHO framework (Table 2). In the articles, even the tools used to assess personnel performance (Quick Investigation of Quality tool) and centre performance (Primary Care Assessment Tool) did not represent measures from three aspects: overall level of health, distribution of health in the population and the distribution of the financial contribution. ${ }^{40,41,47}$

Due to lack of resources and data ${ }^{10,18}$ covering the complete list of WHO aspects to the full extent will be difficult for developing countries. However, a concise list of measures with an appropriate representation of six WHO aspects and requiring minimum resources and data, needs to be developed for PHC performance assessment in developing countries. If the assessment uses standardised measures useful comparisons across regions/countries would be possible. Since the search results indicated that a very small number of articles were published, further research needs to be conducted in the developing countries on PHC performance assessment, enabling cross learning and knowledge base enhancement. ${ }^{21}$

\section{Discussion on methodological quality of articles}

Although the number of articles in this review was limited, the studies covered diverse countries and continents. Assessing the quality of the papers was a challenge as articles used qualitative, quantitative and mixed methodology. The articles demonstrated reliability and validity methods such as correlating provider and user experiences, data/method triangulation, standardised tools/training of researchers. Hence, there is a need for research in developing countries to establish quality of measurement and standardisation of PHC performance assessment using rigorous statistical methods.

\section{Implications for future research}

PHC performance assessment in developing countries is an emerging field but it is fragmented at present. Though human resource for health is a component of the WHO framework, the various subcomponents to be included are not clear. Evaluation of the PHCs is an on-going exercise, but yet 
there is no established standard for assessing performance. Studies have shown that the performance of PHC depends on several things, one critical factor being personnel performance. ${ }^{21,29,50,51,52}$

\section{Implications for practice}

Measures such as skill sets for execution of healthcare focusing on mother and child health, were emphasised in five studies our review and this is in line with Millennium Development Goals and Sustainable Development Goals. ${ }^{1,2}$ However, other aspects are still not covered. The performance measures should be appropriate and adequate enough to enable accurate assessment on an ongoing basis to aid in monitoring and efficient management of the personnel/system. There is urgency to develop such measures as PHC performance is a matter of immense importance for policy agenda and political priorities. ${ }^{53}$

\section{Conclusions}

Although developing countries may have difficulties in applying the entire WHO framework, the current measures for assessment of PHC performance published in scientific journals are limited in scope and lack validation. The standard health indicators for the overall level of health and for the distribution of health in the population were represented least. A comprehensive assessment of primary healthcare can be achieved by integrating personnel performance with that of centre performance. Representation/inputs from both sides of the service delivery, the management and the consumer/public, that is, including the provider's perspective and consumer's perspective, are vital. From this review, it can be concluded that existing measures for PHC performance assessment in developing countries need to be validated and concise measures for neglected aspects need to be developed. 


\section{References}

1. The Millennium Development Goals Report 2015. https://www.un.org. Accessed on 4 Jan 2016.

2. The Sustainable Development 2016. http://www.un.org/sustainabledevelopment/development-agenda/ 2016. Accessed on 4 Jan 2016.

3. UN Press release 2015. Maternal death ratio has fallen 44 percent since 1990-UN. https://www.unfpa.org/press/maternal-death-ratio-has-fallen-44-cent-1990-\%E2\%80\%93-un. Accessed on 7 Oct 2016.

4. The Global strategy for women's children's and adolescent's health 2016-2030: survive thrive transform 2015. http://www.who.int/life-course/partners/globalstrategy/globalstrategyreport2016-2030-lowres.pdf?ua=1. Accessed on 7 October 2016.

5. Donnay F. Maternal survival in Developing countries: what has been done, what can be achieved in the next decade. International Journal of Gynaecology and Obstetrics. 2000;70:89-97.

6. Urban health report. 2016. http://apps.who.int/iris/handle/10665/204715. Accessed on 7 Oct 2016.

7. Global status report on non-communicable diseases 2014. https://apps.who.int/iris/bitstream/10665/148114/1/978941564854_eng.pdf?ua=1. Accessed on 7 Oct 2016.

8. Alma-Ata. 1978. Primary Health Care: Report of the International Conference on Primary Health Care Alma-Ata, USSR: 6-12 September 1978. https://www.who.int.en. Accessed on 5 Jan 2015.

9. Mays G P, Halverson P K, Millerr C A. Assessing the Performance of Local Public Health Systems: A survey of State Health Agency Efforts. Journal of Public Health Management Practice. 1998;4(4):63-78.

10. Groene O, Skau J K H, Frolich A. An international review of projects on hospital performance assessment. International Journal of Quality in Health care. 2008;20(3):162-171.

11. Scutchfield F D, Knight E A, Kelly A V, Bhandari M W, Vasilescu L P. Local Public health agency capacity and its relationship to public health system performance. Journal of Public Health Management Practice. 2004;10(3):204-215. 
12. John R, Kelly J Carlson. National Public Health Performance Standards Assessment: First steps in strengthening North Dakota's Public Health System. Journal of Public Health Management Practice. 2005;11(5):422-42.

13. Panda B, Thakur H P. Decentralization and health system performance - a focused review of dimensions, difficulties, and derivatives in India. BMC Health Services Research. 2016;16 Suppl 6:561. doi 10.1186/s12913-016-1784-9.

14. Carter R, Riverin B, Leversque J F, Gariepy G, Vallee A Q. The impact of primary care reform on health system performance in Canada: a systematic Review. BMC Health Services Research 2016;16:324. doi 10.1186/s12913-016-1571-7.

15. Business dictionary. http://www.businessdictionary.com/definition/performance.html. Accessed on 16 Aug 2017.

16. Hamilton K E, Coates V, Kelly B, Boore J R P, Cundell J H, Gracey J, Mcfetridge B, McGonigle M, Sinclair M. Performance assessment in healthcare providers: a critical review of evidence and current practice. Journal of Nursing Management. 2007;15:773-791.

17. The World Health Report 2000. Health Systems: Improving Performance. https://www.who.int.en. Accessed 1 Nov 2014.

18. Albuquerque I F, Cunha R C. Martins S D, Brito A Sa. Primary health care services: workplace spirituality and organizational performance. Journal of Organizational change management. 2014;27(1): 59-82. https://doi.org/10.1108/JOCM-11-2012-0186

19. Kurk M E, Freedman L P. Assessing health system performance in developing countries: A review of literature. Health Policy. 2008;85:263-276.

20. Unknown Author. Primary Health Care Performance Initiative. 2015. https://www.iapo.org.uk/sites/default/files/files/Final\%20PHCPI\%202-Pager\%206_5_15.pdf. Accessed on 17 Feb 2016.

21. Tashobya C K, Silveira V C, Sengooba F, Orem J N, Macq J, Criel B. Health systems performance assessment in low-income countries: learning from international experience. Globalization and Health. 2014;10:5.

22. Mills A, Palmer Natasha, Gilson L, McIntyre D, Schneider H, Sinanovic E, Wadee H. The performance of different models of primary care provision in Southern Africa. Social Science and Medicine. 2004;5:931-943. 
23. Wong S T, Yin D, Bhattacharyya O, Wang B, Liu L, Chen B. Developing a Performance Measurement Framework and Indicators for Community health service facilities in Urban China. BMC Family Practice. 2010;11: 91.

24. Bandaranayake D. Assessing Performance Management of Human Resources for Health in South-east Asian Countries: Aspects of Quality and Outcome. Workshop on Global Health Workforce Strategy. WHO 2001. 2001. http://www.who.int/hrh/en/Assessing_performance.pdf 1. Accessed on 1 Oct 2015.

25. Essers G, Dulmen S, Weel C, Vlueten C, Kramer A. Identifying context factors explaining physician's low performance in communication assessment: an explorative study in general practice. BMC Family Practice. 2011;12:138. https://doi.org/10.1186/1471-2296-12-138

26. Baars I J, Evers S M AA, Arntz A, Merode G G. Review Performance measurement in mental health care: present situation and future possibilities. International Journal of Health Planning and Management. 2010;25:198-214

27. Terwee CB, Mokkink LB, Knol DL, Ostelo RWJG, Bouter LM, de Vet HCW. Rating the methodological quality in systematic reviews of studies on measurement properties: a scoring system for the COSMIN checklist. Quality of Life Research. 2012;21(4):651-657.

28. Noben, C., de Rijk, A., Nijhuis, F., Knottner, J. \& Evers, S. The exchangeability of self-reports and administrative health care resource use measurements: assessment of the methodological reporting quality. Journal of Clinical Epidemiology. 2016;74:93-106.

29. Health Systems Performance Assessment: Debates, Methods and Empiricism. WHO Publication. 2003. http://www.who.int/health_financing/documents/cov-hspa/en/. Accessed on 10 Sept 2015.

30. Alam, K.S, Tasneem S., \&Oliveras E. Performance of female volunteer community health workers in Dhaka urban slums. Social Science \& Medicine. 2012;75(3):511-515.

31. Ashwell H E, Barclay L. Problems Measuring Community Health Status at a Local Level: Papau New Guineas’s Health Information System. Rural Remote Health. 2010;10(4):1539.

32. Awadalla H I, Kamel E G, Mahfouz E M, Refaat T M. Evaluation of Maternal and Child Health Services in El-Minia City, Egypt. Journal of Public Health. 2009;17(5):321-329.

33. Bradley S, Kamwendo F, Masanja H, Pinho H, Waxman R, Boostrom C, McAuliffe E. District health managers' perceptions of supervision in Malawi and Tanzania. Human Resource for Health. 2013;11:43. 
34. Varatharajan D, Thankappan R, Jayapalan S. Assessing the Performance of Primary Health Centres Under Decentralized Government of Kerala, India. Health Policy and Planning. 2004;19(1):41-51.

35. Fort A L, Voltero L. Factors affecting the performance of maternal health care providers in Armenia. Human Resources for Health. 2004;2-8. https://doi.org/10.1186/1478-4491-2-8.

36. Lannes L. Improving health worker performance: The patient-perspective from a PBF program in Rwanda. Social Science and Medicine. 2015;138:1-11.

37. Stosic M, Lazarevic N, Kuruc V, Ristic L. Assessment of the role of primary health care in tuberculosis control in Serbia. MedicinskiPregled (NoviSad). 2015;68:331-335.

38. Uneo E, Adegoke A. A, Masenga G, Fimbo J, Msuya S E. Skilled Birth Attendants in Tanzania: A descriptive study of cadres and emergency obstetric care signal functions performed. Maternal and Child Health Journal. 2015;19:155-169.

39. Shreedevi D. Gap analysis and the performance of primary health centres in the implementation of the school health programme of NRHM. International journal of Research in Business Management. 2014;2(2):1-8.

40. Macinko J, Almeida C, KlingelhoeferdeSa P. A Rapid Assessment Methodology for the Evaluation of Primary Care Organization and Performance in Brazil. Health Policy and Planning. 2007;22(3):167-177.

41. Macinko J, Almeida C, Oliveira ES, Klingelhoefer P S. Organization and delivery of primary healthcare services in Petropolis, Brazil. International Journal of Health Planning and Management. 2004;19:303-317.

42. Akachi Y, Zumla A, Atun R. Investing in Improved Performance of National Tuberculosis Programs Reduces the Tuberculosis Burden: Analysis of 22 High-Burden Countries, 2002-2009. The Journal of Infectious Diseases. 2012;205: Suppl 284-292.

43. Arakawa. T, Arcencio R. A, Scatolin B E, Scatena L. M, Netto A R, Scatena Villa T C. Accessibility to Tuberculosis treatment: Assessment of Health Service Performance. Rev Lat Am Enfermagem. 2011;19(4):994-1002.

44. Ponce M A Z, Vendramini S H F, Santos M R dos, Santos M L S G, Santena L M, Villa T C S. The Establishment of Bonds between Professional and Patient in TB treatment: The Performance 
of Primary Health care Services in a city in the Interior of Sao Paulo. Rev Lat Am Enfermagem. 2011;19(5):1222-9.

45. Leonard L K, Masatu M C, Herbst C H, Lemiere C. The systematic assessment of health worker performance: a framework for analysis and its application in Tanzania. Discussion paper, World Bank Group: Health, Nutrition and Population. 2015. http://documents.worldbank.org/curated/en/127281467987859436/The-systematic-assessmentof-health-worker-performance-a-framework-for-analysis-and-its-application-in-Tanzania. Accessed on 10 Oct 2016.

46. Measure Evaluation. Quick investigation of quality (QIQ): a user's guide for monitoring quality of care in family planning. 2nd ed. Chapel Hill, North Carolina: MEASURE Evaluation, University of North Carolina; 2016.

47. Primary Care Assessment Tools. http://www.jhsph.edu/research/centers-and-institutes/johns-hopkinsprimary-care-policy-center/pca_tools.html. Accessed on 12 Oct 2016.

48. Drummond M F, O’Brein B, Stoddart G L, Torrance G W, editors. Methods for Economic Evaluation of Health Care Programmes. $2^{\text {nd }}$ ed. Oxford: Oxford Medical Publication; 1997.

49. Donabedian A. The effectiveness of quality assurance. International Journal for Quality in Health Care. 1996;3(4):401-407.

50. Rajan A. India: Health System Performance Assessment. ISBN:978-93-82411-06-2. http://www.shyaminstitute.in/hsperformance.pdf (2013). Accessed 5 Dec 2015.

51. Kalinichenko O, Carla A F, Santos S P. Performance Assessment in Primary Health Care: A systematic Literature Review. CEFAGE-UE Working Paper 2013/03. www.cefage.uevora.pt/en/content/download/3466/45683/version/1/.../2013_03.pdf. (2013). Accessed 10 Oct 2015.

52. Unknown Author. Performance Evaluation Study of NRHM in Karnataka. Final report Vol1, submitted to CEO, Karnataka Evaluation Authority. http://www.graam.org.in. Accessed 1 Oct 2015.

53. Terwindt F, Rajan D, Soucat A. Chapter 4. Priority-setting for national health policies, strategies and plans. In: Schmets G, Rajan D, Kadandale S, editors. Strategizing national health in the 21st century: a handbook. Geneva: World Health Organization; 2016. https:// http://www.who.int/healthsystems/publications/nhpsp-handbook-ch4/en/. Accessed 4 Oct 2017. 


\section{Chapter 3}

\section{Primary Healthcare Centres Performance Assessment: Perspectives of Patients in India}

Bangalore Sathyananda, R. Krumeich, A, Manjunath, U., de Rijk,A., van Schayck,C.P.

Submitted 
Title:_Primary Healthcare Centres Performance Assessment: Perspectives of Patients in India

\begin{abstract}
Introduction: India's healthcare system is, for a large part, organized around a vast network of Primary Healthcare Centres (PHCs) that form the pillar on which the public healthcare sector functions. The World Health Organization (WHO) is emphasizing the important role that PHCs play in strengthening community health and the provision of healthcare. Although a few studies have assessed specific elements of services offered by PHCs, none has evaluated their overall performance particularly in developing countries. The aim of this study was to explore PHC performance from the patient's perspective and in relation to the WHO framework of performance assessment.
\end{abstract}

Methodology: A qualitative research methodology was employed to explore the opinions of 188 patients attending one of three PHCs in Bengaluru (India), using interviews. The topic list covered criteria assessing PHC performance, and information regarding the concerns of patients and the claims they were making. Analysis followed the directions of Fourth Generation Evaluation.

Results: According to the patients, PHC performance includes nine themes: the availability of rich and diverse services; the capability to carry out effective diagnoses; the cost and availability of medicines; the quality of the infrastructure; the cost of care; the behaviour and communication skills of staff; the effectiveness of care and how well it is organized; and the punctuality of staff.

Conclusion: The criteria that are of primary importance to patients should be included in the assessment that are carried out, implying that the WHO framework needs to be adapted thereby contributing towards a holistic PHC performance assessment. 


\section{Introduction}

Global economic and technological developments in the late $20^{\text {th }}$ and in the $21^{\text {st }}$ century have had a huge impact on the lives of millions of people, especially in those areas, such as medical care, where improvements have prolonged longevity and the quality of life. The general improvements in the health of populations in developing countries have reflected this trend. However, while significant progress has been achieved by developing countries, many developing countries are still struggling to reduce critical health challenges, such as the burden of communicable diseases; the death of women and babies during childbirth; the death rates of children under 5 years of age from preventable causes; and the incidence and prevalence of non-communicable diseases among adults. ${ }^{1-}$ 7

It is in response to this struggle that as early as in 1978, the declaration of Alma Ata was adopted at the International Conference on Primary Health Care at Almaty, Kazakhstan, in September of that year, with the principle of establishing "primary healthcare" as the means of improving the provision of local and national healthcare. Primary healthcare addresses the health of the population by focusing on improving the following: reproductive health; children's healthcare; the accessibility of vaccinations; the provision of essential medicines; and the promotion of good healthcare practices and education at specific centres called Primary Healthcare Centres (PHCs), which are an essential component of the United Nations third sustainable development goal. ${ }^{2,8}$ It is in light of these developments that PHCs form the major building block of healthcare systems throughout the world.

India's healthcare system, for instance, is for a large part organized around PHCs. In India, a vast network of PHCs form the pillar on which the public healthcare sector functions, and they focus on maintaining and improving the general health of the population by providing services in the field and at designated centres. These PHCs provide care in relation to reproductive health; children's health; and family welfare programmes, as well as in terms of the prevention and control and treatment of communicable diseases, such as tuberculosis, leprosy, malaria, dengue fever, chikungunya virus infections, and filariasis. In addition, these centres offer diagnosis and treatment for noncommunicable diseases such as diabetes; hypertension; stroke and cancer; care for AIDS patients; deficiency diseases; and blindness. PHCs also offer patients their first contact with medical personnel (doctors) working in the public healthcare system.

Given the important role that PHCs play, an assessment of their performance is a key issue. Although the assessment of general healthcare services has received much attention, ${ }^{9-14}$ the performance of 
PHCs has received less consideration. ${ }^{15}, 16$ While there are a few studies that have assessed specific elements of the programmes or services delivered at PHCs, none of them evaluated the overall functioning of PHCs, especially not in the Indian context. ${ }^{16}$

Although, the World Health Organization (WHO) has developed a framework for carrying out performance assessments of healthcare services, this framework has not been specifically applied to PHCs. ${ }^{15}$ The WHO model broadly distinguishes six aspects that must be considered during a performance assessment: overall levels of health; the distribution of health in the population; the overall level of responsiveness of the health system; distribution of responsiveness; the distribution of resources; and distribution of financial contributions. ${ }^{15,16}$ Measures that form the framework for the WHO model range from general health indicators such as life expectancy and neonatal/infant mortality, to measures that are vast in scope and unspecific, such as the quality of care and client satisfaction.

The literature review on PHC performance assessments carried out in developing countries showed that various aspects and measures from the WHO model were frequently utilized, ${ }^{16}$ and also indicated that evaluations of how well the PHCs were operating involved parameters that assessed the performance of centres and their personnel, all of which involved perspectives from both consumers and providers. Figure 1 depicts a revised model aligned to PHC performance assessment in developing countries. ${ }^{16}$

Furthermore, it has been shown that good performance depends on a large part on the context in which the evaluation is carried out, and so any evaluation should reflect the specificity of the environment in which PHCs operate. Any assessment of performance is a result of the interaction of a number of factors: a person's background, that is, his or her cultural, educational, and socio-economic status; evaluations of his or her past experiences of the healthcare received; and information on his or her underlying expectations. Therefore, what is considered to be a "good" performance differs between stakeholders. ${ }^{17}$

Given that all the preventive and promotive services offered by PHCs are directed at patients in a manner that will enable the centres to fulfil sustainable development goals (SDGs) and that patients are the beneficiaries of the centres, the patients (the "clients") form the fundamental stakeholders in the public healthcare system. Because community participation and monitoring have been recognized by the Indian government as key elements that contribute to the achievement of enhanced health in the population, ${ }^{18}$ it has become important to take into consideration the opinions of various stakeholders and to emphasize the views and expectations of the patients. In line with this, the objective of this study was to explore PHC performance from the perspective of the patients and to 
see how well the application of the WHO's model succeeded in reflecting the level and quality of services delivered "on the ground" and whether this model needs to be adapted.

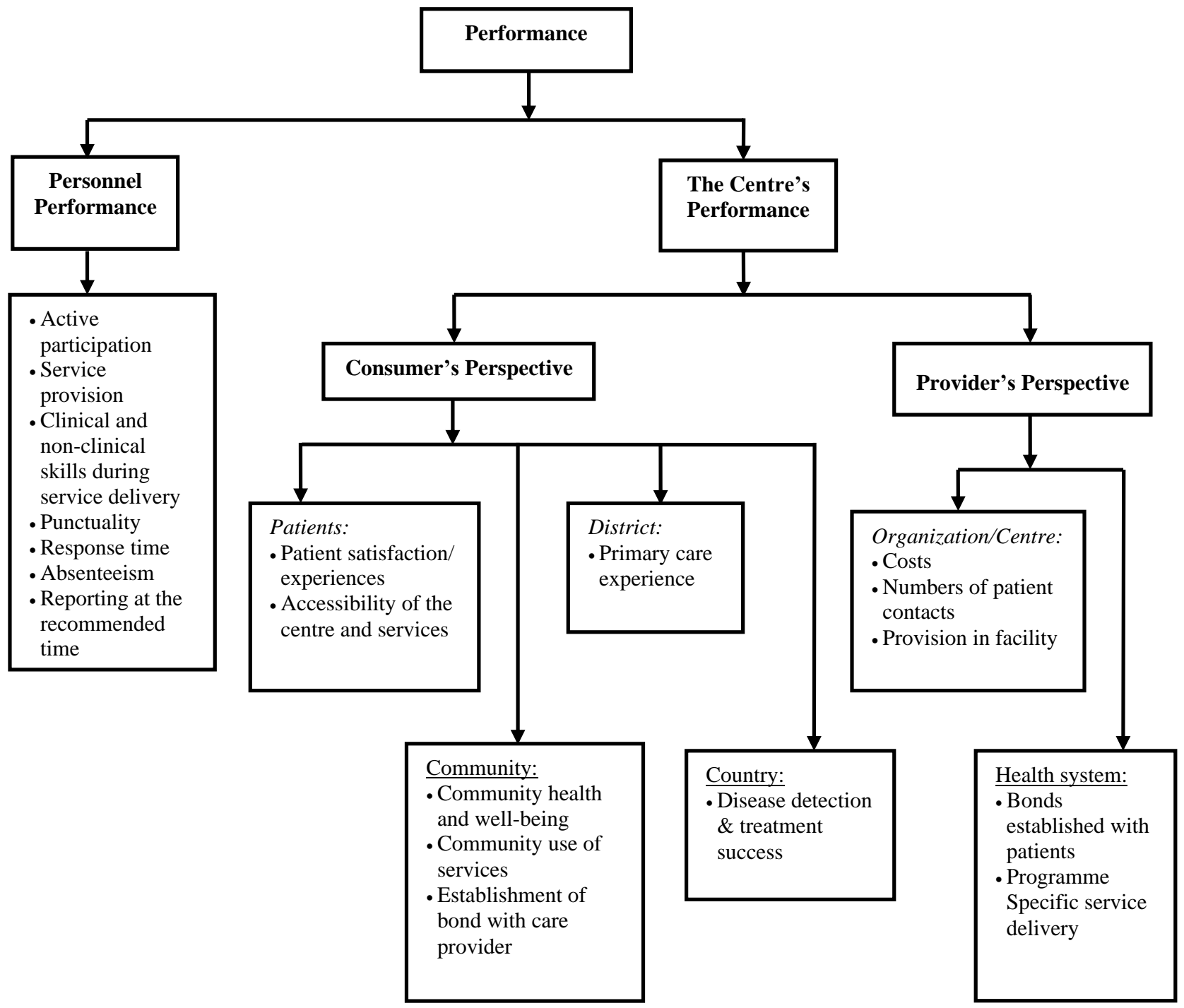

Figure 1: PHC performance in developing countries ${ }^{16}$

\section{Goal of the research and the questions posed during the analysis}

This study will focus on the performance of PHCs from the perspective of patients in the urban district of Bengaluru, Karnataka, India. Indian PHCs deliver preventive care to the community by means of subcentres, each of which focuses on a population of one to five thousand. The subcentres are operated by junior healthcare assistants (both male and female), who are supported by accredited social health activists at the village level and who form the link between the community and the PHC. Here, the major emphasis is on preventive and promotive interventions and interactions, which involve activities such as community-needs assessments; larval surveys; follow-up visits of patients with tuberculosis or leprosy; visits to pregnant and postpartum women; the immunization of children; and other tasks. All of these activities take place in homes located within the communities 
and focus on implementing community health activities that have been initiated by the government. The PHCs involve medical officers, staff nurses, pharmacists, and lab technicians, all of whom deliver basic curative healthcare and maternal and child health services, along with various national health programmes. Because assessments of the performance of these PHCs are important for the continuing functioning of the Indian public healthcare system, the following research questions were crucial in carrying out the analysis described in this article:

1. How do patients describe the functioning of their PHCs?

2. To what extent do the parameters detailed by patients reflect the WHO model for PHC performance?

3. How can the parameters detailed by patients be reflected in a model assessing PHC performance?

\section{Methodology}

\section{Study design}

A qualitative research methodology was employed in this study to explore the opinions of patients. The research carried out and reflected here applied a number of criteria to assess PHC performance, and also explored various matters that are of concern to patients, together with their claims, following Fourth Generation Evaluation methodology. ${ }^{17}$ This study adhered to the strict ethical principles required by legitimate research and incorporated the suggestions and recommendations made by the Ethics Review Committee of Manipal University, Manipal, India.

\section{Study setting and context, including selection of the PHCs to be assessed}

This research was conducted in three PHCs located in an urban district of Bengaluru, Karnataka State, India. The Bengaluru urban district is administratively divided into four talukas/blocks, and there are 20 PHCs that operate 24 hours a day, seven days per week. The numbers of pregnant women who delivered babies at these centres are related to the number of patients utilizing the services at the PHC, thus reflecting the general performance of the PHC concerned; this information is reflected in the reports on performance assessment.${ }^{19}$ Hence, the PHCs were arranged on the basis of the number of deliveries conducted in the last financial year to identify high-, medium-, and lowdelivery load PHCs. Included in this study was one PHC that carried out the most deliveries in terms of the population covered; it was thus assessed as being a high-performing PHC. One PHC which was in the middle of the list was taken as a medium-performing PHC; and the PHC with the least 
number of deliveries was evaluated as the least-performing PHC. These PHCs were included in the study in order to document the response of patients in terms of what they had experienced.

\section{Study participants and sampling}

The adult patients or the parents/guardians of children/patients were approached when they visited PHCs for care, the aim of the study was explained to them with an option to exit interview at any point of time and those willing to provide written informed consent were included in the study. One hundred and eighty-eight persons who were utilising the facilities at three PHCs in the Bengaluru urban district were interviewed between September 2017 and January 2018. The 45 male and 143 female persons who were interviewed were aged between 19 to 84 years of age, and were from various walks of life. They included housewives, students, labourers, and working professionals with experience in various domains; the duration of the interviews varied from 8 to 40 minutes. The details of the interviewees are included in Table 1.

Table 1: Details of the PHCs and the Patients Interviewed

\begin{tabular}{|c|c|c|c|c|c|}
\hline $\begin{array}{c}\text { Name of the } \\
\text { PHC }\end{array}$ & $\begin{array}{c}\text { Total } \\
\text { Population }\end{array}$ & $\begin{array}{c}\text { Number of } \\
\text { Deliveries } \\
\text { Conducted at the } \\
\text { PHC from 2016 } \\
\text { to 2017 }\end{array}$ & $\begin{array}{c}\text { Male } \\
\text { Interviewees }\end{array}$ & $\begin{array}{c}\text { Total } \\
\text { Female } \\
\text { Interviewees }\end{array}$ & $\begin{array}{c}\text { Number of } \\
\text { Patients } \\
\text { Interviewed }\end{array}$ \\
\hline $\begin{array}{c}\text { PHC } \\
\text { Dommasandra }\end{array}$ & 56,081 & 390 & 5 & 29 & 34 \\
\hline $\begin{array}{c}\text { PHC } \\
\text { Hesarghatta }\end{array}$ & 48,037 & 134 & 29 & 64 & 93 \\
\hline $\begin{array}{c}\text { PHC } \\
\text { Sarjapura }\end{array}$ & 54,513 & 22 & 11 & 50 & 61 \\
\hline \multicolumn{7}{c}{ Total } & & $\mathbf{4 5}$ & $\mathbf{1 4 3}$ & $\mathbf{1 8 8}$ \\
\hline
\end{tabular}

\section{Data collection}

The perception of the performance of the PHC and its parameters were obtained from the patients, who were interviewed in their local language in order to elicit their claims and their concerns, and to discover the criteria that they were applying during their evaluations. New patients were included until no new point was added (data saturation). ${ }^{17}$ An interview guide in the local language was used by the first author, who was helped by a research assistant during the data collection. The interview elicited a patient's general information; the reasons for visiting the PHC at that moment in time and in the past; and his/her perceptions/experiences of various services at PHC. Because the interviewees varied in terms of their educational background, it was observed that the information that was given by some interviewees was quite scanty, whereas some were very willing and happy to share 
observations about their experiences. The researchers noted that some interviewees were suspicious at first, but once the details regarding objectives of interview were explained and after assurances of confidentiality were given, they were willing to share their information. The detailed description of the data was obtained mostly from educated patients, from patients who were eager to participate, and from those who were generous in terms of their observations.

\section{Data analysis}

The interviews from patients were translated and were transcribed verbatim; afterwards the data was analysed using Atlas-TI. The participants' personal details were removed and audio files were used in order to maintain confidentiality. Primary and secondary codes were applied during the analysis of the data, which enabled various themes/parameters of the PHC (from the patient's perspective) to be identified. The information was then evaluated by means of the method of thematic analysis ${ }^{20}$ and Fourth Generation Evaluation principles. ${ }^{17}$

\section{Results}

After an analysis of the interviews was carried out, the following criteria emerged as the parameters that patients applied while they were assessing a PHC's performance: What was key for patients was that the services that were provided by the PHC met their expectations in relation to both the centre and its personnel.

The components of performance assessment (themes that emerged) in relation to the PHC were as follows:

\section{Theme one: the PHC — Rich and diverse services are available}

The availability of rich and diverse services (including emergency care, the presence of female doctors, and of specialist services) were understood by patients as follows:

- Patients expected that doctors would be available round the clock or on campus, thus ensuring the uniformity in duration of service delivery. Patients made the following comments: "If services are available 24 hours [a day], it will be really good"; and "The doctor was not there ... I got treatment from the nurse".

- Whether care was available for complicated/emergency cases was expressed in the following manner: "Here they are not treating complicated cases or severe diseases"; "For bigger health problems, there is no good facility to treat them"; "They should have facilities to treat emergencies like accidents, et cetera"; "If children have jaundice, they refer them elsewhere, 
so if there (were) facilities to handle all that, it [would] be nice and all [would] come here"; and finally, "They should have the facility to treat emergencies like accidents, etc. ... It would be improved more, [and] then, [the] public will have faith and come here more".

- They expected that a female doctor would be available at the PHC, because "Ladies will hesitate to tell their problems to a male doctor, for example if they come for a delivery or any other problem, it will be easier if there is a lady doctor".

- Assessments in regard to availability also involved specialist services - for instance one of the patients wanted specialist services at the PHC and said: "If we have a fever, they give injections and tablets; no other specialists are available here. ... It will be good to have specialists. ... If we have specialists then we don't have to go outside [to private hospitals]. [For an] eye specialist... [or for an] ear [specialist), ... we go to private hospitals because no specialists are available". Another patient said that "There should be an orthopaedic doctor; other than [a] the doctor treats everything. ... Here they are not treating complicated cases or severe diseases. ... If we have specialists to treat all these conditions, it will be good. ... If particular specialists are there, it will improve the hospital and more patients will come and it will be helpful to people".

\section{Theme two: the PHC_Diagnostic services are available}

Patients mentioned that an important criterion for assessment was the availability of diverse diagnostic services. Patients gave the following views: "[A] laboratory with facilities [that can give] sugar tests and other tests should be [available], [just] like in bigger hospitals. ... For complete blood check-ups, it [would] be very helpful. ... Doing the blood check-up for proper diagnosis would be good; this is what I feel. If it improves, most of patients will come here". "For scanning, we have to go far from here, so if they provide [a] scanning facility here ... it would be helpful". The reasons given for these answers were to reduce the financial burden on patients, who had to travel and had to pay fees for diagnostic services at private facilities.

\section{Theme three: the PHC-Medicines are readily available}

Patients were positive about the availability of medications: "They give... medicines". On the other hand, they were disappointed if their expectations of free medications were not met: "[A] few medicines are not available here. ... It is not in the medicine rack". "Some time back, tablets for colds were not supplied, and so the doctor was buying them privately for many days". 
The requirements in terms of infrastructure are stricter for private facilities in comparison to government facilities. When assessing the infrastructure in the PHCs, patients expressed the need for better buildings and commented on the following: the availability and quality of toilets; whether the water was clean and good; adequate lighting and electricity; solid furniture; well-tiled floors; and well-painted walls. They made the following comments: "As soon as one looks at the hospital, it should change the mind set and one should want to come to hospital [for care]". "This building is there for a long time; if it is improved a bit, [that would] be good. For a government hospital, this is okay". "Private hospitals have [everything] within the hospital". "Good drinking water... electricity, chairs for patients to sit [are important]". "In our hospital, if toilets are neat, it's enough ... because patients keep going [to use] them, [but] there is only one toilet ... more toilets are needed". "There was no painting [on the] building, but now they have done the painting". "If they put [in] tiled flooring, it would be good. ... It would be cleaner and [would] look better”.

\section{Theme five: the PHC-The cost of care to the patients is a benchmark}

The cost of care and medicines emerged as the fifth benchmark for patients utilizing the services at PHCs, and was a major deciding factor when patients were assessing the services offered. Patients appreciated free services: "We have no brain [We don't understand], so we go to private hospitals. ... Looking at the facilities here, everything is nice. ... I would have saved a lot of money [if I had come here earlier]"; "I would have to spend a lot of money if I had gone to a private hospital". "Here we did not spend any money". "They give medicine free of cost. ... The cure that I got from here was good". Because the PHC is a government facility, patients expected to avail themselves of free services and were disappointed if they had to pay for care: "Here they took money for blood checkups; I did not know that they take money here. ... They said they have to buy some material and we have to pay". "Today, I have been prescribed a spray, and they tell [me] I have to buy it outside".

\section{Theme six: The behaviour and attitudes of PHC personnel are important}

The way in which the staff behaved and their attitudes and how they communicated with the patients emerged as an important criterion for patients accessing the performance of services at a PHC. The evaluation of communication skills involved several different aspects. For instance, one patient stated that "They should be attractive, not [wearing] makeup or [focusing on] looks; firstly, the[ir] way of talking should be good". Comments did not focus on how staff looked physically: what was important was that they were well-spoken, gentle, and caring. One patient stated: "[A] good person; 
takes care [and is] nice; ... will not scold and will not say anything [that make one feel bad]". Caregivers' empathy with patients was also important: “They should understand the patients".

\section{Theme seven: Do personnel effectively care for patients?}

The effectiveness of the treatment provided by doctors and nurses was one of the norms that patients applied when assessing the performance of a PHC. As one patient stated, "Doctors are treating [us] well. ... As soon as we come, they will ask what the problem is; if we have fever and other [conditions], they give tablets and injections". "Whenever I come, my sickness was cured with the medicines they have given". "Everybody used to say that government doctors [are able to] treat well for leg pain".

\section{Theme eight: Personnel are punctual}

The punctuality of doctors was also a significant factor: "In this hospital, before there was a doctor who used to go back very early, around 2 p.m., so I asked her [the following question]: 'You come here to serve patients; if you leave so early, what about your patients?' I asked in this compound only and now she has been transferred. ... There also was a doctor called XXX from YYY [place]. I don't know when he used to have his food or his sleep; he was such a service-oriented person even these two doctors [who are currently working here] are also [the] same like him only [they work well]. Nowadays, we don't get such types of people". The day I came, the doctor was not there; I waited and left, [and] the sister was not there too. ... They apologized for their absence the next time I came".

\section{Theme nine: Personnel are well-organized}

The way services were delivered and whether the facility was well-organized, the ninth criterion, were important factors that were considered by patients during assessments. It was important to patients that the facility functioned efficiently, and they considered that doctors played a key role in this. Doctors were expected to maintain discipline by being strict towards the patients as well as towards other PHC personnel. Disciplining patients was expressed as the doctors emphasizing the following: "They give (out) tokens and we wait for our turn". "If there are many patients, we maintain a queue. ... They instruct us to [respect] the queue and keep silent”. Patients also assessed the performance of the PHC on whether and how doctors controlled other staff, stating: "[A] better maintained PHC would prevent all the staff from acting on their own and neatness should be maintained around the PHC". "Strict doctors should come and should maintain neatness. They should grow plants and trees [in the vicinity of the PHC]". Figure 2 illustrates the themes expressing of the performance of PHCs in an urban public healthcare setting from the perspective of patients. 


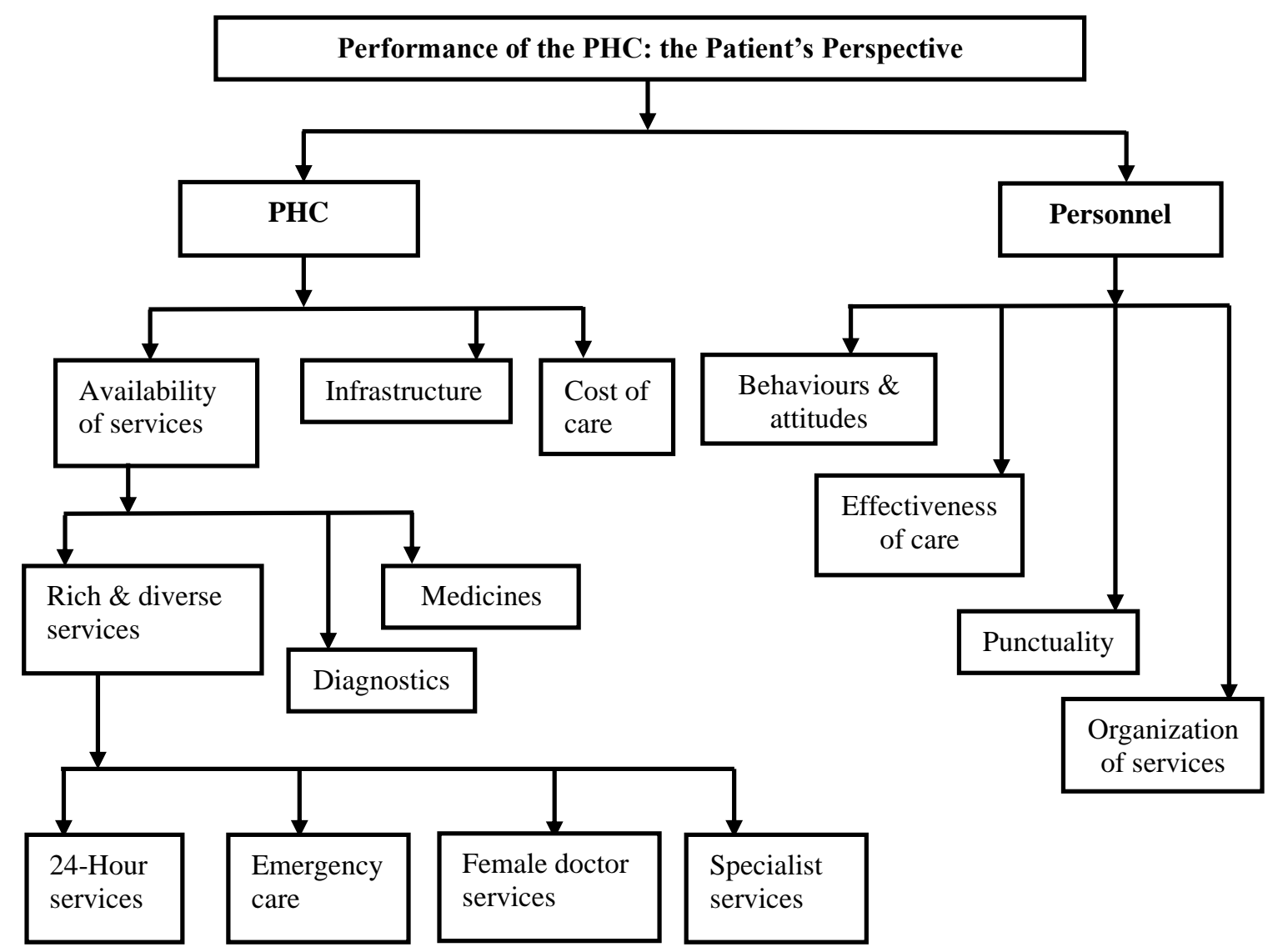

Figure 2: Performance of the PHC from the patient's perspective

\section{Discussion}

The study was conducted at three PHCs in the Bengaluru urban district in the state of Karnataka, India. Interviews with 188 patients were transcribed and were analysed by the application of a qualitative methodology. Nine themes (constituting crucial criteria) were found to be of significance to the patients utilizing services at these PHCs. They are: the availability of diverse and rich care by doctors round the clock and by specialists; access to diagnostic services; the availability of medicines; a well-maintained PHC infrastructure; considerations of the cost of care and medicines; the behaviour and attitude of staff; the punctuality of personnel; the effectiveness of the prescribed treatments; and the presence of well-organized services that enabled the PHC to function efficiently. These performance criteria were important to the patients, irrespective of the positive or negative assessment during interview.

\section{Adaptation of WHO model}

One crucial finding that emerged from these results is that the WHO's parameters for assessing how well a particular country is in meeting the UN's third sustainable goal of improving overall healthcare in a population needs to be adjusted to reflect the reality on the ground. The WHO's 
parameters should include personal patient assessments and the inputs from local populations. Any evaluations about the effectiveness of healthcare provision should transcend the application of rather abstract, administrative and financial goals and should include the views and observations of the people who are actually experiencing the healthcare that is being provided. In other words, the themes from our study can be used to further revise the WHO's performance parameters to reflect the outcomes from the model that has already been adapted on the basis of a literature review. ${ }^{16}$ How further adaptation can be done is represented in Figure 2. Comparisons with the previous model of PHC performance clearly indicate that patients had clear expectations as to what they wanted from the centre and the personnel. The centre was assessed on the basis of the availability of services; and on the quality of the infrastructure and the cost of care, whereas the personnel were judged on the efficiency of care that they provided, something which depended on the knowledge they would have acquired during their education/training, as well as the resources available. ${ }^{21}$ Personnel were also judged on their communication skills and on the personal qualities they brought to their human interactions; they were evaluated on their punctuality and on how well they were organized while delivering services.

An initial observation indicated that the performance of the PHC involves an interaction between various parameters, which include individual expectations about the government facility, as well as patients' experiences at private and government facilities. Healthcare is part of the service industry, and PHCs provide healthcare services to the community. Like all service industries, success depends on the behaviour and attitude of the staff towards their "customers", who in this case are the patients. 22.26 The major criterion that patients considered when judging the quality of services at PHCs was the attitude or the behaviour of the staff, including those of nurses and doctors.

Aspects by which WHO assesses performance are almost totally focused on outputs and outcomes and focus on structures and processes of care delivery that are considered to be intrinsic to the system and they are not sufficiently emphasized. ${ }^{15}$ However, the patients themselves focussed on different criteria, such as the availability of services and the effectiveness of the process of care delivery. An analysis of patients' perspectives in relation to WHO's aspects of performance, confirms the findings of research in the field that some of the subcomponents of various indicators of WHO are usually expressed by patients. The general level of health and the distribution of healthcare did not feature in patient assessments, since these are more important to care providers or to external agencies which monitor and evaluate overall performance. As the provider of healthcare, the government's focus is on key performance indicators of a PHC as per Indian Public Health Standards, ${ }^{27}$ but if the aim is performance, then assessments from the perspective of patients gains significance and relevance. 
The results from this study, when compared with the aspects of the WHO's framework for assessment and the model developed from the review (Figure1), showed that the aspects 'overall level of performance' and 'distribution of responsiveness' and 'distribution of resources' were important to patients. The available literature also reinforces the idea that often these areas were used by researchers to assess the performance of PHCs in developing countries. ${ }^{16}$ The Patient's perspectives on care which emerged from this study are judged to be critical and hence incorporated into the PHC performance model. The changed and improved model should also be simple and clear enough to make it applicable to India, a developing country, and its healthcare services.

Both literature ${ }^{16}$ and the current study indicated that overall responsiveness to the needs of patients is a key factor that enabled positive evaluations from patients. The essential factors are: the availability of drugs; the cost of services and drugs; the cleanliness of the facilities and the environment; opening hours for the PHC that facilitated access; positive doctor-client interactions; and positive staff attitudes and effective personnel coordination. ${ }^{28-33}$ Measures of quality of care and client satisfaction (components of overall level of responsiveness, an aspect of the WHO's parameters of performance) were not entirely reflected during the interviews, but their subcomponents, namely, the effectiveness of care and the organization of services for better care, emerged as being of paramount significance. ${ }^{15,34-36}$ When patients expressed their assessments of the PHCs, both the visible/external behaviour, attitudes, and communication styles of staff were important, but so were the verbal and non-verbal behaviours of doctors-all of which enhanced interactions between the facility and the patients. These factors also form the core of patient-centred care and the patients both recognized this and commented on the importance of these criteria in our study. ${ }^{36}$ The evidence suggests that recognition of the importance of the responsiveness factor in healthcare delivery contributes to improved treatment outcomes and quality of life; unfortunately, this is not sufficiently emphasized in the WHO's framework of performance. ${ }^{15,38,39}$

In the literature, among the elements that the WHO's framework for assessment emphasizes, is the distribution of responsiveness factor, which is expressed as the availability and coverage of care and attributes of primary care, along with utilization of services. In our study, this was represented as assessments related to the availability of general/specialist diagnostics and to treatments and medicines, which were factors that were considered crucial components of a PHC. ${ }^{15}$ Additional factors, namely, availability of female doctors/specialists during routine and emergency care; punctuality and 24-hour availability; and the characteristics of the provider, emerged as critical components. However, these components are not sufficiently emphasized in the WHO's model and therefore have not been sufficiently studied in relation to the performance of PHCs. ${ }^{16,40,41}$ 
Patients' assessment of the distribution of resources, also discussed in the available literature, ${ }^{16}$ involved such factors as the quality of the infrastructure and service provisions, such as the availability of supplies/drugs offered by the PHC. In this context, the subcomponents in WHO aspects- the punctuality and the manner of coordination between the personnel were of significance to patients. The distribution of human resources is of concern to providers and is not always identified or commented upon by patients. However, utilization of these resources is part of distribution of factors related to responsiveness. ${ }^{29.30,39,41-44}$ It is important to note that patients were happy to get treatment from nurses whenever doctors were not available in the PHC; this shows that patients tended to trust the PHCs, a fact which other studies have also demonstrated. ${ }^{45}$ In the literature, it is noted that the effectiveness of the treatments offered by nurses was found to be equivalent to and in some cases better than the care provided by doctors. ${ }^{46}$ How resources were distributed was a key point raised by the patients; this was also a major aspect in the WHO's framework for assessment and was a prerequisite for ensuring the overall health of the population.

The physical setting in which healthcare services were provided was one of the important determinants of perceived quality and customer satisfaction. The presence of adequate and positively evaluated settings ensured that facilities met patient criteria and could lead to a facility having a sustainable competitive advantage. ${ }^{47}$ Overall cleanliness and the decor and cheerfulness of the facilities are tangible aspects and important components of healthcare service, and were found positively related to patient satisfaction. ${ }^{48-51}$ When healthcare services are provided in a welcoming environment, the mood of both patients and care providers is enhanced, contributing an environment that is conducive to healing; these factors are linked to patient satisfaction and indicate that the care providers are well-intentioned towards their customers, thus ensuring that patients recommended the facility to others. ${ }^{22}$ In our study, the participants addressed these factors as involving a better and cleaner infrastructure; the presence of adequate toilets and clean drinking water; the reliability of electrical supplies; and the presence of adequate furniture and decent building conditions. A model for PHC performance should thus reflect these factors when the performance of PHCs is being evaluated. The organization of services and the smooth functioning of the PHC synergize with the positive aspects of their infrastructure, all of which contribute to patient recovery and to better healthcare outcomes. Although the organization of services may be considered as components relevant only to the centre and to personnel, patients clearly indicated that they held personnel responsible for these factors and considered these elements to be a requirement. Thus, the aspect 'distribution of services' from the patient's perspective should be included in any assessment of PHC performance, although this is usually a component that is considered to form the responsibility of the provider. All too often, the patient's opinion is either ignored or simply taken for granted. While utilizing the services of PHCs, the participants compared government PHCs to private facilities and 
the trade-off was achieved between the cost of care and their expectations, as well the experiences from the healthcare facility (government and private).

One of the criteria that the WHO emphasizes is the distribution of financial contributions from providers or from other implementing agencies. This criterion was not considered relevant to patients, who concentrated on the cost of care and of medicines, since these are the components of out-of-pocket expenditure, a factor which significantly affected their decisions on whether to visit a government PHC or to go to a private care provider. In India, a significant proportion of the population tend to fall under the poverty line because of catastrophic health expenditure. Relationship between catastrophic health expenditure and effectiveness of health system functioning is catching the attention of researchers of late but literature related to PHC setting is not available. ${ }^{16}$

\section{Strengths and weaknesses}

The study focused on obtaining patients' views and how their assessments reflected on the WHO's model. The participants were from diverse educational background resulting in a complete array of performance parameters across various aspects of WHO model. As the study was conducted among the patients of urban PHC and not among the community, it is doubtful that we missed results that were relevant to the patients and not applicable to the general public, also the differences in rural and urban perspectives were not captured.

\section{Recommendations for further research and practice}

Given that the public health sector constitutes the single most important healthcare provider, optimizing the provision of services, leads to improvements in the health of the population. Finally, tools for performance assessment of PHCs should include factors from patient perspectives. Validation of such tools including the critical themes and criteria that emerged from the study is implicated. It is crucial to develop a tool to assess PHC performance from the patient's perspective and tested among different PHCs, so that the themes and criteria that emerged from our study can be generalized.

\section{Conclusion}

The patient's perspective, that is, the responses of people who are experiencing the healthcare services at PHCs in India were captured using qualitative research methods. Based on the analysis nine themes were found to represent how the PHC performance assessment could be improvised. The themes are: availability of rich and diverse services, the presence of effective diagnostic services, the cost and availability of medicines, the quality of the infrastructure, the cost of care, the 
behaviour, communications skills, and punctuality of staff, and the effectiveness and organization of care. These factors are judged to cut across various aspects of the WHO's model of PHC performance, rendering the assessment model more inclusive and indicative of the views of those receiving care and of the realities "on the ground". Such a holistic model would further ensure continuous improvement in service delivery leading to better utilization of preventive and promotive services provided by the PHCs. Validation of the criteria from this study across different contexts is further implicated. 


\section{References}

1. The Millennium Development Goals Report 2015. https://www.un.org. Accessed on 4 Jan 2016

2. The Sustainable

Development

Goals

2016 http://www.un.org/sustainabledevelopment/development-agenda/ 2016. Accessed on 4 Jan 2016

3. UN Press release 2015. Maternal death ratio has fallen 44 percent since 1990-UN. https://www.unfpa.org/press/maternal-death-ratio-has-fallen-44-cent-1990-6. \%E2\%80\%93-un. Accessed on 7 Oct 2016

4. The Global Strategy for Women's, Children's and Adolescents' Health 2016-2030: Survive Thrive $\quad$ Transform $2015 . \quad$ https://www.who.int/life-course/partners/globalstrategy/globalstrategyreport2016-2030-lowres.pdf. Accessed on 7 October 2016

5. Donnay F. Maternal survival in Developing countries: what has been done, what can be achieved in the next decade. International Journal of Gynaecology and Obstetrics. 2000;70:89-97

6. Urban health report. 2016. http://apps.who.int/iris/handle/10665/204715. Accessed on 7 Oct 2016

7. Global status report on non-communicable diseases 2014. https://apps.who.int/iris/bitstream/10665/148114/1/978941564854_eng.pdf?ua=1. Accessed on 7 Oct 2016

8. Alma-Ata. 1978. Primary Health Care: Report of the International Conference on Primary Health Care Alma-Ata, USSR: 6-12 September 1978. https://www.who.int.en. Accessed on 5 Jan 2015

9. Mays G P, Halverson P K, Millerr C A. Assessing the Performance of Local Public Health Systems: A Survey of State Health Agency Efforts. Journal of Public Health Management Practice. 1998;4(4):63-78

10. Groene O, Skau J K H, Frolich A. An international review of projects on hospital performance assessment. International Journal of Quality in Health care. 2008;20(3):162-171

11. Scutchfield F D, Knight E A, Kelly A V, Bhandari M W, Vasilescu L P. Local Public health agency capacity and its relationship to public health system performance. Journal of Public Health Management Practice. 2004;10(3):204-215 
12. John R, Kelly J Carlson. National Public Health Performance Standards Assessment: First steps in strengthening North Dakota's Public Health System. Journal of Public Health Management Practice. 2005;11(5):422-42

13. Panda B, Thakur H P. Decentralization and health system performance - a focused review of dimensions, difficulties, and derivatives in India. BMC Health Services Research. 2016;16 Suppl 6:561. doi 10.1186/s12913-016-1784-9

14. Carter R, Riverin B, Leversque J F, Gariepy G, Vallee A Q. The impact of primary care reform on health system performance in Canada: a systematic Review. BMC Health Services Research. 2016;16:324. doi 10.1186/s12913-016-1571-7

15. The World Health Report 2000. Health Systems: Improving Performance. https://www.who.int.en. Accessed 1 Nov 2014

16. Sathyananda R B, de Rijk A, Manjunath U, Krumeich A, van Schayck C P. Primary health Centers' performanc assessment measures in developing countries: review of the empirical literature. BMC Health Services Research. 2018;18:627. doi.org/10.1186/s12913-018-3423-0

17. Guba E G, Lincol Y S. Fourth Generation Evaluation 1989, 21-49, Sage Publication

18. http://apps.who.int/medicinedocs/documents/s18023en/s18023en.pdf. Accessed on 1Nov 2018

19. https://nrhm-mis.nic.in/hmisreports/frmstandard_reports.aspx. Accessed on 10 Jan 2019

20. Castleberry A and Nolen A 2018 thematic analysis

21. Krasner M S, Epstein R M, Beckman H, Suchman A L, Chapman B, Mooney C J, Quill T E. Association of an educational program in mindful communication with burnout, empathy and attitudes among primary care physicians. Journal of American Medical Association. 2009;302(12):1284-1293

22. Fotter MD, Ford R C, Roberts V, Ford E W. Creating a healing environment: the importance of the service setting in the new consumer-oriented healthcare system. 2000;45(2):91-106.

23. Glaser K M, Markham F W, Adler H M, McManus R P, Hojat M. Relationships between scores on the Jefferson Scale of physician empathy, patient perceptions of physician empathy and humanistic approaches to patient care: A validity study. Medical Science Monitor. 2007;13(7):291-294. http://www.medscimonit.com/fulltxt.php?IDMAN=10229 
24. Beatson A T, Lings I, Gudergan S. Employee behaviour and relationship quality: impact on customers. The Service Industries Journal. 2008;28(2):211-223

25. Aliman N K, Mohamad W N. Perceptions of service quality and behavioural intentions: A mediation effect of patient satisfaction in the private health care in Malaysia. International Journal of Marketing Studies. 2013;5(4):15-29. http://dx.doi.org/10.5539/ijms.v5n4p15

26. Mohammadreza H, Daniel L Z, Fred MW, Richard W, Carol R, Joseph GS. Physicians' Empathy and Clinical Outcomes for Diabetic Patients. Academic Medicine. 2011;86(3):359-364. doi: 10.1097/ACM.0b013e3182086fe1

27. http://nhm.gov.in/nhm/nrhm/guidelines/indian-public-health-standards.html

28. Awadalla H I, Kamel E G, Mahfouz E M, Refaat T M. Evaluation of Maternal and Child Health Services in El-Minia City, Egypt. Journal of Public Health. 2009;17(5):321-329

29. Varatharajan D, Thankappan R, Jayapalan S. Assessing the Performance of Primary Health Centres Under Decentralized Government of Kerala, India. Health Policy and Planning. 2004;19(1):41-51

30. Lannes L. Improving health worker performance: The patient-perspective from a PBF program in Rwanda. Social Science and Medicine. 2015;138:1-11

31. Akachi Y, Zumla A, Atun R. Investing in Improved Performance of National Tuberculosis Programs Reduces the Tuberculosis Burden: Analysis of 22 High-Burden Countries, 2002-2009. The Journal of Infectious Diseases. 2012;205: Suppl 284-292

32. Hudon C, Ttibble D SC, Bravo G, Hogg W, Lambert M, Poitras M E. Family physician enabling attitudes: a qualitative study of patient perceptions. BMC Family Practice. 2013;14:8. doi:10.1186/1471-2296-14-8

33. Mercer S W, Jani B D, Maxwell M, Wong S YS, Watt G CM. Patient enablement requires physician empathy: a cross-sectional study of general practice consultations in areas of high and low socioeconomic deprivation in Scotland. BMC Family Practice. 2012;13:6. doi:10.1186/14712296-13-6

34. Ross C K, Colette A S, Sinacore J M. A comparative study of seven measures of patient satisfaction. Medical Care. 1995;33(4):392-406 
35. Campbell S M, Roland M O, Buetow S A. Defining quality of care. Social Science and Medicine. 2000;51(11):1611-1625

36. Lawrence M, Olesen F. Indicators of quality of health care. The European journal of general practice. 1997;3:103-108. DOI: 10.3109/13814789709160336

37. Beck R S, Daughtridge R, Sloane P D. Physician- patient communication in the primary care office: A systematic review. Journal of American Board of Family Practice. 2002;15(1):25-38

38. Epstein R M, Fiscella K, Lesser C S, Stange K C. Why the nation needs a policy push on patientcentered health care. Health Affairs. 2010;29(8):1489-1495

39. Mohammadreza H, Daniel L Z, Fred M W, Richard W, Carol R, Josheph G S. Physicians' empathy and clinical outcomes for diabetic patients. Academic Medicine. 2011;86(3):359-364

40. Stosic M, Lazarevic N, Kuruc V, Ristic L. Assessment of the role of primary health care in tuberculosis control in Serbia. MedicinskiPregled (NoviSad). 2015;68:331-335

41. Macinko J, Almeida C, de Sa P K. A Rapid Assessment Methodology for the Evaluation of Primary Care Organization and Performance in Brazil. Health Policy and Planning. 2007;22(3):167-177

42. Bradley S, Kamwendo F, Masanja H, Pinho H, Waxman R, Boostrom C, McAuliffe E. District health managers' perceptions of supervision in Malawi and Tanzania. Human Resource for Health. 2013;11:43

43. Shreedevi D. Gap analysis and the performance of primary health centres in the implementation of the school health programme of NRHM. International journal of Research in Business Management. 2014;2(2):1-8

44. Macinko J, Almeida C, dos SE, de Sa PK. Organization and delivery of primary healthcare services in Petropolis, Brazil. International Journal of Health Planning and Management. 2004;19:303-317

45. NoroXe K B, Moth G, Maindal H T, Vedsted P. Could the patient have been seen by a nurse; a questionnaire based survey of GP and patient views in Danish general practice. BMC Family Practice. 2013;14:171. doi:101186/1471-2296-14-171 
46. Horrocks S, Anderso E, Salisbury C. Primary Care: Systematic review of whether nurse practitioners working in primary care can provide equivalent care to doctors. British Medical Journal. 2002;324:819-23

47. Taylor SA. 1994. Distinguishing service quality for patient satisfaction in developing health marketing strategies. Hospital and Health Services Administration. 1994;39(2):221-36

48. Hall J, Dornan MC. What patients like about their medical care and how often they are asked: a meta-analysis of the satisfaction literature. Social Science and Medicine. 1988;27(9);935-39

49. Health policy advisory unit. 1989. The Patient satisfaction questionnaire. Scheffield:HPAU, Scheffield University

50. Press Ganey Satisfation Measurement, 1995. The satisfaction report. South Bend, IN:Press Ganey

51. Jun M, Peterson RT, Zsidisin GA. The identification and Measurement of quality dimensions in health care: Focus group interview results. Health Care Management Review. 1998;23(4):81-96 


\section{Chapter 4}

\section{Providers' Perspectives on the Performance of Primary Healthcare Centers in India-The Missing Link}

Bangalore Sathyananda, R., Krumeich, A, Manjunath, U., de Rijk,A., van Schayck,C.P.

Submitted 
Title: Providers' Perspectives on the Performance of Primary Healthcare Centres in India- The Missing Link

\begin{abstract}
Background: Primary Healthcare Centres (PHCs) form the foundation of the Indian public health system, and thus their effective functioning is paramount in ensuring the health of the population. The World Health Organization (WHO) has set six aspects of performance assessment for health systems in general, which are hardly applicable to the PHC setup in a low- and middle-income country. The Primary Health Care Performance Initiative (PHCPI) has prescribed a framework with 36 indicators for primary healthcare performance assessment from a policy point of view. For the assessment to be realistic, it should include inputs from stakeholders involved in care delivery, so this study examines the perspectives of healthcare providers at PHCs in India. Indicators from the providers' perspectives which are in line with their daily work were assessed to assess their alignment with the WHO aspects and the PHCPI framework.
\end{abstract}

Methodology: The authors used qualitative research methodology in the form of responsive evaluations to interview healthcare providers at PHCs and understand their claims and concerns about PHC performance. The study included all the healthcare providers in the selected three PHCs in the Bengaluru urban district of Karnataka, India.

Results: The study results showed that healthcare providers expressed previously untapped firsthand information, stating that the following indicators were crucial to any PHC performance assessment: (1) efficient teamwork at PHCs; (2) the presence of opportunities for healthcare providers to enhance their skills and knowledge advancing their professional careers; (3) job satisfaction; (4) effective administration of PHCs in terms of safety and security, especially in dealing with potential violence; (5) good community relations developed from positive attitudes of healthcare professionals and patients. The study provided vital, but previously missing information on how PHC could be assessed from a more realistic grassroot level.

Conclusion: Additional PHC evaluation indicators could be considered the 'missing link' in PHC assessment, since they are deemed important by providers and did not coincide with the WHO aspects and the PHCPI performance assessment framework. 


\section{Introduction}

Various factors have contributed to increased life expectancy in India, a few of which are education, policy changes and growing awareness about health. One of the many factors that contributed to this improvement is the implementation of a multi-pronged approach concerning healthcare education and promotion, preventive healthcare programmes, along with the provision of curative services through clinics known as Primary Healthcare Centres (PHCs).

India's commitment to primary care dates back to pre-independence (1920s), which over the years has been strengthened by policies and programmes to address health and its related social determinants. ${ }^{1,2}$ Even with these efforts, India has fallen short of achieving the United Nations Millennium Development Goals (SDGs), like other low- and middle-income countries (LMICs). ${ }^{3-7}$ Now India is committed to full implementation of the SDGs in all its public programmes. ${ }^{2,8}$ To achieve better health of the population, a well-performing health system is essential, hence PHC performance assessment is vital to India's case.

PHCs form the foundation of the Indian public health system, which is structured along primary, secondary, and tertiary levels of healthcare provision. As per the norms of Indian Public Health Standards, PHCs are responsible for the health of specific populations of 30,000 citizens, and thus form the critical component of care at the grassroots level. ${ }^{9}$ There are two types of PHCs, categorised by working hours and service provisions: the 24/7 PHCs providing services like baby delivery at any time of the day or night, and the non-24/7 PHCs. In general, the 24/7 PHC has doctors, nurses, pharmacists, laboratory technicians, optometrists, health assistants, and other non-care provider staff (clerks and cleaning staff), which are managed by an Administrative Medical Officer. Organisationally, each PHC has five to eight subcentres for a group of villages, and each subcentre is served by Junior Health Assistants who handle a population of 5,000, primarily providing health education and preventive health care. ${ }^{9}$ Considering the importance of well-functioning PHCs in ensuring the health of the population, the monitoring and performance evaluation of these centres is significant. However, research on how well these PHCs are performing has not been carried out. Therefore, such studies must be undertaken to better understand PHCs and for establishing performance benchmarks. ${ }^{10}$

Although the World Health Organization (WHO) has developed aspects for performance assessment of healthcare systems, critical indicators that could be used for assessing the daily performance of PHCs have not been specified. ${ }^{11,12}$ The six aspects in the WHO health system performance assessment consist of overall level of health, distribution of health in population, overall level of responsiveness, distribution of responsiveness, distribution of resources, distribution of financial 
contributions. ${ }^{10-12}$ The WHO aspects are applicable to health systems as a whole and not to a particular healthcare facility, such as PHCs in India and other low- and middle-income countries.

The Primary Health Care Performance Initiative (PHCPI), a group consisting of the World Bank Group, the World Health Organization, the Bill and Melinda Gates Foundation along with other academic institutes and universities, which is working in the low- and middle-income countries has recently stipulated two sets of performance indicators. ${ }^{13}$ The first set of 36 performance indicators were meant to facilitate comparisons, while the second set of 56 diagnostic indicators served to illustrate fundamental drivers of performance. The initiative prescribed five domains with 10 subdomains and 36 indicators from a policy point of view; table 1 provides details of these indicators.

Although the above model focuses on PHC in LMICs, it does not take into consideration that each country organises its health care system in its own particular way, shaped by culture, history and available resources. Performance assessment should be attuned to these local conditions. A way to take this local context into consideration in PHC assessment is to integrate the perspectives of local stakeholders on what a PHC is supposed to do and how it is supposed to function. These perspectives should then be translated into performance indicators ${ }^{14}$ and added to performance indicators of more formal assessment models identified in our literature review to benefit from mixed research methods.

For the assessment to be realistic and applicable, the indicators should take into account the perspectives of the main PHC stakeholders, and their daily and operational issues, which are specific to the Indian context. According to Guba and Lincoln, effective performance assessment should be context-sensitive, hence including all stakeholders would expand it to include underlying expectations, experiences and personal backgrounds, culture, education, and socioeconomic status, in turn making the performance indicator more acceptable and accurate. ${ }^{10}, 15$ This study explores therefore the perspective of an important stakeholder group, PHC healthcare providers, on the matter of performance. Including performance indicators based on the perspective of healthcare providers helps to enable assessment of the actual functioning and effectiveness of urban PHCs, which formed the objective of our study. The research questions addressed in this study are:

- What are the PHC performance indicators that can be inferred from the providers' perspective?

- How can these indicators strengthen the existing WHO aspects and PHCPI performance assessment framework with respect to PHC assessment? 
Table1. Primary Health Care Performance Initiative's Framework for vital performance indicator

\begin{tabular}{|c|c|c|c|}
\hline SI No & Domain & Sub-domain & Indicator \\
\hline 1 & $\begin{array}{l}\text { System level } \\
\text { Determinants }\end{array}$ & Health Financing & - Per capita primary healthcare expenditure \\
\hline \multirow[t]{3}{*}{2} & \multirow[t]{3}{*}{ Inputs } & Drugs and supplies & $\begin{array}{ll}\text { - } & \text { Basic equipment availability } \\
\text { - } & \text { Availability of essential drugs } \\
\text { - } & \text { Availability of vaccines } \\
& \begin{array}{l}\text { Facilities with clean water, electricity, } \\
\text { sanitation }\end{array} \\
\end{array}$ \\
\hline & & Facility infrastructure & - Health center and health post density \\
\hline & & Workforce & $\begin{array}{l}\text { - Community health workers, nurses and } \\
\text { midwife density }\end{array}$ \\
\hline \multirow{6}{*}{3} & \multirow{3}{*}{$\begin{array}{l}\text { Service } \\
\text { delivery }\end{array}$} & Access & $\begin{array}{l}\text { - Access barriers due to treatment costs } \\
\text { - Access barriers due to distance }\end{array}$ \\
\hline & & $\begin{array}{l}\text { Availability of } \\
\text { effective primary } \\
\text { healthcare services }\end{array}$ & $\begin{array}{ll}\text { - } & \text { Provider absence rate } \\
\text { - } & \text { Diagnostic accuracy } \\
\text { - } & \text { Adherence to clinical guidelines } \\
\end{array}$ \\
\hline & & $\begin{array}{l}\text { High Quality primary } \\
\text { healthcare }\end{array}$ & $\begin{array}{ll}\text { - } & \text { Dropout rate } 1^{\text {st }} \text { to } 3^{\text {rd }} \text { DPT } 3 \text { vaccination } \\
\text { - } & \text { Dropout rate } 1^{\text {st }} \text { to } 4^{\text {th }} \text { antenatal visit } \\
\text { - } & \text { Care-seeking for symptoms of pneumonia }\end{array}$ \\
\hline & Outputs & $\begin{array}{l}\text { Effective service } \\
\text { coverage }\end{array}$ & $\begin{array}{l}\text { - } \text { Demand for family planning satisfied with } \\
\text { modern methods } \\
\text { - } \text { Antenatal care coverage } \\
\text { - } \text { DTilled birth attendance } \\
\text { - } \text { thildren with diarrhea receiving appropriate } \\
\text { - TB cases detected and cured } \\
\text { - } \text { People living with HIV receiving ART } \\
\text { - Cervical cancer screening rate } \\
\text { - Hypertension control } \\
\text { - Diabetes mellitus control } \\
\end{array}$ \\
\hline & \multirow[t]{2}{*}{ Outcomes } & Health status & $\begin{array}{ll}\text { - } & \text { Maternal mortality ratio } \\
\text { - } & \text { Adult mortality from NCDs } \\
\text { - } & \text { Neonder-5 mortality rate } \\
\end{array}$ \\
\hline & & Equity & $\begin{array}{l}\text { Difference between } 1^{\text {st }} \text { and } 5^{\text {th }} \text { wealth } \\
\text { quintiles for under- } 5 \text { mortality }\end{array}$ \\
\hline
\end{tabular}

\section{Methodology}

The authors used qualitative research methodology to conduct in-depth interviews with healthcare providers at PHCs to elicit implicit and explicit indicators of PHC performance and understand their thoughts about the actual performance of their own PHCs. 


\section{Study Design}

In-depth interviews were conducted to understand providers' perspectives on what constituted PHC performance. The interview guide used in this study was dynamic and encouraged the providers to describe how they experienced their daily work, including interaction with patients and colleagues, the community, and the place, along with the role of the PHC in the overall health system and the health of the population. This allowed us to identify what providers expected of a PHC and, indirectly, what kind of indicators they used when assessing its performance.

\section{Study Setting and Context}

This study was conducted in three 24/7 PHCs in the Bengaluru urban district of Karnataka state, India. The quality and quantity of services at PHC have been classically measured by the number of women who delivered babies at the PHC; hence this criterion was considered as one PHC performance indicator. $^{2}$ The Bengaluru urban district has twenty 24/7 PHCs. Among these, the study included PHCs that had the highest, medium and lowest number of deliveries in relation to the total population served by PHCs in the financial year from April 2016 to March 2017. This theoretical sampling approach was used to include a wide spectrum of urban PHCs in terms of performance. The PHCs selected were PHC-1 (population: 56,081), PHC-2 (population: 48,037) and PHC-3 (population: 54,513).

\section{Study Participants}

All the healthcare providers working in the three PHCs were included in the study. The providers included doctors, nurses, health assistants, pharmacists, laboratory technicians, and optometrists. All the healthcare providers in the PHCs agreed to participate in the study and the interviews were conducted between September 2017 and February 2018. Table 2 describes the study participants and their characteristics. Fifty-one healthcare provider positions were approved by the government in these three PHCs, nevertheless 26 of these positions were vacant, a nearly $50 \%$ vacancy rate. In order to overcome this shortage of providers, staff (one doctor and eleven nurses) were recruited yearly on a contractual basis. Table 3 shows the availability of PHC providers. 
Table 2. Characteristics of the study participants

\begin{tabular}{|c|c|c|c|c|c|c|}
\hline \multirow{2}{*}{ Personnel } & \multicolumn{2}{|c|}{ Gender } & \multicolumn{4}{|c|}{ Age in Years } \\
\hline & Male & Female & $<29$ & 30-39 & $40-49$ & $>50$ \\
\hline Doctors & 2 & 2 & 0 & 1 & 2 & 1 \\
\hline Nurses & 0 & 11 & 2 & 6 & 2 & 1 \\
\hline Pharmacists & 0 & 3 & 0 & 1 & 1 & 1 \\
\hline Lab technicians & 0 & 2 & 0 & 2 & 0 & 0 \\
\hline Optometrists & 2 & 0 & 0 & 0 & 0 & 2 \\
\hline Health Assistants ${ }^{*}$ & 3 & 11 & 0 & 7 & 1 & 6 \\
\hline Total Interviewed (36) & 7 & 29 & 2 & 17 & 6 & 11 \\
\hline
\end{tabular}

*Male/Female and Senior/Junior

Table 3. Availability of healthcare providers in the PHCs

\begin{tabular}{|l|c|c|c|}
\hline Staff cadre (involved in patient care) & Approved & Working & Vacancy \\
\hline Doctor & 6 & 3 & $3^{+}$ \\
\hline Nurse & 7 & 0 & $7^{++}$ \\
\hline Pharmacist & 3 & 3 & 0 \\
\hline Laboratory Technician & 3 & 2 & 1 \\
\hline Ophthalmic Technician & 3 & 2 & 1 \\
\hline Senior Health Assistant Male & 3 & 1 & 2 \\
\hline Senior Health Assistant Female & 3 & 1 & 2 \\
\hline Junior Health Assistant Male & 10 & 1 & 9 \\
\hline Junior Health Assistant Female & 12 & $12^{\$}$ & 0 \\
\hline Block Health Education Officer & 1 & 0 & 1 \\
\hline Total healthcare providers & $\mathbf{5 1}$ & $\mathbf{2 5}$ & $\mathbf{2 6}$ \\
\hline
\end{tabular}

+1 doctor employed on contractual basis to overcome shortage

++11 nurses employed on contractual basis to overcome shortage

$\$$ one person was on long study leave hence was not interviewed

\#see text for explanation

\section{Data Collection}

The interviews were conducted at PHCs in the local language to help participants express themselves freely and communicate well. The providers were asked to describe their performance, the performance of their colleagues, and that of the PHC they work in. They were encouraged to describe their views on what they considered as demonstrating effective performance at the PHC. This unstructured open method of interview stimulated them to reflect on their education, work life, personal life, interpersonal interaction, among other factors, thereby allowing them to articulate on an assessment indicator that was usually explicit, but sometimes implicit. These explicit and implicit indicators were analysed to understand the providers' view on PHC performance. 
In line with research ethics principles, this study was conducted after receiving clearance from the Ethics Review Committee of Manipal University, Manipal, India. Participants' written informed consent were obtained before each interview, thus ensuring voluntary participation, confidentiality, and the freedom of participants to exit the study at any point in time.

\section{Data Analysis}

Personal details of the interviewees were removed from the recorded interviews to ensure confidentiality. The recorded interviews were translated into English and transcribed. The data was analysed using Atlas-TI software following the method of thematic analysis to develop primary and secondary codes to identify various themes arising from the providers' perspectives. ${ }^{16}$

\section{Results}

Interview data from 36 healthcare providers (24 regular and 12 contractual) at the three PHCs was analysed and two categories of performance indicators from the providers' perspectives were identified. One category refers to performance indicators mentioned by the care providers that overlap with indicators in the WHO aspects and the PHCPI performance framework. The other category refers to five indicators that the providers came up with that were indicative of PHC performance and external to the WHO framework. These indicators were teamwork, opportunities for growth and development provided by acquiring skills and knowledge, job satisfaction, administration leading to the perception of safety and secure work environment, and good community relations developed through positive perceptions by patients and the community.

\section{Indicators in alignment with the WHO performance assessment aspects}

The providers described numerous indicators that were in line with the aspects of the WHO framework:

1. Overall levels of health: The fulfilment of this aspect of the framework was revealed by general health indicators like maternal mortality ratios and infant mortality rates. Providers explained that they had the responsibility of delivering effective maternal and child healthcare, as well as meeting targets in the prevention and treatment of prevalent diseases, under various national programmes delivered in the field and at PHCs, contributing to better overall levels of health in the population and forming and indicator of PHC performance.

We provided OPD [outpatient department] services, antenatal care, post-natal care, birth services ... 0 to 5 years' children health ... report birth and death ... diagnose and treat TB [tuberculosis] and malaria (Comments from a doctor) 
2. Distribution of health in the population: This aspect of the WHO's performance parameters was evaluated and commented upon by most providers. The PHCs and their subcentres were all structured to ensure the distribution of services in the community to improve health of the population. The providers mentioned healthcare promotion and preventive health services among the community as a major area of PHC performance. This aspect incorporated components such as immunisation coverage, monitoring child growth, prenatal and natal care, contraception, non-communicable disease screening, mosquito larvae surveys to reduce vectorborne diseases, collecting sputum and blood smear samples to prevent tuberculosis and malaria, and health-awareness programmes.

First dose and second doses of TT [anti-tetanus toxoid injections] are given. Then they [health assistants] give all the information about the government hospitals close by, they inform who the doctor is ... Postpartum care visits at home are done by sisters [health assistants]; the sisters give all the information needed, then every Thursday for children they provide immunisation in all four subcentres for maximum coverage in minimum time. (Comments from a doctor)

3. Overall level of responsiveness: According to the providers, this WHO criterion consisting of quality of care and client satisfaction, involved the ability of the PHC to meet and exceed patient expectations. The providers expressed that client satisfaction was always expressed by the patients after care delivery and hence should be considered in PHC performance.

If OPD [outpatient department and services] starts in the morning until the evening, it will go on ... We [providers] can't sit and talk that much as the patient load is high ... Many people are happy with the treatment. Many of them have said so and thanked me as they got treated (Comments from a nurse)

4. Distribution of responsiveness: One of the WHO's performance parameters is availability of resources. The providers assessed this parameter as non-vacant positions, and the availability of infrastructure.

Vacant provider positions at PHCs: All respondents expressed concern about the number of vacant posts in PHCs. All the providers stated that the lack of skilled workforce had led to an increase in the workload for all of them, forcing them to multitask and perform multiple roles. As a result, they were struggling to provide quality care, leading to agitation and sometimes growing friction between providers and patients. It was also observed that the population served by the PHCs was high in comparison to the standard of 30,000 persons per PHC, thereby aggravating the problem. Hence, providers considered the availability of staff members or rather the number of vacant positions as PHC performance. 
[There is] no LHV [Lady Health Visitor, local dialect for Senior Health Assistant Female] and no BHEO [Block Health Education Officer] ... everything sisters [junior health assistants] only should do (Comments from a doctor)

Availability of medicines at PHCs: Providers said that the availability of medicines and other items for patient care was a responsibility of the health system and the duty of the pharmacist, who was responsible for all the stocks in the PHC. The lack of supplies added to the burden of the Administrative Medical Officer, thereby affecting quality of care. The interviewed providers considered availability of medicines as part of PHC performance.

If something [medicine and other medical supplies] is not available, [the] doctor will get it for us... Pharmacist will not get the things for us ... but he [doctor] will get it from somewhere (Comments from a nurse)

5. Distribution of resources: Distribution of human and other resources across the health system could not be adequately assessed because administrative officers and personnel from the government who are in charge of these PHCs were not included in the study. This was out of the scope of the present study.

6. Distribution of financial contributions: The governmental health budget was the only criterion from the WHO's framework that is applicable to PHCs (see figure 1). The budget was allocated for the salary of human resources, infrastructure procurement and maintenance, and provision of healthcare. Providers expressed that the budget allocation and remuneration for the services were not provided on time affecting their abilities to lead a decent life, thus including this factor in PHC performance.

We don't get funds on time ... now they [government] are giving [it] on a performance basis. And we don't know on what performance basis they are calculating the amount ... For [the] lab we don't get anything from the government... still we have to deliver services" (Comments from a doctor on fund allocation)

“... wherever we go [any PHC], the major problem is salaries; we can't expect [our] salaries on time..." (Comments from a health assistant on salary allocation)

\section{Indicators in alignment with the PHCPI framework of performance assessment}

The providers mentioned indicators from all sub-domains except access, availability of effective primary healthcare, and equity, as they were concerned from the system point of view. Though the indicators mentioned were in line with the PHCPI framework, they were mostly applicable to the centre and not for the complete primary healthcare system as designed by the PHCPI. 
Indicators defined by the interviewed providers but external to the WHO aspects and the PHCPI performance framework

In addition to the indicators that were mentioned in the WHO's performance framework, five themes were identified by the providers which, in their view, were essential components of PHC performance. These performance indicators included teamwork, opportunities for skill and knowledge advancement, job satisfaction, PHC administration for safety and security, and positive community relationships.

\section{Theme 1: Teamwork at the PHC is Central to Performance}

All providers identified teamwork as a key element in the performance of a PHC, stressing that the lack of good teamwork led to the poor functioning of the centre. Therefore, teamwork itself is a performance criterion:

I tell my staff that this [delivery services at the PHC] is [based on] teamwork and this $[\mathrm{PHC}]$ is like our family (Comments from a doctor)

The interviewed providers acknowledged that effective teamwork was based on the presence of doctors with suitable skills, and coordination and cooperation among various stakeholders.

\section{Skills and Capabilities of PHC Doctors}

The interviewed providers said that it was important that an adequate number of doctors were available in PHCs, and that those doctors needed to demonstrate administrative abilities, leadership and communications skills, and the right attitude towards other stakeholders. Considering all these qualities, the interviewed providers identified the availability of a good doctor as a PHC performance indicator.

Administrative abilities: All of the interviewed providers identified the fact that the doctors not only played the role of healthcare providers but that they also acted in an administrative capacity and a significant portion of his or her time was allocated to the administration of the PHC. Administration consisted of ensuring the efficient functioning of the PHC, including managing materials and people, among other roles.

If you [doctor] don't know the administrative work, they [other stakeholders] will take you for a ride. (Comments from a doctor)

Leadership skills of doctors: Interviewed providers identified doctors as the leaders of the PHCs, with all other staff reporting to them. Doctors also represented their PHC (and its staff) before higher officials. Providers stated that, given doctors' crucial role, they needed to have the following abilities: communication and coordinating skills; the ability to support staff 
psychologically and boost performance; and the presentation skills to represent the PHC before other stakeholders.

When you [doctor] talk to them, they feel very happy and follow treatment (Comments from a doctor referring to communication with patients)

[If there are] any problems, seniors [higher officers] will be with us, any problem arises in hospital premises I always call the seniors to inform them and they do support. (Comments from a doctor referring to coordination with higher officials)

Anything [local administrative matters with leaders] is there I call local leaders and they call me too [for direct communication]. (Comments from a doctor referring to communication and coordination with the local leaders)

The interviewed providers said that teaching and training various personnel, providing technical support, mentoring and handholding other personnel for better healthcare delivery was an important task of doctors, who were best qualified in the PHC team. This was there appointed as an ideal performance indicator.

Whatever problem happens, adverse drug reactions or anything else, we will immediately call the doctor ... if it is risky, on the phone the doctor will instruct and guide us. (Comments from a nurse)

Attitude of doctors towards other providers and patients: The providers said that the attitude of providers and patients towards each other were essential for the PHC performance. Any evaluation had to take into account whether the professionals involved had a positive and empathetic approach; whether they were dedicated to patient care; whether the doctors recognised, appreciated, and respected all the individuals contributing to patientcare. All these accounts facilitated conducive work environment and better service delivery, consequently the attitude of doctor towards providers and patients were considered as PHC performance.

"Basically, I'm very sensitive. I will not do anything intentionally to hurt someone. One day, without knowing [it], I took the pen, which was on the table to write the report, ... that day she [the doctor] scolded me..." (Comments from a health assistant on positive empathetic approach)

I'm interested in working here, madam. While I'm here I forget outside things. I don't worry about family and all that. Until evening, I'm right here. Sometimes I'm here till 8 or 9 in the evening. (Comments from a doctor on dedication towards patient care)

They [doctors] say so many deliveries happened in 'ABC' $\mathrm{PHC}$, but no one appreciates how much effort we need to put to achieve that, including higher officers [doctors and other senior officers]. (Comments from a health assistant on recognition by senior officers) 


\section{Coordination and Cooperation Between Different Stakeholders}

Intradepartmental cooperation and coordination: According to the providers, healthcare is not just the responsibility of one healthcare provider. In fact, healthcare provision involved the interaction of various internal, external factors and stakeholders, including the prevailing environment in a society. Cooperation and coordination within the department created a supportive administrative environment, prompt and efficient service delivery, and synergy between personnel, all influencing the PHC performance.

People working with me should cooperate well with me. Doctors will cooperate nicely, and if colleagues working here adjust nicely, it will be good... [some colleagues are not cooperative] (Comments from a health assistant)

Interdepartmental cooperation and coordination: According to the interviewed providers, the health of the local population is influenced by sanitation or lack thereof, clean water provision, clean air, appropriate town planning among other factors. Improvements in such basic needs can be achieved through coordination of various departments, leading to optimum standards of living. Achieving synergy between respective departments is critical to promoting better health, so providers included this synergy as a key performance indicator.

When we go to the field, [a] major problem is drainage systems. People don't keep clean and scold us in turn for lack of water and poor drainage. (Comments from a health assistant)

\section{Theme 2: Advancing Skills and Knowledge}

Providers interviewed acknowledged that advancing the skills and knowledge of those providing medical services was an important component of PHC performance. It was important to increase the capacity of PHCs and expand the scope of service availability, thereby leading to better health outcomes. On-the-job learning opportunities at PHCs was limited, as PHCs provide only primary healthcare and refer complicated cases to hospitals and other care facilities. The interviewed providers said that the government does offer opportunities for higher and continuing education thereby contributing to personal growth and career advancement, further improving availability and quality of health care. Hence the opportunities provided for advancing skills and knowledge were also considered as influencing PHC performance.

Here I am feeling good and able to learn new things ... In PHCs we can't learn much [opportunities for skill and knowledge advancement is limited]. When we work in a different, higher-level hospital, like general hospitals, we get to learn more (Comments from a doctor regarding on-the-job learning opportunities)

I want to do a post-graduation by government service quota ... I want to continue with the government service. (Comments from a doctor on higher education) 


\section{Theme 3: Job Satisfaction}

Providers described a well-functioning PHC as offering opportunities for workers to experience job satisfaction, motivating them to perform better, engage their conscience and contribute to their wellbeing. The providers described their job satisfaction as the gratification derived from providing services to patients in need, as well as to women and children. Hence, providers considered job satisfaction as an indicator of PHC performance.

I have satisfaction [in] helping the poor, giving service to them. If they go to [a] private facility ... [just for] for IV fluids, they charge XXX rupees. So, it will help the poor people here [by saving money] (Comments from a doctor on serving poor patients)

If delivery happens very well, I feel satisfied. If [the] mother and child are fine, [then] it's enough — that gives satisfaction ... They should go home well. That's enough, madam. I will not ask [for] anything more. (Comments from a nurse on serving women and children)

\section{Theme 4: PHC Administration in Relation to Safety and Security Standards}

The interviewed providers said that PHC performance was also measured as to whether staff felt secure during work. If staff security was threatened, providers were not encouraged to take risks and were reluctant to do what patients wanted. Providers said that during the day, people and local leaders gather to argue and to harass staff, including doctors. Security was not only a concern in the PHC but also in the field. Poor security and safety standards prevented staff from operating at their best, so the PHC administration in relation to staff safety and security was also considered an factor influencing PHC performance.

We can inform our doctor, but when we do that they will say 'Why did you take a chance with such cases?' (Comments from a nurse on doctor's reaction)

I feel[that] if we have security staff, then it will be good. But some people can thrash the security [people] also... Those kinds of people are also there. (Comments from a nurse)

Going to villages only is a challenge, madam. It will be far away, we won't have bus facility, it will be around $2-3 \mathrm{~km}$, thieves have snatched the chains, it has not happened to me, but it has happened to others in some other route. (Comments from a health assistant on security in field)

Providers explained that during the night, there were no security staff employed by the government or locally recruited by the PHC. This was a huge challenge because nurses were exposed to violence or were often frightened when an agitated mob gathered following a provocation or an untoward incident.

They keep knocking the door of the PHC. If we say we won't open the door at night [and that] we see only pregnant and accident cases at night, they will say, 'Call the president 
[local elected leader to complain].... Oh, you won't give [an] injection to me; I will see you in the morning.' We will listen and keep quiet. [We] don't know if they are drunk or not; we need to face such things. (Comments from a nurse)

\section{Theme 5: Positive Community Relations}

From the providers' perspectives, the attitude of people and the various stakeholders towards healthcare and healthcare providers was a fundamental factor when assessing the PHC performance. Positive community relations were established during the process of service delivery, which needed considerable time, commitment, and patience during care. According to the providers, positive community relations reduced the risk of violence towards doctors. Good relationships with patients and the community also resulted in reasonable expectations from the centres and appropriate coordination and cooperation with local leaders and private players. Positive community relations also provided a conducive environment at the PHC, improving patient and provider satisfaction, directly affecting PHC performance.

\section{Relationships with People in the PHC and the Community}

Providers expressed that expectations and prejudice from patients was a major factor influencing their interactions with patients. The comments from the providers revealed that patients were often prejudiced about care provided in government facilities, with skewed expectations from government doctors. PHC providers said that patients were rude and came with predetermined ideas about the necessary treatment to be provided to them, thereby hindering personnel from delivering optimal care.

Sometimes they [patients] will come and ask 'Give me [an] insulin injection' ... They should come with an open mind. If they tell their problems, we can give [them a] treatment. Instead, they come and say what their problem is and ask for the medicine directly.... Then they won't sit [down] even though we have put chairs for them... I ask them to come one by one also [patients will come into my room and stand], they won't listen. ... Everybody wants to be treated immediately [that is, without considering their fellow patients]. ... [A few] people won't even understand what we advise... as soon as we give [them] medicines, patients expect to be cured immediately." (Comments from a doctor)

This was also the case when health assistants visited homes doing health promotion in the community. People would behave disrespectfully, and it was difficult to predict their response to the preventive care delivered as part of their work. As these responses from patients and the community hindered care delivery, good relations alone would improve quality of care and so they were included as an indicator of good PHC performance. 
People are different from one place to another. When we say something [relating to health education] ... some people take it as positive, some people fight with us (Comments from a health assistant)

Providers described that doctors were often victims of violence from patients and other staff. They also said that good relationships with the community would lead to smoother care provision, whereas aggression and violence disrupt care and demotivates providers. Hence safety was also considered a valid measurement in PHC performance assessment.

One of the interviewed providers described how certain situations arose. According to this provider, relatives of patients sometimes gathered a crowd in the community to question or confront doctors about the treatment that had been provided. The instigators of these confrontations often acted without considering how events had unfolded and often did not consider the condition of the patient when he or she had been brought to the PHC; sometimes these events were instigated by people with other interests, such as those cared for in private hospitals.

Just recently there was an infant death. They took patient to 'XYZ' Hospital and that madam [doctor] said something and did [an] operation. We could have done [a] normal delivery, but they operated on her. [The] baby was not saved, [and] they blamed us for everything... They created a big fight [and] they closed the hospital gate.... they said she [the nurse] did not do [care] correctly.... No one supported [colleagues, local leaders or public]. That time, even our doctor got beatings in the office room. There are such kinds of people. It is very difficult, madam. Panchayat members [local elected members] will take people's side during such situations. (Comments from a nurse)

Providers also mentioned in their interviews that violence did not come exclusively from patients and the community at large, but also sometimes other care providers or support staff members behaved violently with colleagues, upsetting the work environment. Good relationships with the community and among care providers could theoretically avoid these incidents of violence, so this was also added as factor affecting PHC performance.

See, there is one mental [person with psychiatric problem, pointing to a cleaning staff member] here. He is listening to what we are talking [about]. He is problematic. What to do? We can't look anywhere. He feels we are making fun of him and talking about him. ... This one guy is sick. He will go to hit the doctor only. (Comments from a nurse)

Cooperation and Coordination with Local Leaders and Private Players were Considered Important by the Providers

The providers highlighted that the presence and participation of local leaders in the PHC governance facilitated the identification of infrastructural needs and offered local support, thus enhancing the PHC's performance. Political interference by local leaders, their families and friends, and outlaws was a challenge because of their private interests and irrational expectations about what the PHCs 
could accomplish. Cooperation and coordination with local leaders was also considered as a factor affecting PHC performance.

We have given the letter for construction, after demolition [of an old building on the campus]; if MLA [Member of Legislative Assembly] releases the funds faster, it [construction] can happen.... political influence is more here ... if the ' $\mathrm{CCC}$ ' [a political party] does it, 'BBB' [another political party] will not tolerate [it]; they will poke their noses [into it] and say they [politicians] will eat money.... that's why building has not started. (Comments from a doctor)

They [patients] will come and tell 'we are members of Zilla-Panchayath [locally elected body], [and so on]'... They come and interfere with our work, like asking [that they are allowed] to handle patients which we cannot handle.... Sometimes they pressure [us] into doing things like normal delivery only [in complicated cases] (Comments from a nurse)

Our vehicle [experienced problems] when we were doing MR (measles-rubella) vaccinations. We called Gram-Panchayat members [locally elected persons]; if it's possible they will arrange [for a car] ... we ask local people for assistance, [everyone] co-operates with us. (Comments from a health assistant)

Interviewed providers mentioned also that private doctors spread rumours about government facilities, giving patients incorrect or misguided information and leading them to seek services from private centres, all of which damaged the reputation of PHCs. Therefore, good relationship with private healthcare providers was considered a factor in PHC performance.

They took the patient to 'XYZ' Hospital and that, madam, said something; they did [the] operation.... We could have done [a] normal delivery, but they operated on her; [the] baby was not saved [and] they blamed us for everything. They said she [the nurse] did not do it correctly. (Comments from a nurse)

\section{Discussion}

This study aimed to explore the performance of PHCs in Bengaluru urban district, from the providers' perspectives and compare them with the WHO aspects and the PHCPI performance assessment framework. The thematic analysis of the inputs from 36 providers of three PHCs resulted in indicators that overlapped with some components mentioned in the WHO's aspects and the PHCPI framework. These included services provided at centres to: reduce mortality and morbidity; improve overall health by increasing distribution of services through centres; increase in provider availability by reducing vacancy; enhance availability of medicines and infrastructure, and appropriate fund disbursement. However, providers also added a significant number of performance indicators that were not part of either the WHO aspects or the PHCPI performance assessment framework. Many of these performance indicators all involved or were related to the work environment in one way or the other. They included feeling part of a well-functioning, well-led team; the functioning of the team; 
opportunities for professional growth and development; job satisfaction; good rapport with the community, and a safe environment to work in.

The providers' focus on the work environment underscores studies that link work environment to healthcare performance in a number of ways.

First of all, several studies show how quality of the working environment impacted turnover and workforce retention, leading to understaffing and poor healthcare delivery. ${ }^{17-20}$ Other studies show a similar trend when they depict healthcare workforce development as an established investment strategy for improving employee retention and service delivery. ${ }^{21,} 22$ Providing opportunities for staff to advance their skills and knowledge by training and furthering education results in improvements in the health of the population, hence being an excellent criterion for assessing performance. ${ }^{23}$

Second, it has been well established in high-income countries that health systems should invest in providers, who are also referred to as internal customers. Addressing the gaps identified by these providers themselves, giving them voice, building trust, and caring for them would positively impact patient care as well. ${ }^{24,25}$ This is in line with studies that have reported that the satisfaction and motivation of internal customers accounted for better care delivery and patient satisfaction. ${ }^{26,27}$

Third, research has shown that job satisfaction positively influenced patient satisfaction, enhancing the care provider's feeling of achievement and being an essential component of performance assessment. ${ }^{28-30}$ In addition, job satisfaction and positive dynamics among providers are linked as factors contributing to employee retention, further facilitating better provider-patient relationships and better quality of care..$^{28,31}$

Finally, researchers reported increased violence against doctors and other healthcare professionals that has been increasing in both developing and developed countries. ${ }^{32-37}$ This violence is a reflection of the dysfunction of the health system which increases psychological distress among providers and worsen their performance. However, when trust is established, it results in higher patient satisfaction. ${ }^{38-41}$

This literature on work environment and performance show that the indicators brought up by the providers can and should be taken seriously. They should be included in PHC performance assessment in the Indian context. Not only because they help to take an important internal PHC customer seriously, and help adapt performance assessment to the Indian context, but also because literature ascertains that these indicators are indeed important for health and performance. Frameworks such as that of the WHO and PHCPI should therefore include these indicators, especially when applied in the Indian context. 
In light of research that has demonstrated that the technical content of training and education contributed to better patient care, ${ }^{42-44}$ it was a surprising to find that no provider mentioned the technical skills or knowledge of doctors or other healthcare providers as a performance indicator. It seemed providers simply assumed that they had the necessary technical knowledge and healthcare skills essential for patient care. Yet there is also literature in general healthcare or in primary healthcare delivery ${ }^{45,46}$ that shows that as long as health professionals share information on achievement of health outcomes, demonstrate awareness of patients, show commitment, integrity, and authenticity, their technical skills and knowledge are never commented on. Moreover, medical personnel who demonstrate the appropriate attitude contribute to better patient outcomes. ${ }^{23}$

\section{Central Role of Doctors in the PHC}

Another surprising finding was that providers placed a great deal of responsibilities on doctors, while doctors themselves also expected to fulfil these roles. The doctor was seen as central to the performance of the PHC as a team leader, administrator, supervisor, mentor, coordinator and manager . Apparently, according to the providers, the doctor's ability to fulfil these roles forms the basis of the PHC's performance.

This focus on the doctor as central to the functioning of their PHC maybe be explained by the glorified status of doctors in India. ${ }^{47,}{ }^{48}$ In addition to health education, preventive healthcare and curative healthcare delivery, these additional tasks described by providers place excessive strain on doctors, especially if there is one single doctor working in a particular PHC, which was the case in most of the centres included in the study. This can explain the low motivation for persons to seek work in primary care that lack basic amenities further deterring doctors. Disincentives have further complicated the problem of shortage of doctors in Indian primary care. ${ }^{49}$ The multiple roles required from PHC workers only accentuate the challenges of recruiting and retaining doctors for PHCs.

\section{Conclusions}

This study applied a qualitative research approach using a responsive evaluation method to explore PHC performance from the providers' perspective. The authors interviewed providers in selected PHCs seeking to understand their perspectives in relation to the WHO aspects for performance assessment and the PHCPI framework. From the providers' perspectives, the following PHC performance indicators emerged: the existence of good teamwork and a team that worked in a unified and coordinated way; the provision of opportunities for growth and development; the presence of job satisfaction among providers; the provision of a safe and secure work environment by the administration; and positive community relationships as a result of interactions that are 
positively reinforced. These indicators not only signal whether a PHC is performing well or not, but also form a 'missing link' connecting demands from external and internal customers to improve delivery of care and hence the health of the population. These indicators, when included in the WHO aspects and PHCPI performance assessment framework, will lead to a more holistic and practical tool for PHC assessment that would be more relevant to the Indian setting.

\section{Methodological Strengths and Weaknesses}

The strength of the study lies in the sample that included all the providers in a mixture of PHCs that were performing well, regularly and badly according to the institutional performance measurement, i.e., baby delivery. Theoretically, the study includes a wide array of providers, integrating factors on personal diversity that affect performance, thereby addressing the diverse and unique factors that may be present in each PHC setting. Including one PHC from each of the three selected categories in the study could have limitations in terms of generalisation of findings for the health system and further research would be required with a large number of PHCs to confirm the results.

\section{Recommendations for research and practice}

Further research should be conducted to generalise the findings of this study to PHCs in rural areas, in other states, and other low- and middle-income countries. Given that the indicators identified from the providers' perspective were related to the staff's work and life quality and their engagement, further research is needed to establish the interrelations. This research based on responsive evaluation reflecting subjective observations could also be extended to explore the relationship between different performance indicators and criteria from the perspective of multiple stakeholders. 


\section{References}

1. Bhore committee 1946. https://www.nhp.gov.in/bhore-committee-1946_pg Accessed on 1st December 2018

2. https://nrhm-mis.nic.in/hmisreports/frmstandard_reports.aspx. Accessed on 10 Jan 2019

3. UN Press release 2015. Maternal death ratio has fallen 44 percent since 1990-UN. https://www.unfpa.org/press/maternal-death-ratio-has-fallen-44-cent-1990-\%E2\%80\%93-un. Accessed on 7 Oct 2016.

4. The Global strategy for women's children's and adolescent's health 2016-2030: survive, thrive, transform $2015 . \quad$ http://www.who.int/life-course/partners/globalstrategy/globalstrategyreport2016-2030-lowres.pdf?ua=1. Accessed on 7 October 2016.

5. Donnay F. Maternal survival in Developing countries: what has been done, what can be achieved in the next decade. International Journal of Gynaecology and Obstetrics. 2000;70:89-97.

6. Urban health report.2016. http://apps.who.int/iris/handle/10665/204715.Accessed on 7 Oct 2016.

7. Global status report on non-communicable diseases 2014. https://apps.who.int/iris/bitstream/10665/148114/1/978941564854_eng.pdf?ua=1. Accessed on 7 Oct 2016

8. The

Sustainable

Development

Goals

2016.http://www.un.org/sustainabledevelopment/development-agenda/ 2016. Accessed on 4 Jan 2016.

9. Indian Public Health Standards: Guidelines for Primary Health Centres, Revised 2012. Directorate General of Health Services, Ministry of Health and Family Welfare, Government of India. http://nhm.gov.in/nhm/nrhm/guidelines/indian-public-health-standards.html accessed on 19th January 2018

10. Sathyananda R B, de Rijk A, Manjunath U, Krumeich A, van Schayck C P. Primary health Centers' performanc assessment measures in developing countries: review of the empirical literature. BMC Health Services Research. 2018;18:627. doi.org/10.1186/s12913-018-3423-0

11. The World Health Report 2000. Health Systems: Improving Performance. https://www.who.int.en. Accessed 1 Nov 2014 
12. Health Systems Performance Assessment: Debates, Methods and Empiricism. WHO Publication. 2003. http://www.who.int/health_financing/documents/cov-hspa/en/. Accessed on 10 Sept 2015.

13. Veillard J, Cowling K, Bittton A, Ratcliffe H, Kimball M, Barkley S, Mercereau L, Wong E, Taylor C, Hirschhorn L R, Wang H. Better measurement for performance improvement in lowand middle-income countries: The primary healthcare performance initiative (PHCPI) experience of conceptual framework development and indicator selection. The Milbank Quarterly.2017;95(4):836-883

14. Guetterman R C, Fetters M D, Creswell J W. Integrating quantitative and qualitative results in health science mixed methods research through joint displays. Annals of Family Medicine. 2015;13(6):554-561. Doi: 10.1370/afm.1865.

15. Guba E G, Lincol Y S. Fourth Generation Evaluation 1989, 21-49, Sage Publication

16. Castleberry A, Nolen A. Thematic analysis of qualitative research data: Is it as easy as it sounds? Currents in pharmacy teaching and learning. 2018;10(6):807-15. doi: 10.1016/j.cpt1.2018.03.019.

17. Chao M-C, Jou R-C, Liao C-C, Kuo C-W, Workplace stress, job satisfaction, and turnover intention of health care workers in rural Taiwan. Asia-Pacific Journal of Public Health. 2015;27(2):1827-1836. Doi.10.1177/1010539513506604

18. Sokhanvar M, Kakemam E, Chegini Z, Sarbakhsh P. Hospital nurses' job security and turnover intention and factors contributing to their turnover intention: A cross-sectional study. Nursing and Midwifery Studies. 2018;7:133-40. Dor:10.4103/nms_2_17

19. Wan Q, Li Z, Zhou W, Shang S. Effects of work environment and job characteristics on the turnover intention of experienced nurses: The mediating role of work engagement. Journal of Advanced Nursing. 2018;74:1332-1341. Doi:10.1111/jan.13528

20. Almalki M J, FitzGerald G, Clark M. The relationship between quality of work life and turnover intention of primary health care nurses in Saudi Arabia. BMC Health Services Research.2012;12:314

21. Clarke $\mathrm{R}$ L. Invest in Employee Development. Healthcare Financial Management. 2002;56(11):16

22. Pindus N, Tilly J, Weinstein S. Skill Shortages and Mismatches in Nursing Related Health Care Employment http://webarchive.urban.org/publications/410485.html accessed on 3rd Nov 2019 
23. C Vengros J A, Christensen A J, Hillis S L, Rosenthal G E. Patient and Physician Attitudes in the Health Care Context: Attitudinal Symmetry Predicts Patient Satisfaction and Adherence. Annals of Behavioral Medicine. 2007;33(3):262-68

24. Chaston I. Internal customer management and service gaps within the National Health Service. International Journal of Nursing Studies. 1994;31(4):380-90

25. O’Neill M. Employee care, a vital antecedent to customer care in the health care industry An exploratory investigation of the employee satisfaction construct at North East Alabama Regional Medical Center. International Journal of Health Care Quality Assurance. 2005;18(2):131-151. DOI 10.1108/09526860510588160

26. Manolitzas P, Fortsas V, Grigoroudis E, Matsatsinis N. Internal Customer Satisfaction in HealthCare Organizations: A Multicriteria Analysis Approach. International Journal of Public Administration. 2014;37:646-54. DOI:10.1080/01900692.2014.903267

27. Agyepong I A, Anafi P, Asiamah E, Ansah E K, Ashon D A, Narh-Dometey. Health worker (internal customer) satisfaction and motivation in the public sector in Ghana. International Journal of Health Planning and Management. 2004;19:319-336

28. Szecsenyi J, Goetz K, Campbell S, Broge B, Reuschenbach B, Wensing M. Is the job satisfaction of primary care team members associated with patient satisfaction? BMJ Quality and Safety. 2011;20:508-514

29. Prytherch H, Kakoko DCV, Leshabri MT, Sauerborn R, Marx M. Maternal and newborn healthcare providers in rural Tanzania: in-dept interviews exploring influences on motivation, performance and job satisfaction. Rural and Remote Health. 2012;12:2072

30. Taris T W, Schaufeli W B. Individual well-being and performance at work: A conceptual and theoretical overview. 2015 https://www.wilmarschaufeli.nl/publications/Schaufeli/434.pdf Accessed on $9^{\text {th }}$ December 2019 (Wellbeing and performance at work. Edited by van Veldhoven m, Peccei R. Chapter 2)

31. Bhandari P, Bagga R, Nandan D. Levels of Job Satisfaction among Healthcare Providers in CGHS Dispensaries. Journal of Health Management. 2010;12(4):403-22

32. Mishra S. Other side of Moon Violence against Doctors: The Class wars. Indian Heart Journal. 2015;67:289-92 
33. Celik SS, Celik Y, Agirbas L, Ugurluoglu O. Verbal and physical abuse against nurses in Turkey. International Nursing Review. 2007;54(4). doi.org/10.1111/j.1466-7657.2007.00548.x

34. Joa T S, Morken T. Violence towards personnel in out-of-hours primary care: A cross-sectional study. Scandinavian Journal of Primary Health Care. 2012;30:55-60. doi.10.3109/02813432.2012.651570

35. Hobbs F D R, Keane U M. Aggression against doctors: A review. Journal of the Royal Society of Medicine. 1996;89:69-72

36. Ahmed F, Memon M K, Memon S. Violence against doctors, a serious concern for healthcare organizations to ponder about. Annals of Medicine and Surgery. 2018;25:3-5

37. Philips J P. Workplace violence against health care workers in United States. The New England Journal of Medicine. 2016;374:1661-9s

38. Singh M. Communication as a Bridge to Build a Sound Doctor-Patient/Parent Relationship. The Indian Journal of Pediatrics. 2016;83(1):33-37

39. Tucker JD, Cheng Y, Wong B, Gong N, Nie JB, Zhu W, McLaughlin MM, et al. Patientphysician mistrust and violence against physicians in Guangdong Province, China:a qualitative study. British Medical Journal Open. 2015;5:e008221. doi:10.1136/bmjopen-2015-008221

40. Reddy I R, Ukrani J, Indla V, Ukrani V. Violence against doctors: A viral epidemic? Indian Journal of Psychiatry. 2019;61(10):782-85

41. Chandra S, Ward P, Mohammadnezhad M. Factors Associated with Patient Satisfaction in Outpatient Department of Suva Sub-divisional Health Centre, Fiji, 2018: A Mixed Method Study. Front. Public Health. 2019;7:183 doi:10.3389/fpubh.2019.00183

42. Rao G N. How can we improve patient care? Journal of Community Eye Health. 2002;15(41):116.

43. Kennedy D M. Creating an Excellent Patient Experience Through Service Education: Content and Methods for Engaging and Motivating Front-line Staff. Journal of Patient Experience. 2017;4(4):156-161. DOI: 10.1177/2374373517718351.

44. Uneo E, Adegoke A. A, Masenga G, Fimbo J, Msuya S E. Skilled Birth Attendants in Tanzania: A descriptive study of cadres and emergency obstetric care signal functions performed. Maternal and Child Health Journal. 2015;19:155-169. 
45. Shapiro I. Doctor Means Teacher. Academic Medicine. 2001;76(7):711

46. O’Sullivan H, Mckimm J. Doctor as professional and doctor as leader: Same attributes, attitudes and Values? British Journal of Hospital Medicine. 2011;72(8):463-66

47. Bastos C. Doctors for the empire: The medical school of Goa and its narratives. Identities Global Studies in Culture and Power. 2010;8(4):517-548. DOI: 10.1080/1070289X.2001.9962707

48. Makolkin A. The Physician as a Deity: Balzac's meandering between religion and medicine in The Country Doctor. Ultimate reality and meaning, 2006;29(1-2): 5-16.

49. Sharma D C. India still struggles with rural doctor shortages. The Lancet. 2015;386-2381-82 


\section{Chapter 5}

The Performance of Primary Healthcare Centres from the Manager's Perspective: A Qualitative Analysis

Bangalore Sathyananda, R., Krumeich, A, Manjunath, U., de Rijk,A., van Schayck,C.P.

Submitted 
Title: Managers' Perspectives on Primary Healthcare Centre Performance in Bengaluru, India: A Qualitative Analysis

\begin{abstract}
Background: The major provider of basic health needs for the general population in India are centres known as Primary Healthcare Centres (PHCs), which are mostly government owned and operated. PHCs address the basic health needs of the population by providing health education, promotion and preventive healthcare, among other services. The performance of PHCs is therefore critical to public health. The aim of this study is to identify PHC performance indicators and the various factors that affect performance, from the perspectives of mid-level healthcare managers.
\end{abstract}

Methodology: In-depth interviews were conducted among the managers at taluk, block and district level in the Bengaluru urban district to explore and understand their perspective on PHC performance.

Results: Apart from output indicators, managers said that PHC environment and rapport with patients should be considered as PHC performance indicators. The managers identified doctors as key persons for PHC performance. According to the managers, doctors not only contributed to the standard output indicators by delivering preventive and curative services at PHC, but also have multiple responsibilities as able leaders. The managers also specified the PHCs' dependence on the health system and the local political bodies to function in the socio-political atmosphere. The managers also identified themselves as PHC leaders but in a limited role in the overall PHC performance, as centre supervisors. Managers also emphasised that doctors were responsible for the overall harmonisation of all the mentioned components and dependencies of PHC functioning.

Conclusion: According to the managers, PHC performance consisted of PHC environment and rapport with patients in addition to the centres' output indicators. They concluded that doctors at PHCs, as able leaders, played a significant role in PHC performance. 


\section{Introduction}

An efficient health system that promotes health and works towards disease prevention is necessary for improving the health of the population. The public health system in India is structured to address health at multiple levels of care namely primary, secondary and tertiary care. ${ }^{1}$ Primary healthcare delivered at clinics known as Primary Healthcare Centres (PHCs) address the basic health needs of the population. PHCs in India are mostly government owned and operated. PHCs address the basic health needs of the population by providing health education and promotion, and preventive healthcare. The performance of these centres is vital to the health of the population, so assessment of these centres is important. ${ }^{2}$

The World Health Organization (WHO) has specified aspects for health system performance assessment. The WHO aspects focus on outputs and outcomes of a health system, but these are not specified for PHCs in a low-and middle-income country (LMIC) like India, which has financial and data constraints. 2, 3,4 This study aims at contributing to developing performance indicators for PHCs in India, a lower-middle income country. ${ }^{5}$ For performance evaluation to be practical and realistic, it should be attuned to the local context. This can be done best by adding indicators suggested by the different stakeholders to the indicators from existing models, such as the WHO model, and from the literature review we conducted earlier. ${ }^{2,3,4}$ The indicators suggested by the stakeholders help to capture the day-to-day functioning of a PHC in its environment. ${ }^{6,7,8}$

The PHCs are administered by doctors, also called Administrative Medical Officers, who are responsible for the PHCs' complete day-to-day functioning, supported by nurses, health assistants, health-education officers, pharmacists, laboratory technicians, optometrists and other non-care provider staff. The performance of all PHCs in the part of a district called a taluk in Karnataka is the responsibility of the Taluk Officer, who reports to District Programme Officers and District Health Officer at the district. All district officers report to State Programme Officers headed by the state Director. ${ }^{1}$ This study focuses on the PHCs' mid-level managers, important stakeholders, since they are the supervisors of the doctors at PHCs.

The Taluk Health Officers, District Programme Officers and District Health Officer are the mid-level managers of the health system, connecting with higher management at the state, so their views on performance assessment are important. This article focuses on identifying indicators that should be followed to improve performance from the perspectives of mid-level healthcare managers (managers). The research questions addressed in this article are:

a. What are the indicators of well-performing PHCs from the managers' perspectives?

b. How can PHC performance improve from the managers' perspectives? 


\section{Methodology}

Study Design

A qualitative research methodology by in-depth interviews with mid-level healthcare managers was employed to explore and understand how managers define PHC performance.

Study setting and context

The study included managers working in the department of Health and Family Welfare of Bengaluru urban district, the capital of Karnataka state in India. Like any other city in a LMIC, Bengaluru is undergoing extensive urbanisation involving the surrounding suburban and rural areas. Bengaluru has numerous high-risk areas with a vast population migrating into the city, and mostly dependent on the public health system for their healthcare needs, since private health care is too expensive for them. ${ }^{9}$

Ethics

The study was approved by the Manipal University Ethics Review Committee of Manipal University, Karnataka, India. All the participants were included in the study following the principles of ethics in research. The participants were assured of the confidentiality of data, with the choice of refraining from providing input and leaving the study at any point.

Study participants

The Taluk Health Officers, District Programme Officers and District Health Officer of Bengaluru Urban District were included in the study. The Taluk Health Officer is responsible for the functioning of the PHCs in a particular part of the district called a taluk. These officers oversee the functioning of the PHCs that are directly controlled by the Administrative Medical Officer, also referred as a medical officer, who forms the first line of management. Taluk Health Officers form a link between PHCs and district level officers, who are responsible for proper implementation of the various programmes at the PHCs in all the taluks. A few taluks form an administrative district in the state and a District Health Officer is responsible for public health. The District Health Officer is assisted by the District Programme Officer in supervising individual National Health Programme Officers at all the health facilities in a particular district. ${ }^{1}$ Bengaluru urban district had four Taluk Health Officers and six District Programme Officers during the study period. ${ }^{\mathrm{iii}}$

\footnotetext{
' Reproductive and Child Health Officer, District Family Welfare Officer, District Surveillance Officer, District Tuberculosis Officer, District AIDS Prevention and Control Officer, District Blindness Control Officer, and District Leprosy Officer
} 
Eight middle level managers were included in the study: the District Health Officer, all Programme Officers except the District Tuberculosis Officer (who was not available for the interview), and two Taluk Health Officers. Three managers out of the eight were female. The district officers all had more than 18 years' experience and taluk officers had more than 13 years of experience in the health system. All participants started their service in public healthcare as medical officers in PHCs, later taking up positions at taluk and district level as doctors and administrative officers or managers. They had been in their current positions for between three and eight years.

\section{Data collection}

After obtaining written consent from the participants, the interviews were conducted in local language to help them communicate effectively on their experiences and opinions on PHC performance. Adherence to research ethics requirements was achieved by maintaining confidentiality in relation to study participants and not recording their personal details; they could also refrain from giving input if they did not want to and they could exit from the study at any point in time. Following a social constructivist approach, the interview guide was dynamic in nature to accommodate various constructions of the participants' reality. ${ }^{6}$

\section{Data Analysis}

Personal data was removed from the recording to ensure confidentiality. The interviews were translated into English by professional translators and transcribed, this data was analysed by the Atlas TI software for thematic analysis; the themes that represented PHC performance and the factors affecting such performance according to the managers were identified and developed. ${ }^{10}$

\section{Results}

The results from the interviews with eight managers in the Bengaluru urban district are presented below, which are specified as the PHC performance indicator, including the various factors that were conducive to the performance according to the managers.

\section{Indicators of a well-performing PHC}

The in-depth interviews with the managers showed that PHC performance was defined in terms of targets that have to be achieved by the centre as per the guidelines of the department, for example, the number of patients seen in the outpatient department, the number of babies delivered, the percentage of children immunised, outbreaks investigated, screening for infectious diseases like tuberculosis, blood smears for malaria survey, larva survey in community, among others.

We give them the targets and they need to achieve that; these are all fixed ... For example, OPD ... collect blood smears ... (IPHS interview excerpt) 
The managers said that besides the regular services delivered and the programmes implemented to achieve PHC targets, PHC performance also included (1) good environment and (2) rapport with patients.

For PHC to be considered as good performing, first is the environment ... all aspects should be neat and clean. PHC should look good and organised ... then they should keep them [patient] engaged with [information education communication], behave politely and treat well ... the patient should be convinced that the hospital is working nicely, so rapport also will be built up (District Programme Officer interview excerpt)

\section{Factors affecting PHC performance}

When asked about PHC performance, managers spoke about performance indicators, and more extensively about the various factors that would contribute to performance to be considered in the PHC assessment.

According to the managers, the doctor was the key actor in the performance of the PHC; the roles and responsibilities of the doctor were defined as that of active leadership, providing conducive work environment and bridging different stakeholders. The managers also identified their responsibilities along with the roles of the health system and local politics affecting PHC performance.

\section{Doctors are at the core of achieving good PHC performance}

Managers believed that active doctors were imperative for performance in providing services, keeping a good health promoting environment and building rapport with patients so as to enhance patient care experience. The managers reasoned that since doctors were responsible for the functioning of the PHC, they had to fulfil the roles of a good leader, administrator, human resource manager, grievance redresser, supervisor and mentor of other providers, including coordinating and cooperating with external stakeholders, including law enforcement. Managers believed that as these activities were essential components of the work profile of a doctor in the PHC, they should deliver them with utmost dedication and commitment. Managers justified that these performance indicators of the doctor's role would ultimately contribute to PHC performance.

Everything depends upon the local doctors and not on anyone else. (District Health Officer interview excerpt)

Managers believed that doctors had to demonstrate good leadership skills, preferably leading by example and not distance themselves from other providers, seeking to establish good teams at the PHCs.

The medical officer is most important because he has to take the lead; he should be inquisitive; he should be committed ... should have a service motto ... They should not feel that they are the boss and the staff should listen to them ... Some doctors think they are great 
people and their subordinates are low, so with this kind of mindset they will not be able to mingle freely with their staff or build a good team (District Programme Officer interview excerpt)

Managers said that doctors were not professionally trained to be administrators, but management is part of their job at PHCs, so they are expected to excel in managing PHCs, so doctors accomplished it to the best of their abilities by practice. Administration consisted of all the activities contributing towards day-to-day functioning of the PHCs, including submitting reports on PHC functioning to their superiors, influencing doctor performance, which further affected PHC performance.

Once you are in the water you have to learn to swim ... Whatever we learn in theory from administrative point of view, we will not know it [PHC administration] until we work in the field ... That doesn't mean we can't do administration ... But now there is public awareness regarding health ... only poor, uneducated people will have a little problem with awareness, they [health assistants supervised by doctors] should provide right information ... documentation and reporting to higher officers at the end; but they [doctors] should not neglect it, that's more important (District Health Officer interview excerpt)

Managers said that as part of their administrative role, doctors were expected to supervise the activities of other providers in fulfilling their roles and responsibilities, ultimately leading to the PHC excelling in care delivery.

Medical officer should check it [register maintenance by other staff] randomly and sign the registers ... cleanliness should be maintained, doctor should go one round and check on all these (infrastructure management) if monitoring is there, then definitely these things will be taken care of. (District Programme Officer interview excerpt)

Managers also said that as part of administration, doctors had to monitor the work of other providers, provide technical support and build confidence in them to deliver appropriate care, which consequently lead their better performance.

The medical officer should build confidence in them [nurse and health assistants]. They [doctors] should say, 'take the case, I will be there'. Then they [nurse and health assistants] feel 'madam [doctor] is there if anything goes wrong [if the case develops complication]' ... They will develop confidence ... and do well ... [PHC] will get a good name. (District Program Officer interview excerpt)

Managers emphasised the importance of the doctors' performance in their interactions with other providers, such as being impartial when rectifying a provider's actions, and keeping the team motivated to promote a positive work environment in the PHCs, so the doctor's performance aided in PHC performance.

It all depends on the medical officer, you know, they [nurses, health assistants and other staff] used to work [hard and for long hours], so on the last day of the pulse polio [immunisation programme] I used to just give them one gift ... after that some snacks with coffee, once in a while minor spending on snacks and coffee with the staff is not an issue [expensive], the 
feeling they get is great, the feeling they get about the medical officer is unbelievable, we can't gain it by spending any amount of money ... Every monthly meeting, we used to have a thorough review, if I [doctor] need to scold them or correct them I would do that and after the meeting, we [at PHC] used to arrange lunch for them. (District Programme Officer interview excerpt)

Managers believed that doctors, as PHC heads, had to cooperate and coordinate with external stakeholders. The managers also indicated that there were instances when because of the good work of a doctor and the PHC, the local political bodies and other departments would get involved in the functioning of the PHC, providing infrastructure to improve services at the PHC. The managers said that doctors should work with the local bodies in establishing goodwill and developing an inclusive environment, forming a doctor performance indicator.

Inter-departmental interaction plays a big role [in improving PHC], it may be horticulture department, rural development; because the compound will not be there, the gate will not be there, so they [other departments] can get all these done (District Programme Officer interview excerpt)

Managers said that when managing PHCs, doctors will have to deal with complaints from providers and patients, during which time doctors should be highly diplomatic and sort the matter without any prejudice immediately, so that the functioning of the PHC is not affected.

Medical officer[s] should be neutral politically ... you should have a get together; distribute work equally, if you are scolding, you scold everybody ... They [all staff] should be equal ... any differences between the staff or patients, they [doctors] should call and sort it out then and there itself, make them have some tea and finish off the matter. (District Programme Officer interview excerpt)

The managers informed that as mandated by the law, the PHCs were also the centres to address medico-legal cases; it was a legal obligation of doctors to be a neutral party in presenting unbiased reports and medical opinion, and to coordinate with police and other legal entities the smooth delivery of justice.

You get all these PMs [post-mortem] ... I had a good rapport with the police, usually policemen will not have a clash with any medical officer ... The only thing is when we [doctor] used to work in the past, we would not work after five, we used to do it the next day [as per legal instructions] ... so now there is no difference between day and night, any time they [doctors] can do it. (District Programme Officer interview excerpt)

Managers said that doctors were assigned to duties outside the PHC to provide medical support to political persons, which affected the work at the PHC. Since such duties are mandatory for a doctor, they should be considered in doctor performance. The managers also said that because of these kinds of roles assigned to government doctors, there were fewer doctors who opted to work in the government setting. 
As a medical officer, I know the problem. On a daily basis we need to put four duty protocols for visiting VIPs [very important persons visiting Bengaluru] ... If they [political bodies] keep doing teams like this, how will they [doctors] manage? ... what work can they do in PHC? ... they [VIPs] will eat and drink and enjoy, but so sad these doctors should wait outside [doing nothing] ... how should they feel, madam? Who will come forward for such government services? (District Health Officer interview excerpt)

\section{Dependence on health system and local political bodies}

The managers stated that the health system was responsible for providing infrastructure, human resources, and finances for efficient PHC functioning.

Regarding infrastructure, now almost everything is available, but it should be legal. What happens in Bengaluru is, rural setup is good, but in Bengaluru, PHC buildings are not on government lands, someone has donated the land, pakka (complete) documents will not be available ... What happens here is, once in six months or a year, the medical officer will be changed, they will initiate a process and it will stop there itself, they will not continue it further. (District Programme Officer interview excerpt)

Managers emphasised that the department should invest in health education for the general population on all ailments and not focus on just a few challenges. They believed that by not providing sufficient budget for such activities would hinder the overall public health achievements of the department.

Especially, in my programme, which is a family planning programme, there are a lot of misconceptions, superstitions; until we clear these, we cannot implement our programmes ... They say there is no budget and all that. Those things will be spoken there in the DC (District Commissioner) meeting (District Programme Officer interview excerpt)

The managers conveyed that support from local political leaders to the PHC was a major factor in PHC performance, but they did not see themselves responsible for this coordination. However, they said that sometimes providers with a political background were posted to PHCs, and that would not work as they were only interested in their personal agendas, adding to the burden of the doctor. Managers mentioned that the health system and the political leaders should not encourage such decisions, because they demotivate well-performing providers, disrupting the PHC team, since it was the responsibility of the doctor to maintain harmony at the centre. Hence, managing such situations fell to doctors, affecting their performance.

Now everybody will have some influence, even a group D person [cleaning staff] can go to the CM's [Chief Minister] office tomorrow and make them call me on the phone, especially in Bengaluru, so everybody will have some [political] influence. They [staff] shouldn't feel that they are something great ... Everybody should work and then disperse ... He [staff] should not be a problem to the doctor or to the PHC. Whether he has a political background or whether he is a VIP [very important person], it doesn't matter; work is work. After 4:30 p.m. or four o'clock, let him behave as he wants ... even if the candidate is their [political party] side, he [leader] should tell them to work. (District Programme Officer interview excerpt) 


\section{Socio-political atmosphere}

The managers asserted that the socio-political atmosphere played a prominent role in PHC performance. They said that there were incidences of interference from the local people who hindered the PHC's functioning. They said that a lot of local factors should be aligned for PHCs to perform well, for example, local people with vested interests would complain against the doctor. They said that in such cases, the higher officer had to investigate the incident based on the evidence and not penalise the doctors, especially if the PHC was functioning well. Such support from the health system and managers would motivate people to perform well. Consequently, managing such incidences was the responsibility of the doctor, also affecting doctor performance.

One more thing ... whoever enters the government service should be protected in case there is interference by the public and local leaders ... so take his service into account from a technical point ... instead, so they will put an inquiry, issue memo, spoil his work and motivation; this is what they do (District Programme Officer interview excerpt)

This is the experience that I am telling you ... I did a sterilisation operation for a lady ... Her consent was taken ... Then later ... her husband asked me to give 20 lakhs of rupees as compensation ... I was bold enough, so next, I went to the director of health services ... he said, 'we will deal this through the lawyer' ... later I won the case, I thanked him for the support. (District Health Officer interview excerpt)

Managers laid all responsibility related to PHC functioning, and collaboration with the local sociopolitical environment on doctors, thereby crafting doctor performance as the performance of the centres.

\section{My role as a manager}

The managers emphasised their roles in PHC performance as that of trainers and supervisors during their visits to the centres, and during programme implementation. Managers as supervisors in programme implementation would collect data, review progress and acted as a bridge between the health system and the PHC. Managers identified their role as intradepartmental change agents external to the PHC, who could identify gaps between the PHC and the external stakeholder for overall development of the PHC.

The managers indicated that when they went to PHCs for supervisory visits, they would train the providers on how to provide care, maintain records, administration and other aspects of patient care. After this training, it was the responsibility of providers to follow the instructions and provide quality care to patients. Hence the manager's work in PHC supervision was considered as contributing to the PHC performance.

For this [PHC performance] it [training] is not enough if we [programme officers] just bombard [with information] and leave it like that. They [doctors, nurses, health assistants and 
patients] will have developed some doubts, so we [programme officers and doctors] need to clear their doubts; that is what I [district health officer] do when I go to PHCs. (District Health Officer interview excerpt)

The managers said that they were responsible for the services delivered and the execution of programmes at PHCs, so they would conduct review meetings at the district level, which could be considered as part of the performance of the managers, contributing to PHC performance.

If you do random visits, then they feel madam will visit any time and they will work well ... Then I will keep telling them strictly to do a PHC meeting and review, but the way they do the review is just copy and paste ... When I visited the delivery ward in that place (PHC), I had scolded the nurse because it was not maintained well, even in case of entering the records ... we conduct monthly review meeting in districts ... if we ask them why performance is low, they just stand up and keep quiet ... madam [district health officer] scolded him properly (District Programme Officer interview excerpt)

The managers said that they were in a position where they could interact with other external stakeholders to improve the infrastructure and functioning of PHCs, however, they did not specify that they could interact with the health department for the same objectives. Hence, their achievement of collaborations with external stakeholders was considered as manager performance contributing to PHC performance.

I am planning to visit ITBT [Information technology and Biotechnology] minister's office. I want to meet the secretary ... they [private ITBT companies] should adopt one PHC for the maintenance and cleanliness of the hospital premises and hospital garden (District Programme Officer interview excerpt)

\section{Discussion}

The interviews with the eight mid-level managers, that is, two Taluk Health Officers, five District Programme Officers and one District Health Officer were conducted to produce an insight into what the managers found were important performance indicators. According to the managers, performance indicators are the targets set by the department and the environment at PHCs. They also said that the doctors' performances had tremendous influence on PHC performance. The role of managers was to support the doctors in these tasks.

The managers believed that PHC performance depended on good leadership provided by the doctor. This included proper administration, human resource management, supervision of other providers, and mentorship of the team. The doctors' leadership also encompassed reporting on the PHC's activities to higher officials, infrastructure maintenance, overseeing resources and financial allocation, and maintaining good rapport with patients. It also included coordination of healtheducation campaigns and intuitive coordination of collaboration with external stakeholders and political leaders. Providing medical opinion for legal bodies, and medical assistance to persons of 
political importance visiting the city, were also important for the functioning of the PHC and fell under the doctors' tasks as well.

There is evidence in literature that the right attitude, behaviour and communication by the leader facilitates collaboration between various providers, whereas efficient nursing depends on strong, consistent and knowledgeable leaders. ${ }^{11-13}$ In this respect, the managers' emphasis on the importance of these tasks makes sense. The empirical research has shown that motivated leaders inspire their followers to perform their best and enrich the work environment, enhancing employee job satisfaction and patient satisfaction. ${ }^{14-25}$

The question that remains is whether these leadership tasks should be fulfilled by doctors and whether doctors are prepared for this dual role. Being primarily trained to be medical professionals, they are expected to take on managerial roles while lacking a strong foundation in management for better execution of PHC functionalities. Studies in which a similar inconsistency between doctors' tasks and their education ${ }^{26}$ point out that this gap should be addressed by providing necessary skills and management tools along with adequate resources for execution of multiple roles. ${ }^{26,27}$ and that supplementing or complementing doctors' managerial roles by adding adequately trained persons to take on managerial responsibilities should be considered. ${ }^{29}$

The managers' observation that good communication results in better treatment compliance, patient outcome and satisfaction, seems to be confirmed by the literature as well ${ }^{10,30-32}$ and therefore should be included as performance indicator. There has been extensive research on rapport building and patient outcomes, but rapport itself has not been considered as a health system performance indicator, let alone in PHCs.

Having recognised the lack of supportive supervision at multiple levels, Indian health officials are planning multiple interventions to strengthen the country's health system. ${ }^{30}$ With all the emphasis on the role of doctors being synonymous with PHC performance, the issue that has to be considered is how to support the doctor in fulfilling his or her roles and responsibilities, while preserving one's well-being. While doctors' responsibilities were discussed at length by the managers, they did not mention technical skill and medical knowledge of doctors contributing to the quality of care.

\section{PHC environment and performance}

The managers perceived the environment at the PHC to be an important performance indicator. A better environment meant that patients perceived the centre as good and providers had a better workplace, which is a good indicator of PHC performance. Indeed research has associated the environment at a care facility, as well as better patient-provider communication, as preconditions to 
good performance, good patient outcomes, and better patient and provider satisfaction. ${ }^{33-37}$ When assessing PHC environments, one would simulate multiple indicators of PHC performance, such as patient and provider satisfaction, so PHC environment would indeed form an excellent PHC performance indicator.

\section{Role of managers in relation to PHC performance}

The well-functioning of PHCs also depends on supportive supervision of PHCs by the managers themselves and on the managers' success in interacting with other departments (external stakeholders) in a meaningful way.

In the literature, the manager's role has been established as a pre-condition of health system performance, ${ }^{38,39}$ but the managers in our study seemed to reserve managerial tasks within the PHC to doctors, claiming representation and advocacy on behalf of the centre as their own major responsibility. Studies on this topic seem to confirm that although doctors often lack leadership skills as government agents and administrators, they often retain enormous public respect and support. ${ }^{47}$ Providing doctors with relevant skills so they can take the responsibilities not only within the system but also advocate for better functioning should be considered, as this would facilitate a PHC doctor to focus on healthcare delivery, improving PHC performance. ${ }^{40-46}$

\section{Role of the health system and local politics in PHC performance}

The managers identified the support and conditions that would be conducive for the PHCs to perform, which included provision of resources from the health system, and conducive sociopolitical environment locally by the community and leaders. As these conditions are preconditions for performance, they should be fulfilled for PHCs to perform well.

\section{Lack of attention to medical role of doctors}

It is striking that the managers did not address the actual medical tasks of doctors, including technical skills and professional values, as part of PHC performance. It seemed that they assumed it to be a given for just being a doctor. However, taking care of medical tasks, leadership and management, patient education, relationships with the health system and local political actors, might place excessive demand on doctors, who might fail to deliver because of these multiple tasks set with high expectations. ${ }^{47,48}$

\section{Conclusion}

In-depth interviews with mid-level managers in Bengaluru district showed that PHC performance indicators consisted of targets set by the department, good PHC environment, an established rapport 
with the patients, doctors' leadership, support from the health system and local politics, sociopolitical coordination and the supporting supervision role of managers. The managers conveyed that for them PHC performance was synonymous with good leadership by the doctors at the PHCs, plus the doctors' ability to balance between the health system and local politics. While placing the responsibility for PHC performance on doctors, the managers identified their own contribution as supportive supervisors and as change agents.

\section{Methodological strengths and weaknesses}

Including both the block level and the district level managers can be considered a strength of the article, as it provides diverse perspectives from the managers' experiences. The involvement of the managers who had worked at grassroots level at PHCs in rural and urban areas meant that they had a clear understanding of the system. On the other hand, it also means that having worked and moved on to higher levels, they always compared PHC performance with their own work and in the process could have developed tunnel vision about the role of doctors in PHC performance, overemphasising the doctors' influence on PHC performance.

\section{Recommendations}

The managers highlighted the key role that doctors play in fulfilling the prerequisites for good PHC performance. Although they emphasised the role of doctors, the managers also noticed that doctors need to learn how to be good leaders. Doctors might be overburdened by managers, the system and the patients. Investment in good training to address leadership gaps might be essential to augment their capacities, which could be considered to support doctors and other providers at PHCs achieve better performance. ${ }^{38,46}$ There is need for further research on the capacity of doctors and managers as leaders in the context of PHC performance. 


\section{Reference:}

1. Directorate of Health and Family Welfare Services: Annual report 2015-16. Page 1-2. https://www.karnataka.gov.in/hfw.

2. Sathyananda R B, de Rijk A, Manjunath U, Krumeich A, van Schayck C P. Primary health Centers' performance assessment measures in developing countries: review of the empirical literature. BMC Health Services Research. 2018;18:627. doi.org/10.1186/s12913-018-3423-0

3. The World Health Report 2000. Health Systems: Improving Performance. https://www.who.int.en. Accessed 1 Nov 2014.

4. Health Systems Performance Assessment: Debates, Methods and Empiricism. WHO Publication. 2003. http://www.who.int/health_financing/documents/cov-hspa/en/. Accessed on 10 Sept 2015.

5. https://datahelpdesk.worldbank.org/knowledgebase/articles/906519

6. Guba E G, Lincol Y S. Fourth Generation Evaluation 1989, 21-49, Sage Publication.

7. Tenkorang E Y. Health Provider Characteristics and Choice of Health Care Facility among Ghanaian Health Seekers. Health Systems and Reforms. 2016;2(2):160-170. DOI:10.1080/23288604.2016.1171282.

8. Orler R L, Friedberg MW, Adams JL, McGlynn E A, Mehrotra A. Associations between Physician Characteristics and Quality of Care. Archives of Internal Medicine. 2010;170(16):1442-1449. Doi:10.1001/archintermed.2010.307.

9. National Family Health Survey-4 2015-16: District fact sheet Bangalore, Karnataka,. https://nrhm-mis.nic.in/DLHS4 Accessed on 28th Oct 2019.

10. Castleberry A, Nolen A. Thematic analysis of qualitative research data: Is it as easy as it sounds? Currents in pharmacy teaching and learning. 2018;10(6):807-15. Doi: 10.1016/j.cpt1.2018.03.019.

11. Kumar R DC, Khiljee N. Leadership in healthcare. Anaesthesia and Intensive Care Medicine. 2015;17(1):63-65.

12. Rolfe P. Transformational Leadership Theory: What Every Leader Needs to Know. Nurse Leader. 2011;54-57. Doi:10.1016/j.mnl/2011.01.014. 
13. Kramer M W, Crespy DA. Communicating collaborative leadership. The Leadership Quarterly. 2011;22:1024-1037. Doi:10.1016/j.leaqua.2011.07.021.

14. Boamah S A, Spence Laschinger H K, Wong C, Clarke S. Effect of transformational leadership on job satisfaction and patient safety outcomes. Nursing Outlook. 2017;66(2):180-189. https://doi.org/10.1016/j.outlook.2007.10.004.

15. Alilyyani B, Wond C A, Cummings G. Antecedents, mediators, and outcomes of authentic leadership in healthcare: A systematic review. International Journal of Nursing Studies. 2018; 83:34-64. https://doi.org/10.1016/j.ijnurstu.2018.04.001.

16. Xu J H. Leadership theory in clinical practice. Chinese Nursing Research. 2017;4:155-157. https://doi.org/10.1016/j.cnre.2017.10.001.

17. Cummings G G, Tate K, Lee S, Wong C A, Paananen T, Micaroni S PM, Chatterjee G E. Leadership styles and outcome patters for the nursing workforce and work environment: A systematic review. International Journal of Nursing Studies. 2018;85:19-60. https://doi.org/10.1016/j.ijnurstu.2018.04.016.

18. Kumar R DC. Leadership in healthcare. Anaesthesia and Intensive Care Medicine. 2013;14(1):39-41.

19. Kark R, Dijk van D. Motivation to lead, motivation to follow: The role of the self-regulatory focus in leadership process. Academy of Management Review. 2007;32(2):500-28.

20. Rad A M M, Yarmohammadian M H. A study of leadership between managers' leadership style and employees's job satisfaction. Leadership in Health Services. 2006;19(2):11-28. Doi.10.1108/13660750610665008.

21. McCutcheon AS, Doran D, Evans M, Hall LM, Pringle D. Effects of leadership and span of control on nurses' job satisfaction and patient satisfaction. Nursing Leadership. 2009;23(3):4867.

22. Carol A, Wong R N, P Elliott-Miller R N, Laschinger H, Cuddihy M, Meyer R M, Keatings RN, Burnett C, Szudy N. Examining the relationships between span of control and manager job and unit performance outcomes. Journal of Nursing Management. 2013;23(2). https://doiorg.ezprozy.ub.unimaas.nl/10.1111/jonm.12107. 
23. Shuck, Reio. The Employee Engagement Landscape and HRD: How do we link theory and scholarship to current practice? Advances in developing human resources 2011.13(4)419-428.

24. Kahn, W.A. 'Psychological conditions of personal engagement and disengagement at work', Academy of Management Journal. 1990;33:692-724.

25. Rowe A. K., de Savigny D, Lanata C. F., Victora C. G., How can we achieve and maintain high-quality performance of health workers in low-resource settings? Lancer.2005;366:1026-35. Doi:10.1016/S0140-6736(05)67028-6

26. Witman Y, Smid G A C, Meurs P L, Willems D L. Doctor in the lead: balancing between two worlds. Organization.2010;18(4):477-495

27. Chervenak F A, McCullough L B, Brent R L. The professional responsibility model of physician leadership. Americal Journal of Obstetrics and Gynecology.2013;208(2):97-101. doi.10.1016/j.ajog.2012.03.005

28. Goodall A H. Physician-leaders and hospital performance: Is there an association? Social Science and Medicine.2011;73;535-539. doi:10.1016/j.socscimed.2011.06.025

29. McGivern G, Currie G, Ferlie E, Fitzgerald L, Waring J. Hybrid manager-professionals’ Identity work: The maintenance and hybridization of medical professionalism in managerial contexts. Public Administration. 2015;93(2):412-432. doi: 10.1111/padm.12119

30. Macintosh G. The role of rapport in professional services: antecedents and outcomes. Journal of Services Marketing. 2009;23(2):71-79.

31. Leach M. Rapport: A key to treatment success. Complementary Therapies in Clinical Practices. 2005;11(4):262-65 https://doi.org/10.1016/j.ctcp.2005.05.005.

32. Ponce MAZ, Vendramini SHF, dos Santos MR, Santos MLSG, Santena LM, Villa TCS. The establishment of bonds between professional and patient in TB treatment: the performance of primary health care services in a city in the interior of Sao Paulo. Rev Lat Am Enfermagem. 2011;19(5):1222-9.

33. Sustainable Development Goals: Agenda 2030, India, A civil Society Report. 2017 p-28. https://gcap.global Accessed on 22 Oct 2019.

34. Mroczek J, Mikitarian G, Vieira E K, Rotarius T. Hospital Design and Staff Perceptions, An Exploratory Analysis. The Health Care Manager. 2005; 24(3):233-44. 
35. Rice G, Ingram J, Mizan J. Enhancing a primary care environment: a case study of effects on patients and staff in a single general practice. British Journal of General Practice. 2008. Doi:10.3399/bjgp08X319422.

36. Alfa M T, Ozturk A. perceived indoor environmental quality of hospital wards and patient's outcome: A study of a general hospital, Minna, Nigeria. Applied Ecology and Environmental Research. 2019;17(4):8235-8259. Doi:10.15666/aeer/1704_82358259.

37. Awoke M A, Negin J, Moller J, Farell P, Yawson A E, Biritwum R B, Kowal P. Predictors of public and private healthcare utilization and associated health system responsiveness among older adults of Ghana. Global Health Action. 2017;10:1, 1301723, doi.org/10.1080/16549716.2017.1301723.

38. LaFond A K, Brown L, Macintyre K. Mapping capacity in the health sector: a conceptual framework. International Journal of Health Planning and Management. 2002;17(1):3-22. DOI:10.1002/hpm.649

39. Von Knorring M, de Rijk A, Alexanderson K. Managers' perceptions of the manager role in relation to physicians: a qualitative interview study of the top managers in Swedish healthcare. BMC Health Services Research. 2010;10:271. http://biomedcentral.com/1472-6963/10/271.

40. Davari A, Rashidi A. Assessing the most-in-need leadership skills among community nutrition managers: A qualitative exercise in Iranian health system. International Journal of Healthcare Management. 2016;9(1):18-27. DOI:10.1179/2047971915Y.0000000023.

41. Gatenby M, Rees C, Truss C, Alfes K, Soane E. Managing Change, or Changing Managers? The role of middle managers in UK public service reform. Public Management Review. 2015;17(8):1124-1145, DOI: 10.1080/14719037.2014.895028.

42. Townsend K, Wilkinson A, Bamber G, Allan C. Accidental, unprepared, and unsupported: clinical nurses becoming managers, The International Journal of Human Resource Management. 2012;23(1):204-220. DOI: 10.1080/09585192.2011.610963.

43. Kisakye A. N, Kananura R M, Kiracho E E, Bua J, Akulume M, Namazzi G, Kiwanuka S N. Effect of support supervision on maternal and newborn health services and practices in Rural Eastern Uganda. Global Health Action. 2017;10:50-59. DOI: 10.1080/16549716.2017.1345496. 
44. Jenkins D, Palmer S. Job stress in National Health Service managers: A qualitative exploration of the stressor-strain-health relationship. The 'fit' and 'unfit' manager. International Journal of Health Promotion and Education. 2004;42(2):48-63. DOI: 10.1080/14635240.2004.10708013.

45. Nkomazana O, Mash R, Wojczewski S, Kutalek R, Phaladze N. How to create more supportive supervision for primary healthcare: lessons from Ngamiland district of Botswana: co-operative inquiry group. Global Health Action. 2016;9(1);31263, DOI: 10.3402/gha.v9.31263.

46. Bartee R T, Winnail S D, Olsen S E, Diaz C, Blevens J A. (2003). Assessing Competencies of the public health workforce in a frontier state. Journal of Community Health, 28(6), 459-469.

47. Holden H M. The needs and expectations of doctors and patients. Journal of Royal College of General Practitioners. 1977;27:277-79

48. Irvine D. The performance of doctors: the new professionalism. Lancet. 1999;353:1174-77. 


\section{Chapter 6}

\section{Performance of PHC and Provider wellbeing: A quantitative analysis of centre, patient and provider related measures}

Bangalore Sathyananda, R., de Rijk,A., Manjunath, U., Krumeich, A, van Schayck,C.P.

Submitted 
Title: Performance Indicators of Primary Healthcare Centres: Exploring Patterns Across Centre, Provider and Patient Using New Quantitative Measures

\begin{abstract}
Background: Primary healthcare in India comprises of health promotion and preventive health interventions at the population level, which are rendered at dedicated centres called Primary Healthcare Centres (PHCs). The performance of PHCs is vital for overall improvement in the general health of the population, specifically in a low- and middle-income country like India. It is unknown how performance at centre level is related to performance at provider and patient level. The aim of this study is to explore patterns in the performance of three PHCs with a low, medium and high number of deliveries regarding (1) the centre's availability of infrastructure and services; (2) providers' well-being; and (3) the patient view, recorded using a newly developed questionnaire.
\end{abstract}

Methodology: Three PHCs with high, medium and low number of deliveries in the urban district of Bengaluru, Karnataka, India, were selected. Several classical indicators of the availability of infrastructure and services at PHCs (e.g. number of deliveries) were collected by observation and from secondary data respectively. Two questionnaire studies were done: one on the well-being of providers ( $\mathrm{n}=11,13,12$ respectively) (Quality of Life and Engagement), and another on PHC performance as assessed by patients ( $\mathrm{n}=100,100,101$ respectively) using the newly developed tool 'Questionnaire for Patient's Perspective on Performance of Primary Healthcare Centres' (Q4PHC). The data from the centre, provider and patient levels were compared across the three centres using ANOVA tests.

Results: The results of the study showed that the centre with the highest infrastructure and service availability had significantly less provider quality of life and work engagement $(p<0.000)$. The Q4PHC consisting of seven dimensions and 41 items had high internal consistency at Cronbach's alpha score of 0.938. It was found that the PHC with the least delivery had significantly higher PHC performance using Q4PHC score in comparison with high and medium delivery PHCs $(\mathrm{p}<0.000)$.

Conclusion: The PHC performance assessment from multiple perspectives offers a realistic insight into the centres, which is valid even though agreement on the various perspectives could not be obtained. The new Q4PHC is a reliable instrument to assess PHC performance from the patient's perspective. 


\section{Introduction}

Human lifespan has been greatly extended in the last century. One of the reasons for this would be attributed to the advances in healthcare and universal uptake of primary health care following the declaration of Alma-Ata. ${ }^{1}$ Primary healthcare comprises health promotion and preventive health intervention at the population level. In India, primary healthcare is rendered at dedicated centres called Primary Healthcare Centres (PHCs). ${ }^{2}$ Performance of these centres is vital for overall improvement in the general health of the population, specifically in a developing country like India. ${ }^{3}$ With a fast growing economy and more than a third of the world's population, India's disparities in the health of the population vary from state to state, from rural to urban areas and also within the same urban settings. ${ }^{4,5}$ In this scenario, PHC performance grows in importance, greatly contributing to the health of the masses. Optimising PHC performance therefore is the key to the PHCs' success.

Research in performance of public healthcare is usually based on the number of services delivered with emphasis on care effectiveness, access, equity, and efficiency. ${ }^{6-8} \mathrm{~A}$ framework for the assessment of primary healthcare consisted of health financing, drug and supplies, facility infrastructure, density of workforce, access, availability of effective primary healthcare services, high quality primary healthcare, effective services coverage, health status and equity. ${ }^{9}$ Traditionally in India, performance of PHC has been assessed based on output and outcome indicators, such as number of patients served, maternal mortality rate, infant mortality rate, cost of care, etc., along with patient satisfaction, cost effectiveness and fund utilisation. ${ }^{10}$ While there has been some emphasis on the performance of the primary healthcare system, there is a general lack of knowledge on what works in a primary healthcare setting, thus including inputs from various stakeholders based on the principles of co-design is the way forward. ${ }^{9,11}$

Researchers believe that there is a need for agreement on the indicators that fit the purpose, as only a few validated primary care performance measurement instruments exist, but they are not validated for PHCs in low- and middle-income countries. ${ }^{12}$ There is also a need for knowledge on the effects of various components of performance in these countries. ${ }^{6}$

Performance of PHC itself has been assessed from the perspectives of the centre and that of the providers. ${ }^{3}$ Provider performance is generally assessed based on the number of cases treated or other output indicators but no single standard measure exists. ${ }^{13}$ Provider performance could be tested with well-being tools, such as the Work Engagement Scale. ${ }^{14,15}$ Kahn defined employee engagement or rather work engagement as 'the harnessing of organisation members' selves to their work roles; in engagement, people employ and express themselves physically, cognitively, and emotionally during role performances". ${ }^{16}$ This concept has further evolved to a positive, fulfilling and work-related state 
of mind that is characterised by vigour, dedication and absorption. ${ }^{17}$ Thus, engagement means being psychologically as well as physically present when working. This refers to work-related well-being, while quality of life is an indicator of the functional dimension in all life spheres of a person in relation to their health. ${ }^{18-21}$

Next, when assessing a centre there is need for it to be evaluated by the patients who are utilising the services. This assessment should be relevant locally and to the centre that is being evaluated. ${ }^{22}$ A tool to measure patient satisfaction, the 'Patient Satisfaction Questionnaire - Short Form 18' has been established and long being used ${ }^{23}$, however a tool to measure PHC performance in an Indian setting is not available and there is a need for developing such a tool to include the experiences of patients and that is appropriate to the local context.

With these concepts and measures related to PHC performance in the background, we intend to explore PHC performance in the Indian context from the perspectives of the centre, the providers, and the patients, and discover any relationships between them. The research questions addressed in this study are:

1. What is the performance in terms of infrastructure and services at each PHC?

2. What is the performance of the providers in terms of quality of life and engagement at each PHC?

3. How can we best measure PHC performance from the patient's perspective?

4. What is the performance of each PHC from the patient's perspective?

5. Can we distinguish patterns among these three (centre, providers and patients) levels of performance across different PHCs?

\section{Methodology}

A quantitative methodology was employed.

\section{Study design}

A cross sectional analysis of a selected PHC was done individually as a case to develop a case series of three PHCs in the Bengaluru Urban District, to explore a pattern across PHCs. The centre performance was assessed based on the availability of the infrastructure and the quantity of the services delivered, whereas the providers were assessed based on their quality of life and their work engagement. The performance of the centre in total was assessed by the patients using a newly developed questionnaire. The data was collected at the various levels, namely the centres, providers and the patients between September 2017 and July 2019 in multiple phases. 


\section{$\underline{\text { Ethics }}$}

The study was approved by the Manipal University Ethics Committee, Manipal University, Manipal, Karnataka. Ethics in research procedures were followed in the study by obtaining written consent from the participants with assurance of confidentiality.

\section{PHC sample}

This research was conducted in three PHCs located in the urban district of Bengaluru, Karnataka State, India. The Bengaluru urban district is administratively divided into four talukas or blocks, and there are 20 PHCs that operate 24 hours a day, seven days per week. The number of pregnant women who delivered babies at these centres are related to the number of patients utilising the services and their perceived quality of care at the PHC, thus reflecting the general performance of the PHC concerned; this information is reflected in the reports on performance assessment. ${ }^{24}$ Hence, the PHCs were selected based on the basis of the number of pregnant women who delivered babies in the centre for the population covered in the financial year 2016-2017. The high, medium and low delivery loads in relation to the population served per PHC was considered as performance and included in the study. The well performing PHC-1 had five subcentres, while both the medium PHC2 and the low-performing PHC-3 had four subcentres, each delivering community care under them. It was observed that all the PHCs had buildings in government-owned lands with sufficient vacant area around its designated boundary (compound). The PHCs were included in the study to explore the relation of the performance of PHC from provider's well-being and patient's perspective.

\section{Provider sample}

On visiting the PHC, all the healthcare providers (doctors, staff nurses, lab technicians, pharmacists, optometrist and health assistants) at these PHCs were requested to participate in the study to record their quality of life and their work engagement. All the providers participated in the study by offering their consent and the details of personnel included are in the table 1. 
Table1. Details of Providers participated in the study

\begin{tabular}{|c|c|c|c|c|c|c|c|c|c|}
\hline \multirow[t]{2}{*}{ Personnel } & \multicolumn{2}{|c|}{$\begin{array}{c}\text { Well } \\
\text { performing } \\
\text { PHC-1 }\end{array}$} & \multicolumn{2}{|c|}{$\begin{array}{c}\text { Medium } \\
\text { performing } \\
\text { PHC-2 }\end{array}$} & \multicolumn{2}{|c|}{$\begin{array}{c}\text { Poor } \\
\text { performing } \\
\text { PHC-3 }\end{array}$} & \multicolumn{2}{|c|}{ Gender Total } & \multirow[t]{2}{*}{ Total } \\
\hline & Male & Female & Male & Female & Male & Female & Male & Female & \\
\hline Doctors & 1 & 0 & 0 & 1 & 1 & 1 & 2 & 2 & 4 \\
\hline Staff Nurses & 0 & 4 & 0 & 3 & 0 & 4 & 0 & 11 & 11 \\
\hline Pharmacists & 1 & 0 & 0 & 1 & 0 & 1 & 1 & 2 & 3 \\
\hline Lab technicians & 0 & 0 & 0 & 1 & 0 & 1 & 0 & 2 & 2 \\
\hline Optometrists & 1 & 0 & 1 & 0 & 0 & 0 & 2 & 0 & 2 \\
\hline Health Assistants & 0 & 4 & 2 & 4 & 0 & 4 & 2 & 12 & 14 \\
\hline Total & 3 & 8 & 3 & 10 & 1 & 11 & 7 & 29 & 36 \\
\hline Mean Age (SD) & \multicolumn{2}{|c|}{$47.3(9.5)$} & \multicolumn{2}{|c|}{$40.2(9.8)$} & \multicolumn{2}{|c|}{$39.0(10.0)$} & & & $\begin{array}{l}41.94 \\
(10.2)\end{array}$ \\
\hline Population covered & \multicolumn{2}{|c|}{56,081} & \multicolumn{2}{|c|}{48,037} & \multicolumn{2}{|c|}{54,513} & & & 158631 \\
\hline
\end{tabular}

\section{Patient sample}

All the patients attending a PHC were approached after their consultation by a doctor, nurse or healthcare worker to participate in the survey, with the aim of including 100 willing patients who had received care at each PHC. For patients under 18, their parents were asked to participate or if the patients wanted their guardians to participate on their behalf, they were included in the study.

\section{Performance Measurements}

\section{Centre measurement}

PHC service delivery data was captured and maintained by the Health Management Information System. Retrospective secondary data for the year 2016-2017 was utilised. The following service delivery data was collected from the Health Management Information System:

1. The number of patients treated on an outpatient basis;

2. The number of patients in the middle of the night was considered equal to the number of inpatients;

3. The number of pregnant women who received three pre-natal check-ups;

4. The number of children older than 16 months who received measles vaccine (full immunisation);

5. The number of women who delivered babies in the PHC

The availability of infrastructure and services were assessed based on the Indian Public Health Standards checklist on the first day of visit to the PHC. ${ }^{24,25}$ This tool had 216 items that can be assessed. In order to attain a numerical value to aid in the comparison, these items were scores as: 
0 - not available; 1 - available but not functioning; 2 - available but partly functioning; and 3 available and fully functioning. Negative items like 'Is there a garbage dump close to PHC', 'Is there any incidence of any sexual advances., oral or physical abuse, sexual harassment by the doctors or any other paramedical?' were reverse scored to attach more numbers to the absence of the event and increase total score. The maximum score a PHC could obtain was 648 and the minimum was 0 .

\section{Provider measurement}

The World Health Organization Quality of life Bref (WHO QoL BREF) ${ }^{26}$ : The WHO developed a short version of the questionnaire (original with 100 questions), which consisted of four domains with 26 items: D1-Physical Health (7 questions); D2-Psychological (6 questions); D3-Social Relationships (3 questions); D4-Environment (8 questions), along with general questions on quality of life (Q1) and general health (Q2). ${ }^{26-28}$ The questions were scored on a Likert scale of 1 (not at all) to 5 (extreme/completely). Some examples of questions were: How much do you enjoy your life? How often do you have negative feelings, such as blue mood, despair, anxiety, depression? The questionnaire was applied in English as well as the local language to aid in better interpretation and understanding of the questionnaire by the participants.

The Utrecht Work Engagement Survey (UWES): Utrecht Work Engagement Survey tool (UWES) was used to capture health professional engagement, which is a positive job outcome. ${ }^{29}$ The UWES questionnaire has been validated for the Indian setting and applied in research. ${ }^{30,31}$ The instrument contained 17 items and was applied in English as well as the local language to aid in better interpretation and understanding of the questionnaire by the participants. ${ }^{29}$ The items were scored on a Likert scale from 0 (never) to 6 (always or every day). The items covered three dimensions of engagement: vigour (6 items), dedication (5 items) and absorption (6 items). An example of an item in the absorption subscale was 'Time flies when I'm working'.

\section{Patient measurement}

The patient's assessment of the PHC was accompanied using the tool developed 'Questionnaire for Patient's Perspective on Performance of Primary Healthcare Centres' (Q4PHC). The details of the development of the tool are as follows.

- In-depth interviews were conducted with 188 patients at the selected PHCs to develop insights from the patient's perspective on PHC performance. Interviews with the consenting patients were conducted in the local language to aid in communication. The recorded interviews were translated into English by professionals, transcribed and analysed thematically using ATLAS-TI software to develop themes for PHC performance assessment by the patients. ${ }^{32}$ 
- This data showed that PHC performance for patients consisted of: behaviour and attitude of providers; availability of 24/7 diverse services; availability of diagnostic services; diagnosis and treatment for emergencies; availability of medicines; cost of care and medicines; effectiveness of treatment; PHC infrastructure; organisation of services for better functioning of the PHC.

- The Q4PHC tool consists of nine dimensions and 53 items based on 188 patient interviews (Appendix 1). These items were finalised based on discussion with the authors. The items were scored on a Likert scale of 1(totally disagree) to 5(totally agreed). The tool was tested for validity and reliability with Cronbach's alpha score of more than 0.6 considered as sufficient and more than 0.8 as high.

- Validity was tested using Principal Component Analysis and Factor Analysis which showed considerable overlap at item level and did not contradict the theoretical scales. ${ }^{33}$, 34 The Principal Component Analysis and the Factor Analysis showed that the items loaded on 11 factors as opposed to the original nine domains, however the loading was inconclusive on the factors except for the domain 'cost of care and medicines'. Hence all nine domains were retained and subjected to reliability analysis.

- After initial reliability analysis, to obtain better Cronbach's scores, two domains (availability of medicines and organisation of services) and certain items were deleted to develop the tool with seven domains and 41 items. The Cronbach's alpha for the final tool was found to be significant at 0.938 (Appendix 2). The Cronbach's alpha for individual domains of the tool was sufficient to high. Table 4 gives the details of the number of items per domain and the Cronbach's alpha. The final tool consisted of seven dimensions and 41 items used to analyse and compare the PHCs' performances.

The RAND short-form patient satisfaction questionnaire-18 consisted of seven domains, namely general satisfaction, technical quality, interpersonal manner, communication, financial aspects, time spent with doctor, accessibility and convenience with 18 statements (nine positive and nine negative) and was scored from 1 (strongly agree) to 5 (strongly disagree); the negative statements were reverse coded in the analysis of the tool for appropriate scoring. ${ }^{23}$

The patient feedback form from the Urban PHC Quality Manual of Ministry of Health and Family Welfare, Government of India was used. This tool included 10 statements addressing behaviour and attitude of staff, the waiting time, promptness, availability of drugs, tests and information at PHC, time spent in care, cost of care and cleanliness of PHC with scoring on Likert scale of 1 (poor) to 5 (excellent). ${ }^{35}$ 


\section{$\underline{\text { Data analysis }}$}

The data were cleaned and analysed using SPSS 25. The validity of the Q4PHC tool was tested using Principal Component Analysis and Factor Analysis, while the reliability was tested with Cronbach's alpha. The data from the centres, providers and patients were analysed within the PHC as means and distribution that were computed per centre. One-way ANOVA with Scheffé test was conducted to check for differences between the centres (threshold: $p<0.05$ ). Any patterns of relation between the data were identified.

\section{Results}

The availability of the infrastructure and services delivered at the PHCs, the quality of life and engagement of the providers, and the PHC performance from the patient's perspective were analysed to identify patterns and understand the relations between various components. The results of the analysis and comparison between the PHCs were presented in tables 2, 3 and 4 . The results of the PHC analysis can be presented as follows.

\section{Availability of infrastructure and services delivered at PHCs}

It was observed that the PHCs did not have any significant difference in the availability of infrastructure as assessed and based on the Indian Public Health Standards check list (Table 2). The availability of the infrastructure was better in PHC 1 (score 484) and PHC 2 (score 479) in comparison with PHC 3 (score 433). Even though PHC 2 served less people, the PHCs showed no significant difference in total population: PHC 1 (56,081), PHC $2(48,037)$ and PHC $3(54,513)$. On examining the availability of infrastructure, PHC 1 performed best, followed by PHC 2 and PHC 3.

The number of deliveries conducted, the number of outpatients treated, the number of inpatients, the number of women who received three antenatal check-ups were all highest in PHC 1, followed by PHC 2 and PHC 3. The number of children who received full immunisation was highest in PHC 1, followed by PHC 3 and PHC 2. On the whole, PHC 1 performed best in the quantity of services delivered.

\section{Performance of PHCs in relation to provider well-being}

Provider well-being represented as quality of life and work engagement was analysed in the PHCs individually (Table 3). Provider quality of life did not show any significant difference between the PHCs, however PHC 3 seemed to perform better than PHC 2, which seemed to perform better than PHC 1. On examining the work engagement of providers, PHC 2 was significantly better than PHC 1 $(\mathrm{p}<0.030)$, nevertheless there was no significant difference between PHC 1 and PHC 3. 
Comparison of PHCs using the total score from Q4PHC (Table 4) found that PHC 3 performed best, followed by PHC 1 and PHC 2 ( $\mathrm{p}<0.000)$. Patient PHC assessment based on the total score of shortform patient satisfaction questionnaire-18 showed that PHC 3 was performing the best, followed by PHC 1 and PHC $2(\mathrm{p}<0.000)$. The patient's assessment based on patient feedback form from Urban PHC quality manual showed that PHC 3 performed best, followed by PHC 1 and PHC 2 ( $<<0.000)$. 
Table 2. Analysis of Infrastructure and Services provided at the PHCs

\begin{tabular}{|c|c|c|c|c|c|c|c|}
\hline Component & Source & Variable (Measure) & Statistics & $\begin{array}{c}1 \\
\text { High Delivery } \\
\text { PHC }\end{array}$ & $\begin{array}{c}2 \\
\text { Medium } \\
\text { Delivery PHC }\end{array}$ & $\begin{array}{c}3 \\
\text { Poor Delivery } \\
\text { PHC }\end{array}$ & Difference $^{* *}$ \\
\hline Population served & $\begin{array}{l}\text { Indian Public Health } \\
\text { Standards tool survey }\end{array}$ & & Number & 56,081 & 48,037 & 54,513 & $1>3>2(1,3,2)$ \\
\hline Infrastructure & $\begin{array}{l}\text { Indian Public Health } \\
\text { Standards tool survey* }\end{array}$ & & $\begin{array}{l}\text { Total } \\
\text { Score }\end{array}$ & 484 & 479 & 433 & $1>2>3,1 \sim 2(1,2,3)$ \\
\hline \multirow{5}{*}{ Service delivered } & \multirow{5}{*}{$\begin{array}{l}\text { Health Management } \\
\text { Information System } \\
\quad(2016-17)\end{array}$} & $\begin{array}{l}\text { women who delivered } \\
\text { babies in PHC }\end{array}$ & \multirow{5}{*}{ Number } & 399 & 133 & 22 & $1>2>3(1,2,3)$ \\
\hline & & Out-Patients treated & & 16474 & 15114 & 10457 & $1>2>3,1 \sim 2(1,2,3)$ \\
\hline & & $\begin{array}{l}\text { In-Patient Head Count at } \\
\text { midnight }\end{array}$ & & 792 & 240 & 44 & $1>2>3(1,2,3)$ \\
\hline & & $\begin{array}{l}\text { women who received } 3 \\
\text { ANC check-ups }\end{array}$ & & 681 & 190 & 0 & $1>2>3(1,2,3)$ \\
\hline & & fully Immunized children & & 332 & 169 & 322 & $1>3>2,1 \sim 3(1,3,2)$ \\
\hline
\end{tabular}

*PHC (216 items with maximum score of 648); **1- High Delivery PHC, 2- Medium Delivery PHC, 3- Low Delivery PHC.

Table 3. Analysis of Provider data

\begin{tabular}{|c|c|c|c|c|c|c|c|}
\hline Group & Source & Variable (Measure) & Statistics & $\begin{array}{c}1 \\
\text { High Delivery PHC }\end{array}$ & $\begin{array}{c}2 \\
\text { Medium Delivery PHC }\end{array}$ & $\begin{array}{c}3 \\
\text { Poor Delivery PHC }\end{array}$ & Scheffé test** \\
\hline \multirow{8}{*}{ Provider } & \multirow{8}{*}{$\begin{array}{l}\text { Employee } \\
\text { survey }\end{array}$} & \multirow{4}{*}{$\begin{array}{c}\text { Quality of Life (QoL } \\
\text { Bref) }\end{array}$} & $\mathrm{N}$ & 11 & 13 & 12 & \multirow{4}{*}{$\begin{array}{c}\text { No significant } \\
\text { difference but trend in } \\
3>2>1 \text { seen }(3,2,1)\end{array}$} \\
\hline & & & Mean & 13.7053 & 14.6053 & 14.9648 & \\
\hline & & & $\mathrm{F}$ & 2.515 & & & \\
\hline & & & Sig. & 0.096 & & & \\
\hline & & \multirow{4}{*}{$\begin{array}{l}\text { Work Engagement } \\
\text { (UWES) }\end{array}$} & $\mathrm{N}$ & 11 & 13 & 12 & \multirow{4}{*}{$2>1,1 \sim 3$} \\
\hline & & & Mean & 4.5936 & 5.2443 & 4.8971 & \\
\hline & & & $\mathrm{F}$ & 3.923 & & & \\
\hline & & & Sig. & 0.030 & & & \\
\hline
\end{tabular}


Table 4. Analysis of Patient data

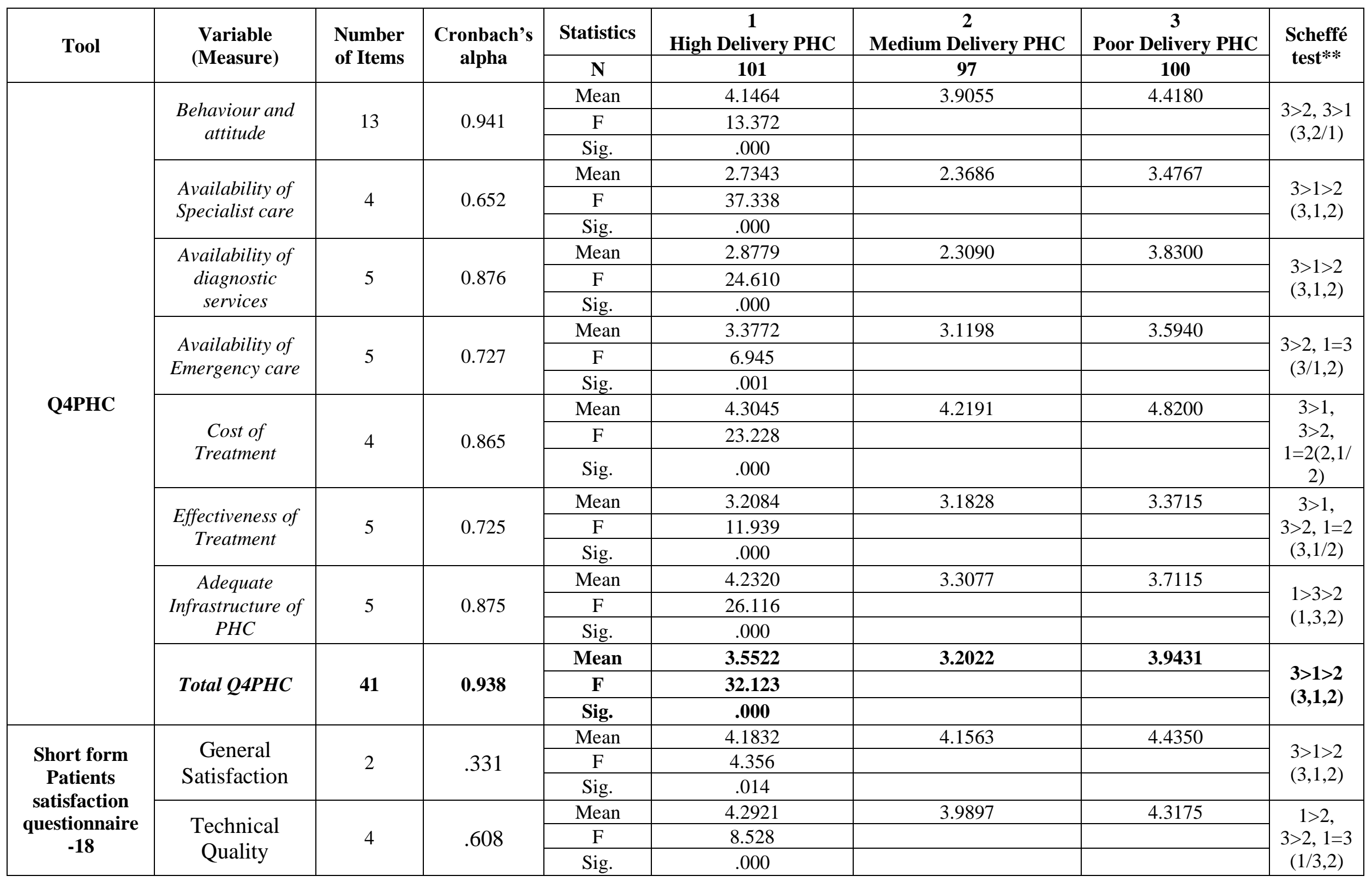




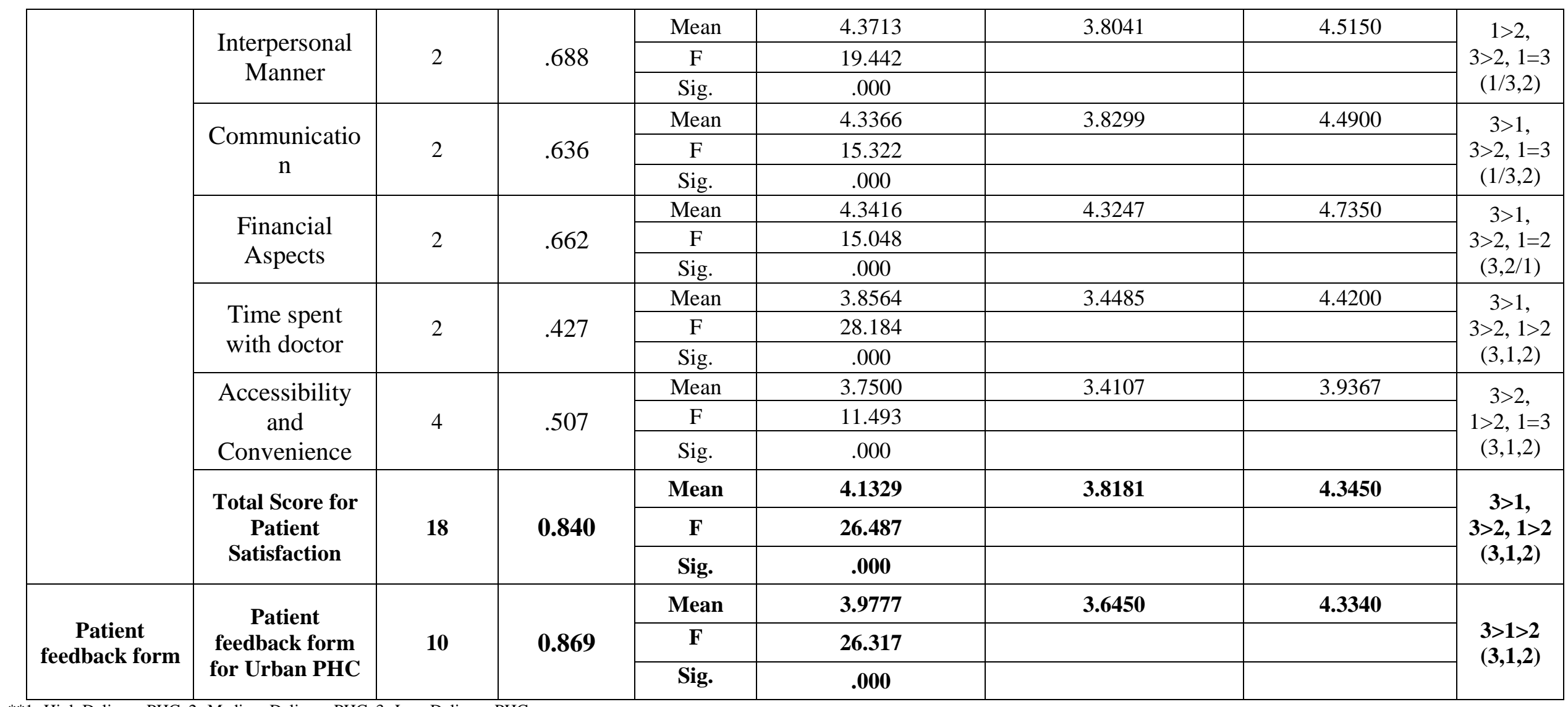

**1- High Delivery PHC, 2- Medium Delivery PHC, 3- Low Delivery PHC. 


\section{Discussion}

The three PHC selected based on the number of deliveries conducted at the centres were compared on the availability of the infrastructure and services delivered, provider engagement and quality of life and PHC performance from the patients' perspectives to explore patterns among them. A new questionnaire from the patient perspective was developed. The results showed that the centre that was delivering the most care had the lowest provider well-being and the centre that delivered the least number of services had scored significantly well in provider well-being and in the patients' PHC performance assessment. The new questionnaire Q4PHC appeared to be valid.

\section{PHC performance as availability of infrastructure and service delivery}

In the literature both availability of infrastructure and quantity of service delivery have been consistently considered as indicators of PHC performance. ${ }^{9,10,36}$ As PHCs in this study were sampled on the basis of varying numbers of women who delivered babies in the centres, it is also evident that they varied similarly in availability of infrastructure and showed significantly different service delivery. That is, number of deliveries still remains a good indicator of centre performance. However, this study clearly showed that this was not related to the other performance indicators, which will be discussed below.

\section{PHC performance and provider well-being}

The results showed that the centres with high service delivery did not correspond with better quality of life and employee engagement. Provider quality of life (significant) and work engagement (insignificant) were better in the centre that delivered less in comparison with the other PHCs probably because they had less stress from the workload and were able to provide the needed attention to patients. The positive association between quality of life, work engagement, workload, patient satisfaction has long been established. ${ }^{37}$ The improved time and attention for patients not only would improve patient's perception of the centre but also provider satisfaction, which was depicted in the patients' assessment of PHC performance.

The literature has shown that provider performance and provider well-being are related, that is, providers with low engagement are less productive. ${ }^{14}$ There is no established method of assessing provider performance at PHC level other than the quantity of care delivered or quality of care measured as patient satisfaction. ${ }^{3,9,10,13}$ However, our results showed that higher performance in terms of increased patient service at PHCs may be associated with the providers being low on quality of life and work engagement. This association, which has been established in the literature, seemed 
to be confirmed by our study. This might be explained by reverse causality: the workload might have been so high that engagement was hampered. ${ }^{38}$

\section{PHC performance from the patient's perspective}

PHC performance has been evaluated in two ways: through patient satisfaction according to the

WHO aspects for performance assessment, which are also being followed by other researchers, ${ }^{10,39,40}$ and by a new reliable tool to assess the performance of PHCs from the patient's perspective that was developed based on the interviews. The aim of the latter was to encompass the experiences of people, which would be appropriate to the local context of the current study. The significance of the new Q4PHC tool, which had high internal reliability, is that it was developed based on the assessment criteria of the patients utilising the services of the PHC. Thus, the assessment of PHC using Q4PHC is more realistic in the local context than the patient satisfaction assessed using the short-form patient satisfaction questionnaire or the patient feedback form from the quality manual. As the number of items is higher, it would aid as a compass for addressing various local concerns of patients, aiding in further PHC improvement, if attempted.

\section{Holistic model for PHC performance}

PHC performance assessment is a complex phenomenon, since PHC functioning involves multiple stakeholders of different calibre and an apt representation of reality is possible only when performance is represented from various perspectives reflecting the local context. It is essential to include various perspectives to get a valid picture. ${ }^{41}$ There seems to be a trade-off between working hard, being vital providers and having enough time and energy for good communication with patients. A blend of primary and secondary data also aids in minimising the errors in assessment, as evaluation in developing countries encounter constraints in resources and data. ${ }^{42}$ It seems that a balance between the availability of infrastructure, service delivery, provider well-being and patient perception of PHC performance could enable better assessment for enhancing performance.

\section{Methodological Consideration}

Assessing performance by the availability of infrastructure and services along with both the provider and the patients provides a multimodal approach that would result in a complete PHC assessment. However, inclusion of only three PHCs out of the available 20 in the urban setting could be considered as a small sample. For the results to be more general in their application to urban and rural settings and to other low- and middle- income countries, further large-scale research replicating the study is recommended. 
The Q4PHC developed from the in-depth interviews with patients provided a strong theoretical base to assess performance as envisaged by patients themselves, thereby making it highly applicable to the setting. As the validity of most of the items did not load appropriately on the factors, further research on factor validation is needed.

\section{Conclusion}

PHC performance as studied in the three urban PHCs seems to be a trade-off between the available infrastructure and the quantity of services delivered that could be achievable by maintaining adequate provider well-being with acceptable PHC performance from the patient's perspective. The new Q4PHC seems promising to measure patient perspective of PHC performance in an Indian context. The seven scales not only provide an opportunity to assess but also to improve PHC service delivery. The PHC performance assessment from multiple perspectives offers a realistic view of the centre encompassing the local context, which is valid even though agreement on the various perspectives could not be obtained. Further research is needed to study the interrelationship of various components of PHC performance. 


\section{Reference}

1. Alma-Ata. 1978. Primary Health Care: Report of the International Conference on Primary Health Care Alma-Ata, USSR: 6-12 September 1978. https://www.who.int.en. Accessed on 5 Jan 2015.

2. Indian Public Health Standards: Guidelines for Primary Health Centres, Revised 2012. Directorate General of Health Services, Ministry of Health and Family Welfare, Government of India. http://nhm.gov.in/nhm/nrhm/guidelines/indian-public-health-standards.html accessed on 19th January 2018

3. Sathyananda R B, Manjunath U. An Assessment of quality of life among the workers of primary health centres managed by a nongovernment organization in Karnataka, India: A case study. International Journal of Health and Allied Sciences. 2017;6(4):240-44. Doi:10.4103/ijhas.IJHAS_128_17.

4. Global status report on non-communicable diseases 2014. https://apps.who.int/iris/bitstream/10665/148114/1/978941564854_eng.pdf?ua=1. Accessed on 7 Oct 2016.

5. Urban health report. 2016. http://apps.who.int/iris/handle/10665/204715. Accessed on 7 Oct 2016.

6. Munar W, Snilstveit B, Aranda L E, Biswas N, Baffour T, Stevenson J. Evidence gap map of performance measurement and management in primary healthcare systems in low-income and middle-income countries. BMJ Global Health. 2019;4:e001451. Doi:10.1136/bmjgh-2019001451

7. Kurk M E, Freedman L. Assessing health system performance in developing countries: A review of the literature. Health Policy. 2008:85:263-276. Doi:10.1016/j.healthpol.2007.09.003

8. Oyekale A S. Assessment of primary health care facilities' service readiness in Nigeria. BMC Health Services Research.20117;17:172. Doi:10.1186/s12913-017-2112-8

9. Veillard J, Cowling K, Bitton A, Ratcliffe H, Kimball M, Barkley S, Mercereau L, Wong E, Taylor C, Hirschhorn L R, Wang H. Better measurement for performance improvement in Lowand Middle-Income countries: The primary health care performance initiative experience of conceptual framework development and indicator selection. The Milbank Quarterly.2017;95(4):836-883 
10. Varatharajan D, Thankappan R, Jayapalan S. Assessing the performance of primary health centres under decentralized government in Kerala, India. Health Policy and Planning. 2004;19(1):41-51. Doi: 10.1093/heapol/czh005

11. Palagyi A, Dodd R, Jan Stephen, Nambiar D, Joshi R, Tian M, Abimbola S, Peiris. Organisation of primary health care in the Asia-Pacific region: developing a prioritized research agenda. BMJ Global Health. 2019;4:e00467. Doi:10.1136/bmjgh-2019-001467

12. Bresick G, Christians F, Marwero M, Besigye I, Malope S, Dullie L. Primary health care performance: a scoping review of the current state of measurement in Africa. BMJ Global Health. 2019;4:e001496. Doi:10.1136/bmjgh-2019-001496

13. Stc Hamilton K E, Coates V, Kelly B, Boore J R P, Cundell J H, Gracey J, Mcfetridge B, McGonigle M, Sinclair M. Performance assessment in health care providers: a critical review of evidence and current practice. Journal of Nursing Management. 2007;15:773-91.

14. Taris T W, Schaufeli W B. Individual Well-being and performance at work A conceptual and theoretical overview. 2015. https://www.wilmarschaufeli.nl/publications/Schaufeli/434.pdf

15. Shuck, Reio. The Employee Engagement Landscape and HRD: How do we link theory and scholarship to current practice? Advances in developing human resources 2011.13(4)419-428.

16. Kahn, W.A. 'Psychological conditions of personal engagement and disengagement at work', Academy of Management Journal. 1990;33:692-724.

17. Bakker A. B., Schaufeli W. B., Leiter M. P., Taris T. W. Work engagement: An emerging concept in occupational health psychology. Work and Stress. 2008;22:187-200.

18. Salvador-Carulla L, Lucas R, Ayuso-Mateos J L, Miret M. Use of terms "Wellbeing" and "Quality of life" in health sciences: A conceptual framework. European Journal of Psychiatry.2014;28(1):50-65

19. Wadi B, Alonazi, Thomas S A (2013). Quality of Care and Quality of Life: Convergence or Divergence? Health Services Insights 2014:7 1-12 doi:10.4137/HSI.S13283.

20. WHOQOL Measuring Quality of Life: Programme on Mental Health WHO/MSA/MNH/PSF/97.4 (1997). http://www.who.int/mental_health/media/68.pdf (accessed on $19 / 3 / 15)$. 
21. Sathyananda R B, Manjunath U. Assessment of quality of life among the health workers of primary health centres managed by a nongovernment organization in Karnataka, India: A case study. International Journal of Health and Allied Sciences. 2017;6(4):240-44 Doi:10.4103/ijhas.IJHAS_128_17

22. Arnetz J E, Arnetz B B. The development and application of a patient satisfaction measurement system for hospital-wide quality improvement. International Journal for Quality in Health Care. 1996;8(6):555-566

23. Marshall G N, Hays RD. The patients' satisfaction questionnaire short form (PSQ18) RAND publication,1994. https://www.rand.org/content/dam/rand/pubs/papers/2006/P7865.pdf accessed on 1st Feb 2019.

24. https://nrhm-mis.nic.in/hmisreports/frmstandard_reports.aspx. Accessed on 10 Jan 2019

25. Indian Public Health Standards: Guidelines for Primary Health Centres, Revised 2012. Directorate General of Health Services, Ministry of Health and Family Welfare, Government of India. http://nhm.gov.in/nhm/nrhm/guidelines/indian-public-health-standards.html accessed on 19th January 2018

26. The WHOQOL Group. Development of World Health Organization WHOQOL-BREF Quality of Life Assessment. Psychological Medicine. 1998;28:551-558.

27. Skevington S M, Lotfy M, O'Connell K A. The World Health Organization's WHOQOL-BREF quality of life assessment: Psychometric properties and results of international field trial A Report from QHOQOL Group. Quality of Life Research. 2004;13:299-310.

28. Saxena S, Carlson D, Billington R, Orley J. The WHO quality of life assessment instrument (WHOQOL-Bref): The importance of its items for cross-cultural research. Quality of Life Research. 2001;10:711-721

29. Schaufeli W B, Bakker A, Salanova M. The Measurement of work engagement with a short questionnaire. Educational and Psychological Measurement. 2006;66(4):701-716.

30. Chaudhary R, Rangnekar S, Barua M K. Psychometric evaluation of Utrect Work Engagement Scale in an Indian sample. Asia-Pacific Journal of Management Research and Innovation. 2012;8(3):343-350

31. Kataria A, Gard P, Rastogi R. Work engagement in India: validation of the Utrect Work Engagement. Asia-Pacific Journal of Management Research and Innovation. 2013;9(3):249-260 
32. Castleberry A, Nolen A. Thematic analysis of qualitative research data: Is it as easy as it sounds? Currents in pharmacy teaching and learning. 2018;10(6):807-15. doi: 10.1016/j.cptl.2018.03.019.

33. McKinley R K, Mabku-Scott T, Hastings A M, French D P, Baker R. Reliability and validity of a new measure of patient satisfaction with out of hours primary medical care in the United Kingdom: development of a patient questionnaire. The British Medical Journal. 1997;314(7075):193-205. Doi:10.1136/bmj.314.7075.193

34. Dufrene R L. an evaluation of a patient satisfaction survey: validity and reliability. Evaluation and Program Planning.2003;23:293-300

35. Ministry of Health and Family Welfare, Government of India. Quality Standards for Urban Primary Health Centre. 2015, Annexure D, 260.

36. Bitton A, Fifield J, Ratcliffe H, Karlage A, Wang H, Veillard J H, Schwarz D, Hirschhorn L R. Primary healthcare system performance in low-income and middle-income countries: a scoping review of the evidence from 2010 to 2017. BMJ Global Health.2019:4:e001551. Doi:10.1136/bmjgh-2019-001551.

37. Halbesleben J R B. The consequences of engagement: The good, the bad, and the ugly. European Journal of Work and Organizational Psychology. 2011;20(1):68-73. DOI:10.1080/1359432X.2010.514327

38. Shuck B, Reio Jr T G, Employee engagement and well-being: A moderation model and implications for practice. Journal of Leadership and Organizational Studies. 2014;21(1):43-58. Doi: $10.1177 / 1548051813494240$

39. The World Health Report 2000. Health Systems: Improving Performance. https://www.who.int.en. Accessed 1 Nov 2014.

40. Health Systems Performance Assessment: Debates, Methods and Empiricism. WHO Publication. 2003. http://www.who.int/health_financing/documents/cov-hspa/en/. Accessed on 10 Sept 2015.

41. Piligrimienė Ž, Bučiūnienė I. Different perspectives on health care quality: Is the consensus possible? Engineering Economics. 2008;56(1):104-110

42. Groene O, Skau J K H, Frolich A. An international review of projects on hospital performance assessment. International Journal of Quality in Health care. 2008;20(3):162-171. 


\section{Appendix 1}

\section{Questionnaire for the Patient's Perspective on Performance of PHC (Q4PHC)}

Scoring pattern: 1-Totally disagree; 2-Disagree; 3-Do not disagree or agree; 4-Agree; 5-Totally agree

\begin{tabular}{|c|c|c|c|c|c|c|}
\hline \multicolumn{7}{|c|}{ Behaviour and Attitude of staff } \\
\hline SI No & Details & 1 & 2 & 3 & 4 & 5 \\
\hline 1 & I/patient feel welcomed in this Primary Healthcare Centre (PHC) & & & & & \\
\hline 2 & My doctor treats me/patient with respect & & & & & \\
\hline 3 & My doctor explains me/patient about the disease/illness & & & & & \\
\hline 4 & $\begin{array}{l}\text { My doctor raises his voice when I have/patient has doubts about medication/ } \\
\text { illness [R] }\end{array}$ & & & & & \\
\hline 5 & My doctor shows sincere interest in solving my/patient's problems & & & & & \\
\hline 6 & My doctor and nurse tell me/patient exactly when services are provided & & & & & \\
\hline 7 & My doctor and nurse are always willing to help me/patients & & & & & \\
\hline 8 & My doctor is busy to respond to my/patient's requests [R]* & & & & & \\
\hline 9 & My doctor spends adequate time in treating me/ patient & & & & & \\
\hline 10 & The staff are neat in appearance & & & & & \\
\hline 11 & The staff are empathetic to me/patient during the visits & & & & & \\
\hline 12 & I am happy that I/patient came to this hospital for treatment & & & & & \\
\hline 13 & My/patient's expectations from this hospital were fulfilled & & & & & \\
\hline 14 & I/patient will recommend this hospital to my friends and relatives & & & & & \\
\hline
\end{tabular}

\begin{tabular}{|c|c|c|c|c|c|c|}
\hline \multicolumn{7}{|c|}{ Availability of diverse and rich care by doctor round the clock and specialists } \\
\hline SI No & Details & 1 & 2 & 3 & 4 & 5 \\
\hline 15 & All my/ patient's health problems are addressed here & & & & & \\
\hline 16 & I/patient can get my eye check-up done in this hospital* & & & & & \\
\hline 17 & I/we can get my/ patient's spectacles in this hospital* & & & & & \\
\hline 18 & There is need for an additional lady doctor in this hospital [R] & & & & & \\
\hline 19 & There is need for an additional male doctor in this hospital [R] & & & & & \\
\hline 20 & I am /patient is happy to get specialist care from a private setup [R] & & & & & \\
\hline
\end{tabular}

\begin{tabular}{|c|l|c|c|c|c|c|}
\hline \multicolumn{1}{|c|}{ Availability of diagnostic services } \\
\hline Setails & $\mathbf{1}$ & $\mathbf{2}$ & $\mathbf{3}$ & $\mathbf{4}$ & $\mathbf{5}$ \\
\hline 21 & Blood tests are always available in this hospital & & & & & \\
\hline 22 & I am/patient is paying for the blood tests in this hospital [R] & & & & \\
\hline 23 & I am/ patient is happy to have an ECG facility in a private hospital [R] & & & & & \\
\hline 24 & I am/ patient is happy to get x-ray facility in private hospital [R] & & & & \\
\hline 25 & I am/patient is happy to get scanning facility in private hospital [R] & & & & & \\
\hline
\end{tabular}

\begin{tabular}{|c|c|c|c|c|c|c|}
\hline \multicolumn{7}{|c|}{ Diagnosis and treatment for emergencies } \\
\hline SI No & Details & 1 & 2 & 3 & 4 & 5 \\
\hline 26 & I/patient get emergency services like care during accidental and heart attack & & & & & \\
\hline 27 & $\begin{array}{l}\text { I am/patient is happy to get emergency services like care during accidental } \\
\text { and heart attack in private hospital [R] }\end{array}$ & & & & & \\
\hline 28 & I/patient prefer to come to this hospital for dog bite & & & & & \\
\hline 29 & I/patient prefer to come to this hospital for snake bite & & & & & \\
\hline 30 & $\begin{array}{l}\text { I/patient prefer to go to private facility in case of emergency like accident/ } \\
\text { heart attack }[R]\end{array}$ & & & & & \\
\hline
\end{tabular}




\begin{tabular}{|c|l|c|c|c|c|c|}
\hline \multicolumn{1}{|c|}{ Availability of medicines } \\
\hline Details & $\mathbf{1}$ & $\mathbf{2}$ & $\mathbf{3}$ & $\mathbf{4}$ & $\mathbf{5}$ \\
\hline 31 & The medicines that the doctor prescribes are available in this facility only* & & & & & \\
\hline 32 & The doctor prescribes some medicines to be bought outside [R]* & & & & & \\
\hline
\end{tabular}

\begin{tabular}{|c|l|c|c|c|c|c|}
\hline \multicolumn{1}{|c|}{ Cost of care and medicines } & \multicolumn{1}{|c|}{ Details } & $\mathbf{1}$ & $\mathbf{2}$ & $\mathbf{3}$ & $\mathbf{4}$ & $\mathbf{5}$ \\
\hline SI No & \multicolumn{1}{|c|}{} & & & & \\
\hline 33 & I/patient have to pay for some services here [R] & & & & \\
\hline 34 & I/patient have to pay for doctor's consultation here [R] & & & & \\
\hline 35 & I/patient have to pay for medicines here [R] & & & & & \\
\hline 36 & I/patient have to pay for baby delivery services here [R]* & & & & \\
\hline 37 & I/patient have to pay for blood tests here [R] & & & \\
\hline
\end{tabular}

\begin{tabular}{|c|c|c|c|c|c|c|}
\hline \multicolumn{7}{|c|}{ Effectiveness of treatment } \\
\hline Sl No & Details & 1 & 2 & 3 & 4 & 5 \\
\hline 38 & My/patient's illness is cured in this government hospital most of the time & & & & & \\
\hline 39 & $\begin{array}{l}\text { Most of the time I/patient go to private set up for care as treatment is better } \\
\text { there }[\mathrm{R}]\end{array}$ & & & & & \\
\hline 40 & I/patient go to private set up for care as treatment is not available here [R] & & & & & \\
\hline 41 & When costs are ignored, recovery is quicker in private setup [R] & & & & & \\
\hline 42 & Most of the time treatment is better in a government hospital & & & & & \\
\hline 43 & Someone (sister/brother) from the PHC visits me at home* & & & & & \\
\hline
\end{tabular}

\begin{tabular}{|c|l|c|c|c|c|}
\hline \multicolumn{5}{|c|}{ Infrastructure of PHC } & $\mathbf{1}$ \\
\hline Si No & \multicolumn{1}{|c|}{ Details } & $\mathbf{2}$ & $\mathbf{3}$ & $\mathbf{4}$ & $\mathbf{5}$ \\
\hline 44 & This hospital has adequate number of beds & & & & \\
\hline 45 & $\begin{array}{l}\text { The physical facilities at PHC are visually appealing (building is aesthetic } \\
\text { with good roof, wall and flooring) }\end{array}$ & & & \\
\hline 46 & There is need for more furniture in this hospital [R]* & & & & \\
\hline 47 & The hospital should be cleaner than it is at present [R]* & & & & \\
\hline 48 & There is adequate drinking water facility & & & \\
\hline 49 & The delivery room is comfortable and clean & & & & \\
\hline 50 & The PHC building should be extended as there are more patients [R]* & & & & \\
\hline 51 & The toilet facility (with water) in this hospital is adequate & & & & \\
\hline
\end{tabular}

\begin{tabular}{|c|c|c|c|c|c|c|}
\hline \multicolumn{7}{|c|}{ Organization of services for better functioning of $\mathrm{PHC}$} \\
\hline SI No & Details & $\mathbf{1}$ & 2 & 3 & 4 & 5 \\
\hline 52 & $\begin{array}{l}\text { I/patient was received by nurse/other hospital staff as soon as I/patient } \\
\text { came* }\end{array}$ & & & & & \\
\hline 53 & The delivery facility is well organized in this $\mathrm{PHC}^{*}$ & & & & & \\
\hline
\end{tabular}

[R]Reverse coded (23 items)

*Deleted from final analysis of the PHCs 
Appendix 2

Reliability scores of various tools and its subscales

\begin{tabular}{|c|c|c|c|c|c|}
\hline $\begin{array}{c}\text { Sl } \\
\text { No }\end{array}$ & Tool & Subscale & $\begin{array}{l}\text { Cronbac } \\
\text { h's } \\
\text { Alpha }\end{array}$ & $\begin{array}{l}\text { Items to be } \\
\text { deleted for Alpha } \\
\text { to increase }\end{array}$ & $\begin{array}{c}\text { Alpha after } \\
\text { deleting } \\
\text { affecting items }\end{array}$ \\
\hline \multirow{4}{*}{1} & \multirow{4}{*}{ QolBref* } & Physical Health & 0.443 & & \\
\hline & & Psychological & 0.531 & & \\
\hline & & Social relationships & 0.573 & & \\
\hline & & Environment & 0.543 & & \\
\hline \multirow{3}{*}{2} & \multirow{3}{*}{ UWES* } & Vigor & 0.558 & & \\
\hline & & Dedication & 0.558 & & \\
\hline & & Absorption & 0.450 & & \\
\hline 3 & $\begin{array}{l}\text { Patient } \\
\text { satisfaction } \\
\text { questionnaire } \\
\text { from UPHC }\end{array}$ & & $0.869^{\$}$ & & \\
\hline \multirow{8}{*}{4} & \multirow{8}{*}{ RAND } & General Satisfaction & 0.331 & & \\
\hline & & Technical Quality & $0.608^{\#}$ & & \\
\hline & & Interpersonal Manner & $0.688^{\#}$ & & \\
\hline & & Communication & $0.636^{\#}$ & & \\
\hline & & Financial Aspects & $0.662^{\#}$ & & \\
\hline & & Time spent with doctor & 0.427 & & \\
\hline & & $\begin{array}{l}\text { Accessibility and } \\
\text { Convenience }\end{array}$ & 0.507 & & \\
\hline & & Total RAND & $0.840^{\$}$ & & \\
\hline \multirow{10}{*}{5} & \multirow{10}{*}{ Q4PHC } & $\begin{array}{l}\text { Behaviour and Attitude of } \\
\text { Staff }\end{array}$ & 0.906 & $8: 0.941^{\$}$ & \\
\hline & & $\begin{array}{l}\text { Availability of rich and } \\
\text { diverse care round the } \\
\text { clock }\end{array}$ & 0.389 & $\begin{array}{l}\text { 16: } 0.486 \\
17: 0.480\end{array}$ & $0.652^{\#}$ \\
\hline & & $\begin{array}{l}\text { Availability of Diagnostic } \\
\text { services }\end{array}$ & $0.876^{\#}$ & & \\
\hline & & $\begin{array}{l}\text { Diagnosis and treatment } \\
\text { for emergencies }\end{array}$ & $0.727^{\#}$ & & \\
\hline & & Availability of medicines & -0.362 & 31,32 & \\
\hline & & Cost of care and medicines & 0.847 & 36: 0.865 & $0.865^{\$}$ \\
\hline & & Effectiveness of treatment & 0.625 & $43: 0.725$ & $0.725^{\#}$ \\
\hline & & Infrastructure of PHC & 0.690 & $\begin{array}{l}46: 0.761 \\
47: 0.720 \\
50: 0.697 \\
\end{array}$ & $0.875^{\$}$ \\
\hline & & Organization of services & 0.577 & 52,53 & \\
\hline & & Total Q4PHC & $0.938^{\$}$ & & \\
\hline
\end{tabular}

Items deleted from Q4PHC after Cronbach's alpha for ANOVA analysis: 8, 16, 17, 31, 32, (31 and 32 are all items in the dimension availability of medicine) $36,43,46,47,50,52,53$ (52 and 53 are all items in the dimension organization of services)

*Small sample size of $39 ;$ \# Sufficient; ${ }^{\$}$ High 


\section{Chapter 7}

General Discussion \& Conclusion 


\section{General Discussion}

\section{Background}

Primary healthcare centres (PHC) represent the first line of healthcare providers in India's health system, working on community health by delivering health promotion, preventive health care and curative health. ${ }^{1}$ Therefore, performance assessment of these centres is essential to ensure optimum functioning, thus influencing the health of the population. The essential problem contextualized and studied in this thesis is that low- and middle-income countries (LMIC) need practical, easy to administer assessment tools reflecting reality from various perspectives to reveal the complete functioning of PHCs. Hence, there is a need for establishing criteria for PHC performance assessment, which are feasible and grounded in reality at the same time.

The aim of this study was to develop a tool for assessing the performance of PHCs in LMIC, tailored to the needs of those countries. We accomplished this goal using: an empirical literature review of PHC performance assessment in LMICs to learn about current knowledge and practices, and to build on the existing established model; and a multiple stakeholder analysis of PHCs to develop an assessment tool that takes all these important perspectives into consideration. We included patients, who are the most important stakeholders and ultimately the users of healthcare centres. The various healthcare providers at the centres were included, since their involvement and well-being are essential for the functioning of PHCs. The managers' perspectives on PHC performance were also included, for us to get an overview of the centres' functioning, so as to finally develop a tool to evaluate the PHCs and to enhance the existing performance frameworks into a multi-stakeholder, context-sensitive performance model. The reflections on the main findings of the study are presented as follows.

\section{Review of literature}

In chapter 2, we present a review of the empirical literature and compare the results with the aspects of the WHO performance assessment. The review indicated that there were no specific performance measuring tools for PHCs in general and in particular not for LMICs. Various PHC functional components were measured either from the perspective of centres or providers, using qualitative or quantitative methodologies. Comparing the performance measures used in the studies with measures from the WHO aspects of health system performance assessment, we found that the studies had utilised limited measures from the WHO aspects probably because of the limited applicability of all the measures in LMICs, which have data and resource constraints. ${ }^{2-4}$ This review indicated that there is a need to develop locally applicable measures to assess complete PHC functionality in India. ${ }^{5-8}$ 
Comparing the results of this review with the measures of the Primary Health Care Performance Initiative (PHCPI) framework, we noted that the researchers in the reviewed literature had used most of the indicators from the PHCPI framework in their assessment of the centres. However, comparing the results of the review with the PHCPI framework, we found that, in the review, the providers' perspectives were represented by the providers' absence rates, diagnostic accuracy, adherence to clinical guidelines and daily caseload per provider, without any consideration of the local circumstances of service delivery at PHCs. ${ }^{9}$ Thus, the need to develop context- specific, locally applicable PHC performance measures and indicators was reinforced.

\section{Patients' perspectives on PHC performance}

In chapter 3, we present the results of the interviews with 188 patients across three PHCs in Bengaluru Urban District so as to understand the criteria they used to assess the PHCs. The number of patient interviews is large, as we looked for data saturation within PHCs to avoid missing any PHC-specific details. Patients in India assessed PHC performance based on nine themes, which can be grouped in performance of centres and providers. Based on these indicators flagged by the patients, we developed a tool to assess PHC performance and to further assess the centres from the patients' perspectives. The nine performance themes are the following.

(1) Availability of rich and diverse services at the PHC, consisting of availability of emergency care, female doctors, specialist doctors, and services 24 hours a day;

(2) Availability of effective diagnoses at the centre - This includes ultrasound scans and X-rays at the centre, so patients do not need to visit other facilities;

(3) Availability of medicines at the PHC as prescribed by the doctors;

(4) Good infrastructure - Infrastructure was described in terms of water and sanitation facilities, appropriate flooring, adequate furniture and appropriate construction, etc.;

(5) Cost - Patients always compared the care provided by PHCs with private healthcare providers before using healthcare services;

(6) Behaviour and attitude of providers during care delivery;

(7) Punctuality of providers - Whether they are available at the centre and delivering prompt care;

(8) Effectiveness of care - Quick recovery from health problems.

(9) Service organisation and infrastructure at PHCs.

\section{Providers' perspectives on PHC performance}

In chapter 4, the results of interviews with 36 providers of three PHCs alerted us to the fact that PHCs should perform not only for external customers, i.e. patients, but also for internal customers, 
meaning the providers. The interviewed providers said that PHC performance should be assessed by the following:

(1) Presence of efficient teamwork at PHC - Providers placed great emphasis on doctors providing leadership in aiding cohesion among those delivering care as members of a team.

(2) Opportunities for on-the-job skills development - Providers perceive opportunities for skills advancement and knowledge acquisition provided by the health system as possibly enhancing their service capability and performance.

(3) Job satisfaction - Providers described job satisfaction as a reflection of their interaction with patients and service delivery.

(4) Effective administration - PHC administration in terms of safety and security, especially in terms of dealing with potential violence was considered to improve the work environment and in turn the well-being of providers.

(5) Community relations - Good community relations were the result of persistent effective care delivery and positive attitudes from healthcare professionals, reinforced by positive interaction with patients and the community.

Even though these were the performance indicators identified by the healthcare providers themselves, they did not mention their own current level of skill, knowledge and ethical practices. We conclude therefore that unsatisfactory work conditions resulted in high turnover and understaffing undermined performance, ${ }^{10,11}$ while fulfilling these indicators enhances patient care. ${ }^{12,13}$ Therefore, including these performance indicators would lead to a realistic assessment of the centres. While these indicators relate to the providers' quality of life and work engagement, they may also reflect PHC performance and should be used in PHC performance assessment in LMICs. ${ }^{14,15}$

\section{Managers' perspectives on PHC performance}

In chapter 5, we present the interviews conducted with the eight mid-level healthcare managers in Bengaluru Urban District, who provided their own perspectives on PHC performance criteria. According to the managers, performance indicators were the targets set by the health department for the centres on implementation of service delivery and national health programmes. Some of these targets include the number of outpatients treated, the number of admitted patients, the number of women delivering in a PHC, the percentage of children receiving full immunisation, the number of women receiving complete antenatal check-ups, the number of tuberculosis cases fully treated, the number of cases of malaria detected and treated, and the number of disease outbreaks in the community. ${ }^{16}$ Managers also believed that PHC performance included yet a good environment at the 
PHC and good rapport developed with patients as a result of good service delivery. The managers also emphasised the role played by the health system and the local political bodies in PHC performance. Managers also seemed to assume that the doctors are directly responsible for the centres' performance.

The managers believe that PHC performance depends on effective leadership provided by the doctors. This leadership includes efficient administration, human resource management, supervision of other providers, and mentorship of the team. The doctors' leadership also includes reporting PHC activities to higher officials, PHC infrastructure maintenance, overseeing resources and financial allocation, and maintaining good rapport with patients. It also includes overseeing health education campaigns in the community and intuitive coordination of collaboration with external stakeholders and political leaders. The doctors' responsibilities, in addition to their roles at the centres, also includes providing medical opinion for legal bodies, and medical assistance to persons of political importance visiting the city. As leaders at the PHCs, doctors are fundamental for a conducive work environment, enhancing interpersonal relations among stakeholders to ensure efficient healthcare delivery at the centres. According to the managers, the performance of a PHC depends on a doctor performing all these tasks adequately.

Managers also emphasised the role of managers, the health system and local politics in PHC performance. The manager's position to interact with various stakeholders to initiate change in the system, lead providers and contribute to better PHC performance was also highlighted. According to the managers, PHC performance was also influenced by the support and conducive conditions provided by resources from the health system, and a constructive local socio-political environment provided by the community and its leaders. These were mentioned as preconditions for good PHC performance, which had to be fulfilled for PHCs to perform well. Hence, including these aspects in the PHC performance would help in assessing the prevailing conditions, thereby contributing towards a more complete evaluation.

\section{Questionnaire for patient perspective on primary healthcare centre performance - Q4PHC}

Based on interviews with the patients, we designed a questionnaire originally consisting of 53 items divided over nine dimensions to evaluate PHC performance from the patient's perspective. A few items and two total dimensions were deleted to retain 39 items and seven dimensions to form the Q4PHC, with moderate to high reliability (Cronbach's alpha) ranging between 0.652 to 0.941 for each dimension, and Cronbach's alpha score of 0.938 for the total questionnaire. The results from the new tool were compared to the patient satisfaction questionnaire-18 from RAND publications and patient feedback form from the Urban PHC quality manual by the Indian Ministry of Health and 
Family Welfare. From this analysis, we can affirm that the tool was reliable, context sensitive and locally applicable to address PHC functionality from the patients' perspectives, hence including the Q4PHC in PHC evaluations is indicated.

\section{Performance of PHCs: A Quantitative Analysis}

In chapter 6, PHCs were compared on their availability of infrastructure, service delivery, provider well-being and PHC patient assessment using an ANOVA with Scheffé test to identify any significant difference or rather patters between centres. The availability of infrastructure at PHCs was assessed using the Indian Public Health Standards and data on the quantity of service delivered from the Health Management Information Systems (secondary data). ${ }^{1,16}$ Provider well-being was evaluated as quality of life using the WHOQOL-BREF and work engagement using the UWES-17 questionnaire. ${ }^{19,20}$ The patients' PHC assessments were evaluated with the Q4PHC, the patient satisfaction questionnaire-18 from RAND publications and the patient feedback form from the Urban PHC quality manual by the Indian Ministry of Health and Family Welfare. ${ }^{17,18}$

The data showed that the centres with high output performed poorly in relation to provider quality of life and patient assessment. The PHCs with medium delivery load had better provider work engagement than the other centres. We conclude that the high PHC performance in terms of increased patient care services comes with a price of lower provider well-being. This might be because of high workload leading to lower engagement. The literature shows that provider performance and provider well-being are related, meaning providers with low engagement are less productive. ${ }^{21}$ Patients assessed the centres with the smallest delivery loads to be performing well; they also expressed more satisfaction and provided more positive reports in the Urban PHC feedback form. These results could be the result of more time spent with each patient and better provider wellbeing thanks to smaller workloads. The positive association between quality of life, work engagement, workload, and patient satisfaction has long been established in the literature. ${ }^{22}$ The higher performance in terms of increased patient service at PHCs may be associated with the providers having low quality of life and work engagement, which might be explained by reverse causality: the workload might have been so high that engagement was hampered. ${ }^{23}$

PHC performance assessment is a complex phenomenon. This is because PHC functioning involves multiple stakeholders of different influence levels, so an apt representation of reality is possible only when performance is assessed from various perspectives reflecting the local context. It is essential to include various perspectives to get a valid picture. ${ }^{24}$ We believe that there may be a trade-off between working hard, being vital providers and having enough time and energy for good communication with patients. 
From this study we conclude that PHC assessment using multiple perspectives provides a realistic, context-relevant assessment of centres. We believe that a balance between the availability of infrastructure, service delivery, provider well-being and patient perception of PHC performance could enable better assessment and may contribute towards enhancing performance.

\section{PHC performance in low- and middle-income countries}

LMICs face challenges in availability of data and resources, so having PHC performance measured would make service delivery more realistic and less demanding. ${ }^{25,26}$ Employing available secondary data along with optimal primary secondary data should aid in realistic performance assessment with minimal errors, ${ }^{25}$ making PHC performance assessment optimal. This study has identified significant indicators from the perspectives of multiple stakeholders which can be used to assess PHCs primarily and can be utilised as a benchmark for further improvement. In comparison with the performance criteria from the WHO and in the PHCPI framework, ${ }^{3,9}$ the stakeholders' contributions to the PHC performance assessment led to the development of holistic performance indicators that are locally applicable and grounded in the reality. Figure 1 depicts the measures and criteria contributed by the stakeholders towards PHC performance assessment.

Patients
-Availability of rich and
diverse services
-Availability of effective
diagnoses
-Availability of medicine
- Availability of the
infrastructure
- The cost of care
- The behaviour and attitude
of staff during care
delivery
- The punctuality of staff
- The effectiveness of care
- Organization of services

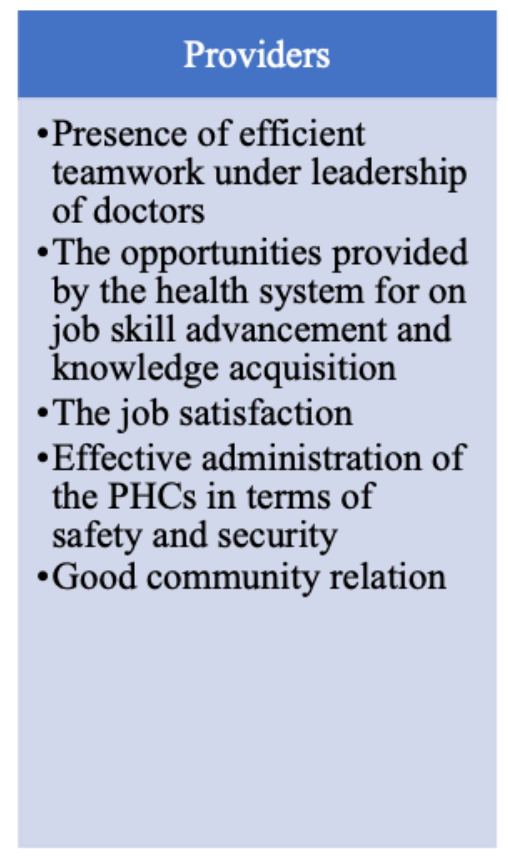

Managers
- Output indicators of the
services delivered and
program implemented at
PHCs
- outcome indicators of the
services delivered and
program implemented at
PHCs
-Ambience of PHCs
- Rapport with the patients
-Leadership of doctor
-Supervison by Managers
- Resources from health
system
-Support, cooperation and
coordination from local
political persons

Figure 1. Criteria of PHC performance from various stakeholders

Comparison of the stakeholders' criteria with aspects of the WHO health system performance assessment and the PHCPI framework

Comparing the indicators from the study with aspects of the WHO assessment and the PHCPI performance framework, we note that various stakeholders not only spoke of PHC performance for 
external customers (patients) but also internal customers (providers). While aspects of the WHO health system performance assessment had diverse measures for the health system at large, the PHCPI framework focused on the primary healthcare system. What's we find also striking is that aspects of both the WHO assessment and the PHCPI framework focus on PHC performance from a policymaker point of view to assess PHCs for follow-up and comparison, without considering and reflecting the local challenges and the environments in which PHCs operate ${ }^{3,9}$; we believe that their indicators assume a constant ideal scenario at the centres. The indicators suggested by the various stakeholders not only covered the structural requirements of PHCs but emphasised the process, output and outcome of the care delivery processes, which is context specific for Indian PHCs. As the indicators identified by the stakeholders in our study are focused on day-to-day functioning, they may be considered as practical and might result in betterment of the centres by consistent implementation.

From the analysis of the centres by the various stakeholders' perspectives, we conclude that the analysis is realistic in depicting the actual functioning of PHCs, capturing its consequences to the system and providers. The ideal PHC performance assessment should evaluate the availability of standard infrastructure and services by both the centre and its patients. The cost of care to patients should also be considered along with the effectiveness of care. The patients' perceived behaviour, the providers' attitudes and punctuality should also be assessed, along with teamwork at the centre, and good community relationships and positive rapport between patients and providers. The organisation and administration of PHCs both from the patients' and the providers' points of view should also be included. The providers' job satisfaction and the opportunities for enhancement of their care capabilities should also be evaluated. We note that the stakeholders we interviewed strongly emphasised the process of care delivery with adequate support as a structural component of the healthcare system and a necessary factor for optimum performance assessment. ${ }^{27,}{ }^{28}$ Considering these criteria to evaluate PHCs would lead to a holistic assessment focused towards performance improvement. For the assessment to be complete, all of these factors should be assessed along with an evaluation of the environment provided by the health system and the local political circumstances from the providers' perspectives.

\section{Performance and work engagement}

Performance and work engagement have long been associated by various studies. Employee engagement leads to meaningful organisational outcomes ${ }^{29}$, improvement in financial turnover ${ }^{30}$, better academic performance ${ }^{31}$, increased service quality as perceived and rated by customers ${ }^{32}$, increase in organisational commitment, and reduction in intention to leave. ${ }^{33}$ Performing in an 
organisation is the result of the interaction between job demands and resources, which is known as the job demand-resources model. ${ }^{33,34}$ The job demands require efforts that are related to physiological and psychological costs, like fatigue, however job resources promote personal growth and learning, which are motivational in nature. ${ }^{35}$ Based on this conceptualisation, a brief work engagement questionnaire consisting of three interrelated dimensions — vigour, dedication, and absorption $^{18}$ — was used in the current study to assess provider engagement along with the WHOQOL-Bref to assess provider well-being. In line with existing research, the results of the current study show that the centres with fewer patients had higher engagement and patient satisfaction, and were assessed by patients as performing better. ${ }^{22,23}$

\section{Doctors in focus}

We find it striking that among the interviewed stakeholders, only patients identified technical skills, such as efficient care, and professional values, such as behaviour, attitude, and punctuality, as performance indicators, while neither providers nor managers mentioned them. We find it striking that both the WHO aspects and the PHCPI framework were oblivious of the providers' technical skills and professional values in their assessments. ${ }^{3,9}$ Taking care of medical tasks, leadership and management, patient education, relationships with the health system and local political actors, all at the same time, might place excessive demand on doctors, who might fail to deliver, faced with multiple tasks and high expectations. ${ }^{36,37}$ On the one hand, there is a large discrepancy between the actual work, doctor's values and their training, which could explain the high turnover of staff and the difficulties India's public healthcare institutions have with recruiting. ${ }^{38-40}$ On the other hand, studies on this topic indicate that although doctors usually do not receive training in leadership nor in acting as government agents and administrators, they often enjoy enormous public respect and support. ${ }^{36}$ These high expectations seem to be associated with the high societal status doctors have in Indian society. Doctors in high-income countries like the United Kingdom may be highly regarded, ${ }^{41}$ but not nearly as high as is the case in India, where they are seen as demigods. Studies indicate that the god-like status of doctors in India dates back to old values in Hindu society - vaidyo narayano hari is part of a Rigveda hymn that equates doctors to god $)^{42}$ — which have been reinforced in the colonial era, when Christianity also spread the idea of Jesus healing the sick. ${ }^{43}$ As modern medicine was introduced in India, its practitioners being trained abroad or by foreigners, it also assumed a stance of superiority and strict hierarchy ${ }^{44}$, which could explain patients' high expectations from doctors, providers and managers. These expectations add considerably to the workload and stress of doctors. Being primarily trained to be medical professionals, they are expected to take on managerial roles while lacking a strong foundation in management for better execution of PHC functionalities. Studies that identified similar inconsistencies between doctors' tasks and their education ${ }^{45}$ point out 
that this gap should be addressed by providing necessary skills and management tools, along with adequate resources for performing multiple roles. ${ }^{45,46}$ The literature also suggests supplementing or complementing doctors' managerial roles by adding adequately trained persons to take on managerial responsibilities. ${ }^{47,48}$

\section{Performance and leadership}

There is evidence that under good leadership, organisations will perform well and sustain their performance in search of excellence. ${ }^{49}$ Leadership is essential for enhancing healthcare services provision and the relevance of various leadership styles has been explored in the healthcare setting. ${ }^{50}$ There is an ongoing debate on whether physicians make better leaders than non-physicians, with little to none empirical evidence on the subject, however physician managers tend to overlook their medical performance in favour of their management duties. ${ }^{45,47}$

Developing leadership in healthcare has been acknowledged as a significant challenge for the future. ${ }^{51,52}$ The leader of a PHC may have to apply different leadership approaches while interacting with different stakeholders and managing the centre. ${ }^{53}$ Some of the applicable principles include transformational leadership, where a doctor will communicate with other providers to work effectively towards a collective purpose creating unity. ${ }^{53,54}$ The collaborative leadership will have to be applied during interactions with external stakeholders to help them make informed decisions, and to create synergy in the functioning of the PHC. ${ }^{53}$ The leadership quality of engaging with others, the engaged leadership, has been a significant predictor of organisational performance and outcomes ${ }^{55}$, with direct effect on outcomes — such as employability, performance and commitment — and an indirect effect on burnout and employee engagement via job demands and job resources. ${ }^{21,55}$ The findings of the current study indicate that doctors at the centres were considered as leaders of the centres by multiple stakeholders, including patients, providers and managers. This points at the necessity of developing multiple leadership competencies ${ }^{56}$ among doctors to facilitate sustainable PHC performance.

\section{Methodological consideration}

\section{Strength}

Including all the stakeholders at a PHC is a significant strength, because views on the same function differed among stakeholders, providing an internal and external perspective on various functionalities at the centre. The study utilised qualitative methods to get insights into the beliefs, claims, and concerns of various stakeholders involved in healthcare delivery, making it a holistic approach. The comparison of PHCs by the indicators of PHC infrastructure availability and service 
delivery, patients' evaluation of PHC performance, and providers' well-being, gave a multipronged approach to the PHC performance assessment, providing a clear view for working on improving performance in a sustainable manner.

\section{Weakness}

The weakness of the study lies in the study sample. Only three of the 20 functioning PHCs in the Bengaluru Urban District were included, even though they were selected on theoretical basis to represent a variety of PHCs. In addition, the PHCs were in urban areas, so applicability of the results to rural PHCs will need to be evaluated. Including all the PHCs in Bengaluru Urban District along with those in the rural district or any other district with a combination of urban and rural areas would provide a more complete picture for comparison and generalisation.

\section{Conclusion and recommendations}

We conclude that the concept of what PHC performance entails was viewed differently by various stakeholders assessing the centres. However, they mentioned all the components of the system: structure, process, output and outcome. There were some commonalities in the fact that all the stakeholders considered the doctor central to PHC performance, including appropriate resources and support from the health system, and local political circumstances. Assessing the centres based on the availability of infrastructure ${ }^{1}$ (IPHS) and services ${ }^{16}$ (HMIS), provider well-being ${ }^{17,18}$ (QoL-Bref, UWES-17) and patients' assessment of the PHC (Q4PHC) depicted a realistic evaluation offering a complete picture of the PHC. As only three centres in the Bengaluru Urban District were assessed in the current study, we recommended similar studies including other PHCs in urban and rural set-ups be conducted, so that the results can be generalised.

\section{Implications of study in India and future research}

This study indicates that for holistic PHC performance assessment, various components specified by different stakeholders should be evaluated. Assessing centres based on the performance criteria suggested by different stakeholders would lead to the identification of gaps that can be addressed for sustained improvement. ${ }^{27,57}$ As there has been certain overlap and differences in the indicators from the perspectives of various stakeholders, further research on prioritisation and assigning weight to these indicators should be explored to broaden the practical implications of the current research. Further research should be conducted to enable the system to offer centre-specific or even personal interventions to enhance performance, which would work towards sustainable PHC performance.

Healthcare providers expected doctors to provide mentoring, supervision and support, emphasising the role of teaching and training. Doctors should be trained to effectively provide this kind of 
support. Supportive supervision should not only be prioritised at all levels of the health system but should be adequately resourced. ${ }^{58}$ Managers highlighted the importance of their supervisory role, the support received from the health system and local political persons, so further research on how to strengthen these roles is necessary, to also enhance PHC performance. 


\section{Reference}

1. Indian Public Health Standards 2016. http://nhm.gov.in/nhm/nrhm/guidelines/indian-publichealth-standards.html (Accessed on 12th November 2018).

2. The World Health Report 2000. Health Systems: Improving Performance. https://www.who.int.en. Accessed 1 Nov 2014.

3. Health Systems Performance Assessment: Debates, Methods and Empiricism. WHO Publication. 2003. http://www.who.int/health_financing/documents/cov-hspa/en/. Accessed on 10 Sept 2015.

4. Donnay F. Maternal survival in Developing countries: what has been done, what can be achieved in the next decade. International Journal of Gynaecology and Obstetrics. 2000;70:89-97.

5. Scutchfield F D, Knight E A, Kelly A V, Bhandari M W, Vasilescu L P. Local Public health agency capacity and its relationship to public health system performance. Journal of Public Health Management Practice. 2004;10(3):204-215.

6. Panda B, Thakur H P. Decentralization and health system performance - a focused review of dimensions, difficulties, and derivatives in India. BMC Health Services Research. 2016;16 Suppl 6:561. DOI:10.1186/s12913-016-1784-9.

7. Hamilton K E, Coates V, Kelly B, Boore J R P, Cundell J H, Gracey J, Mcfetridge B, McGonigle M, Sinclair M. Performance assessment in healthcare providers: a critical review of evidence and current practice. Journal of Nursing Management. 2007;15:773-791.

8. Kurk M E, Freedman L P. Assessing health system performance in developing countries: A review of literature. Health Policy. 2008;85:263-276.

9. Veillard J, Cowling K, Bitton A, Ratcliffe H, Kimball M, Barkley S, Mercereau L, Wong E, Taylor C, Hirschhorn L R, Wang H. Better measurement for performance improvement in Lowand Middle-Income countries: The primary health care performance initiative experience of conceptual framework development and indicator selection. The Milbank Quarterly. 2017;95(4):836-883.

10. Homburg V, Van Der Heijden B, Valkenvurg L. Why do nurses change jobs? An empirical study on determinants of specific nurses' post-exit destinations. Journal of Nursing Management. 2013;21:817-826. DOI:10.1111/jonm.12142. 
11. Chao M-C, Jou R-C, Liao C-C, Kuo C-W, Workplace stress, job satisfaction, and turnover intention of health care workers in rural Taiwan. Asia-Pacific Journal of Public Health. 2015;27(2):1827-1836. DOI:10.1177/1010539513506604.

12. Sokhanvar M, Kakemam E, Chegini Z, Sarbakhsh P. Hospital nurses' job security and turnover intention and factors contributing to their turnover intention: A cross-sectional study. Nursing and Midwifery Studies. 2018;7:133-40. DOI:10.4103/nms_2_17.

13. Wan Q, Li Z, Zhou W, Shang S. Effects of work environment and job characteristics on the turnover intention of experienced nurses: The mediating role of work engagement. Journal of Advanced Nursing. 2018;74:1332-1341. DOI:10.1111/jan.13528.

14. Almalki M J, FitzGerald G, Clark M. The relationship between quality of work life and turnover intention of primary health care nurses in Saudi Arabia. BMC Health Services Research. 2012;12:314.

15. Kartal N. Evaluation the relationship between work engagement, work alienation and work performance of healthcare professionals. International journal of healthcare management. 2018;11(3):251-259.

16. https://nrhm-mis.nic.in/hmisreports/frmstandard_reports.aspx. Accessed on 10 Jan 2019.

17. Marshall G N, Hays RD. The patients' satisfaction questionnaire short form (PSQ18) RAND publication,1994. https://www.rand.org/content/dam/rand/pubs/papers/2006/P7865.pdf accessed on 1st Feb 2019.

18. Ministry of Health and Family Welfare, Government of India. Quality Standards for Urban Primary Health Centre. 2015, Annexure D, 260.

19. The WHOQOL Group. Development of World Health Organization WHOQOL-BREF Quality of Life Assessment. Psychological Medicine. 1998;28:551-558.

20. Schaufeli W B, Bakker A, Salanova M. The Measurement of work engagement with a short questionnaire. Educational and Psychological Measurement. 2006;66(4):701-716.

21. Taris T W, Schaufeli W B. Individual well-being and performance at work: A conceptual and theoretical overview.2015. https://www.wilmarschaufeli.nl/publications/Schaufeli/434.pdf Accessed on 9th December 2019 (Wellbeing and performance at work. Edited by van Veldhoven m, Peccei R. Chapter 2). 
22. Halbesleben J R B. The consequences of engagement: The good, the bad, and the ugly. European Journal of Work and Organizational Psychology. 2011;20(1):68-73. DOI:10.1080/1359432X.2010.514327.

23. Shuck B, Reio Jr T G, Employee engagement and well-being: A moderation model and implications for practice. Journal of Leadership and Organizational Studies. 2014;21(1):43-58. Doi:10.1177/1548051813494240.

24. Piligrimienė Ž, Bučiūnienė I. Different perspectives on health care quality: Is the consensus possible? Engineering Economics. 2008;56(1):104-110.

25. Groene O, Skau J K H, Frolich A. An international review of projects on hospital performance assessment. International Journal of Quality in Health care. 2008;20(3):162-171.

26. Albuquerque I F, Cunha R C. Martins S D, Brito A Sa. Primary health care services: workplace spirituality and organizational performance. Journal of Organizational change management. 2014;27(1): 59-82. https://doi.org/10.1108/JOCM-11-2012-0186.

27. Akachi Y, Kurk M E. Quality of care: measuring a neglected driver of improved health. Bulletin of the World Health Organization: Policy and Practice. 2017;95(6), 465 - 472. http://dx.doi.org/10.2471/BLT.16.180190.

28. Hanefeld J, P-Jackson T, Balabanova D. Understanding and measuring quality of care: dealing with complexity. Bulletein of World Health Organization. 2017;95:368-374. doi: http://dx.doi.org/10.2471/BLT.16.179309 Accessed on 18th January 2020.

29. Choi Y. The differences between work engagement and workaholism and organizational outcomes: An integrative model. Social Behavior and Personality.2013;41(10):1655-1666. DOI:10.2224/sbp.2013.41.10.1655.

30. Xanthopoulou, D., Bakker, A. B., Demerouti, E., \& Schaufeli, W. B. (2007). Work engagement and financial turnover: A diary study on the role of job and personal resource. Journal of Occupational and Organizational Psychology.2009;82:183-200. DOI:10.1348/096317908X285633.

31. Schaufeli, W. B., Martinez, I., Marques Pinto, A., Salanova, M., \& Bakker, A. B.. Burnout and engagement in university students: A cross-national study. Journal of Cross-Cultural Psychology. $2002 ; 33 ; 464-481$. 
32. Salanova, M., Agut, S., \& Peiro' , J. M. Linking organizational resources and work Engagement to employee performance and customer loyalty: The mediating role of service climate. Journal of Applied Psychology. 2005; 90:1217-1227.

33. Schaufeli, W. B., \& Bakker, A. B. Job demands, job resources, and their relationship with burnout and engagement: A multi-sample study. Journal of Organizational Behavior. 2004;25:293-315.

34. Bakker, A. B., \& Demerouti, E. The Job Demands-Resources model: State of the art. Journal of Managerial Psychology. 2007;22:309-328.

35. Bakker A B, Schaufeli W B. Positive organizational behaviour: Engaged employees in flourishing organizations. Journal of Organizational Behavior. 2008;29:147-154. DOI:10.1002/job.515.

36. Holden H M. The needs and expectations of doctors and patients. Journal of Royal College of General Practitioners. 1977;27:277-79.

37. Irvine D. The performance of doctors: the new professionalism. Lancet. 1999;353:1174-77.

38. Bajpai V. The challenges confronting public hospitals in India, their origins, and possible solutions. Advances in Public Health. 2014;898502. DOI:10.1155/2014/898502.

39. Raha S, Berman P, Rao D K. Challenges in recruitment of doctors by government. India Health Beat: Supporting Evidence-based Policies and Implementation. 2009;1(4):70242. Accessed 16 ${ }^{\text {th }}$ April 2019.

40. Chakravarthi I. Effectiveness of financial incentives for recruitment and retention of skilled health professionals for the public health system in Orissa, India. BMC Proceedings. 2012;6(Suppl 5):O2. DOI:10.1186/1753-6561-6-S5-O2.

41. Irvine D. The performance of doctors. I: professionalism and self regulation in a changing world. The British Medical Journal.1997;314:1540. DOI:10.1136/bmj.314.7093.1540.

42. Brahmakarma Samucchaya, Vishnudharmottara Purana, Dalbhya Pulastha Samvada.

43. Makilkin A. The physician as a Deity: Balzac's Meandering between Religion and Medicine in The Country Doctor. https://www.utpjournals.press/doi/pdf/10.3138/uram.29.1-2.5 Accessed on 15th December 2019. 
44. Bastos C. Doctors for the empire: The medical school of Goa and its narratives. Identities Global Studies in Culture and Power. 2001;8(4):517-548. Doi:10.1080/1070289X.2001.9962707.

45. Witman Y, Smid G A C, Meurs P L, Willems D L. Doctor in the lead: balancing between two worlds. Organization. 2010;18(4):477-495.

46. Chervenak F A, McCullough L B, Brent R L. The professional responsibility model of physician leadership. American Journal of Obstetrics and Gynecology. 2013;208(2):97-101. DOI.10.1016/j.ajog.2012.03.005.

47. Goodall A H. Physician-leaders and hospital performance: Is there an association? Social Science and Medicine. 2011;73;535-539. DOI:10.1016/j.socscimed.2011.06.025.

48. McGivern G, Currie G, Ferlie E, Fitzgerald L, Waring J. Hybrid manager-professionals' Identity work: The maintenance and hybridization of medical professionalism in managerial contexts. Public Administration. 2015;93(2):412-432. DOI: 10.1111/padm.12119.

49. Kaufman K, Goldstein L. Leadership and successful financial performance in Heatlhcare. Modern Healthcare. 2008;S(1):9-21.

50. Kumar R D C. Leadership in healthcare. Anesthesia and intensive care medicine. 2013;14(1):3941.

51. Borkowski N, Deckard G, Weber M, Padron L A, Luongo S. Leadership development initiatives underlie individual and system performance in a US public healthcare delivery system. Leadership in Health Services. 2011:24(4):268-280. DOI:10/1108/17511871111172321.

52. McAlearney A S. Leadership development in healthcare: A qualitative study. Journal of Organizational Behavior. 2006;27:967-982. DOI: 10.1002/job.417.

53. Al-Sawai A. Leadership of Healthcare Professionals: Where do we stand? Oman Medical Journal. 2013;28(4):285-287, DOI:10.5001/omj.2013.79.

54. Mah'd Alloubani A, Almatari M, Almukhtar M M. Review: Effects of leadership styles on quality of services in healthcare. European Scientific Journal. 2014;10(18):118-129.

55. A-Metcalfe B, A-Metcalfe J, Bradley M, Mariathasan J, Samele C. The impact of emerging leadership on performance, attitudes to work and wellbeing at work A longitudinal study. Journal of Health Organization and Management. 2008;22(6):586-598. DOI:10.1108/14777260810916560. 
56. Oyewunmi A E, Ojo I S, Oludayo O A. Leaders' emotional intelligence and employees' performance: A case in Nigeria's public healthcare sector. International Journal of Human Resources Studies. 2015;5(3):23-37. DOI:10.5296/ijhrs.v5i3.7854.

57. Hogg W, Dyke E. Improving measurement of primary care system performance. Canadian Family Physician. 2011;57:758-760.

58. Nkomazana O, Mash R, Wojczewski S, Kutalek R, Phaladze N. How to create more supportive supervision for primary healthcare: lessons from Ngamiland district of Botswana: co-operative inquiry group. Global Health Action. 2016;9(1);31263, DOI: 10.3402/gha.v9.31263. 
Summary 
This thesis is about improving the measurement of performance assessment for primary healthcare centres in a specific context, the Bengaluru Urban district, in Karnataka, India. Performance was explored from the perspective of the key stakeholder of the centres : the patients, providers and the middle level managers.

Chapter 1 provides a general introduction on the background of performance assessment in primary health care. Further, the standards in the field are addressed: the WHO aspects of performance assessment and the framework from the Primary Health Care Performance Initiative. The chapter also describes the structure of primary healthcare system in the Indian context. Further, the literature on the contribution of health care providers to performance and how performance is related to their involvement in their work, is addressed. Aim of this research was intended to fill the gap in the understanding of how to assess PHCs performance. The research questions included

1. How are PHCs being evaluated in developing countries? What measures of PHC performance have been utilised in empirical literature in developing countries?

2. What are PHC performance indicators from the perspectives of key stakeholders (patient, provider and mid-level healthcare manager) of the PHCs?

3. How can we assess PHC performance from multiple perspectives and what are the relationships between various perspectives of PHC performance assessment?

4. What criteria contribute to the existing health system performance frameworks?

Chapter 2 presents a narrative review of empirical literature on the performance of the primary healthcare centres in low- and middle- income countries (LMIC) to develop an understanding of the measures that are being used by researchers in assessing the PHC performance and compare it with the World Health Organization's (WHO's) framework for performance assessment that forms a comprehensive global standard to identify the gaps in assessment. The initial search yielded 4,359 articles of which fifteen articles met the specified inclusion and exclusion criteria. Nine articles used quantitative methods, one article used qualitative methods exclusively and five used mixed methods. Fourteen articles had a good description of the measurement properties. None of the articles presented validity tests of the measures but eleven articles presented measures that were well established. Mostly studies included components of personnel competencies (skilled/ un-skilled) and centre performance (patient satisfaction/cost/efficiency). The measures in the articles were limited in scope as they did not represent all service components of PHCs from the WHO framework. Hence, PHC performance assessment should include system components along with relevant measures of personnel performance beyond knowledge of protocols. It was concluded that existing measures for 
PHC performance assessment in developing countries need to be validated and concise measures for neglected aspects need to be developed.

Chapter 3 describes PHC performance from the perspective of the patients. The aim of this study was to explore PHC performance from the patient's perspective and in relation to the WHO framework of performance assessment. 188 patients attending one of three PHCs in Bengaluru (India), were interviewed to identify nine themes that formed the areas of PHC assessment from patient's perspective, these themes included: the availability of rich and diverse services; the capability to carry out effective diagnoses; the cost and availability of medicines; the quality of the infrastructure; the cost of care; the behaviour and communication skills of staff; the effectiveness of care and how well it is organized; and the punctuality of staff. The criteria that are of primary importance to patients were varied and not only covering multiple aspects of WHO framework but also their local relevancy. It was concluded that the factors cut across various aspects of the WHO's model of PHC performance, rendering the assessment model more inclusive and indicative of the views of those receiving care and of the realities "on the ground". Such a holistic model would further ensure continuous improvement in service delivery leading to better utilization of preventive and promotive services provided by the PHCs.

Chapter 4 explores the perspective on performance of an important stakeholder group: the PHC healthcare providers. Including performance indicators based on the perspective of healthcare providers are expected to enable assessment of the actual functioning and effectiveness of urban PHCs. It was aimed to collect the providers' perspectives and compare them with the WHO aspects of performance assessment and with the framework of Primary Health Care Performance Initiative (PHCPI). Interviews with 36 providers at three PHCs provided the previously untapped first-hand information, stating that the following indicators were crucial to any PHC performance assessment: (1) efficient teamwork at PHCs; (2) the presence of opportunities for healthcare providers to enhance their skills and knowledge advancing their professional careers; (3) job satisfaction; (4) effective administration of PHCs in terms of safety and security, especially in dealing with potential violence; (5) good community relations developed from positive attitudes of healthcare professionals and patients. The study provided vital, and previously missing information on how PHC could be assessed from a more realistic grassroot level. It was concluded that these PHC performance indicators could be considered the 'missing link' in PHC assessment, since they are deemed important by providers and did not coincide with the WHO aspects and the PHCPI performance assessment framework. 
Chapter 5 aims to identify PHC performance indicators and the various factors that affect performance, from the perspectives of mid-level healthcare managers. In-depth interviews with 8 managers from taluk/ block and district level in the Bengaluru urban district resulted in indicators for PHC performance assessment. Apart from output indicators of the centres, managers emphasised that PHC environment and rapport with patients should be considered as PHC performance indicators. The managers identified doctors as key persons for PHC performance. According to the managers, doctors not only contributed to the standard output indicators by delivering preventive and curative services at PHC, but also had multiple responsibilities as able leaders. The managers also specified the PHCs' dependence on the health system and the local political bodies to function in the sociopolitical atmosphere. The managers also identified themselves as PHC leaders but in a limited role in the overall PHC performance, as centre supervisors. Managers also emphasised that doctors were responsible for the overall harmonisation of all the mentioned components and dependencies of PHC functioning. They concluded that doctors at PHCs, as able leaders, played a significant role in PHC performance. It was concluded that in-depth interviews with mid-level managers in Bengaluru district showed that PHC performance indicators consisted of targets set by the department, good PHC environment, an established rapport with the patients, doctors' leadership, support from the health system and local politics, socio-political coordination and the supporting supervision role of managers. The managers conveyed that for them PHC performance was synonymous with good leadership by the doctors at the PHCs, plus the doctors' ability to balance between the health system and local politics. While placing the responsibility for PHC performance on doctors, the managers identified their own contribution as supportive supervisors and as change agents.

Chapter 6 explores the patterns in the performance of three PHCs with a low, medium and high number of deliveries regarding (1) the centre's availability of infrastructure and services; (2) providers' well-being (quality of life and work engagement); and (3) the patient view. To tap the patient view, a newly developed measure 'Questionnaire for Patient's Perspective on Performance of Primary Healthcare Centres' (Q4PHC) was used, based on the results from the study in Chapter 3. The Q4PHC consists of 41 items in 7 subscales and showed to have high overall reliability with Cronbach's alpha score of 0.938 . The results of the study showed that the centre with the highest infrastructure and service availability had significantly less provider quality of life and work engagement $(\mathrm{p}<0.000)$. Further, the PHC with the least delivery had significantly higher PHC performance using the Q4PHC score in comparison with high and medium delivery PHCs $(\mathrm{p}<0.000)$. It was concluded that PHC performance as studied in the three urban PHCs seems to be a trade-off between the available infrastructure and the quantity of services delivered that could be achievable by maintaining adequate provider well-being with acceptable PHC performance from the patient's perspective. The new Q4PHC seems promising to measure patient perspective of PHC performance 
in an Indian context. The seven scales not only provide an opportunity to assess but also to improve PHC service delivery. The PHC performance assessment from multiple perspectives offers a realistic view of the centre encompassing the local context, which is valid even though agreement on the various perspectives could not be obtained.

In Chapter 7 a discussion is provided on the main findings of this thesis, along with the methodological considerations and implications of research and practice. This thesis contributes to the understanding of the measures of performance assessment, their interrelationship so as to create a realistic picture of a $\mathrm{PH}$ centre when assessing performance. We conclude that the concept of PHC performance entails views that vary differently by various stakeholders. There were some commonalities in the fact that all the stakeholders considered the doctor to be central to PHC performance, along with provision of appropriate resources and support from the health system, with positive synergistic local political circumstances. All the stakeholders laid a great emphasis on the doctor's ability in providing and organising services by way of good leadership skills in ensuring team work not only within the centre but between the centre and the local socio-political environment as well as with the health system.

This thesis emphasises the applicability of provider wellbeing as the quality of life and their work engagement in providing a clear vision on the local work context, its toll on the provider and may be how to work towards sustainable PHC performance. The strength of this thesis lies in including all the stakeholders at a PHC, because views on the same function differed among stakeholders, providing an internal and external perspective on various functionalities at the centre. The study utilised qualitative methods to get insights into the beliefs, claims, and concerns of various stakeholders involved in healthcare delivery, making it a holistic approach. Also, the quantitative comparison of PHCs by the indicators of PHC infrastructure, availability and service delivery, patients' evaluation of PHC performance, and providers' well-being, gave a multipronged approach to the PHC performance assessment.

We conclude that the concept of what PHC performance entails was viewed differently by various stakeholders assessing the centres. However, they mentioned all the components of the system: structure, process, output and outcome. There were some commonalities in the fact that all the stakeholders considered the doctor central to PHC performance, including appropriate resources and support from the health system, and local political circumstances. Assessing the centres based on the availability of infrastructure and services, provider well-being and patients' assessment of the PHC (Q4PHC) depicted a realistic evaluation offering a complete picture of the PHC. 
In conclusion, the findings of this thesis have implications for future research and practice. Further research is indicated to enable the system to assess the centres from perspectives of key stakeholder to develop a realistic assessment, so as to offer centre-specific or even personal interventions to enhance performance, which would work towards sustainable PHC performance. 
Valorisation 


\section{Valorisation}

The research conducted in the course of this Ph.D. has produced knowledge for health system strengthening, particularly for PHC performance assessment. Review of empirical literature helped identifying the topics a comprehensive assessment of PHC should consist of, and which can be achieved by integrating personnel performance with that of centre performance. Both sides of services delivery, namely providers and centre managers as well as patients' perspectives, were identified as critical for arriving at a comprehensive assessment plan. The proposed measures for the assessment of Primary Healthcare Centre (PHC) performance in low- and middle- income countries (LMIC) represent the perspectives of key stakeholders. A new measure, the 'Questionnaire for Patient's Perspective on Performance of Primary Healthcare Centres' (Q4PHC) was developed based on the patient perspective and validated. Further, this study contributed to shedding more light on the cultural context of performance assessment for PHCs in India.

\section{Societal Relevance}

The design and delivery of the public health services would be able to achieve its goals when the society and the community not only willingly utilize the services but are also satisfied with the services, and are able to be healthy and enjoy feelings of well-being. This research provides very useful insights from the patient's perspective, on which PHCs should focus while delivering their services. Expectations and benchmarking of community experience would be enhanced if focused on the nine critical areas for PHC performance that emerged from this research. They are: (1) availability of rich and diverse services; (2) presence of effective diagnostic services; (3) cost and availability of medicines; (4) quality of the infrastructure; (5) cost of care; (6) behaviour; (7) communications skills; (8) punctuality of staff; and (9) the effectiveness and organization of care.

\section{Public Healthcare Personnel Well Being}

The research outcomes showcased the providers' perspective as the 'missing link' between what providers are required to meet to fulfil the patients' needs while enhancing the delivery of care and thus improving the health of the population. As other research shows, the providers' quality of life and their work engagement both have a direct impact on PHC performance. ${ }^{1}$ Factors such as worklife balance, stress management, support from the health system are very critical to maintain the workforce well-being and motivation. ${ }^{2,3}$ In the much-stressed public health system in India with limited resources, vacancies and lack of recognition of the personnel, the research output identifies specific areas for improvement. The PHC performance assessment framework should include factors such as provider's personal aspects of comfort/safety, resource availability and its interactions with 
the work environment. ${ }^{4}$ Often productivity of the PHCs is measured in terms of increased service delivery or utilization and achieving of the targets set by the health department, and the research in this thesis showed that this is not sufficient. If providers' quality of life, satisfaction, work-life balance and motivation are negatively affected while working in the system, its negative implication on quality of services, continuity and in turn patient satisfaction is obvious. ${ }^{1}$

\section{Health System Strengthening in India}

There are three important ways this research can help assist the Health System Strengthening in India, especially at PHC level. Nearly 70 percent of Indian population live in the rural areas and their first line of healthcare services is through the PHCs. With the National Health Mission's focus on urban health, PHCs again are the focus of the health system considering that a large population of migrant labour and urban poor would need preventive, promotive and basic curative care at the urban PHCs. ${ }^{5}$ Thus the target for implementing the results of this research is the health system in India, which would benefit in the following ways contributing towards system strengthening.

First, the insights gained by research comprehensively showed that the mid-level managers in the system rightly identified the PHC targets set by the department along with good PHC environment, rapport with the patients, doctors' leadership, support from the health system and local politics, socio-political coordination and the supporting supervision role of managers are critical measures of PHC performance. The managers conveyed that for them, PHC performance was synonymous with good leadership by the doctors at the PHCs, plus the doctors' ability to balance between the health system and local politics. While placing the responsibility for PHC performance on doctors, the managers identified their own contribution as supportive supervisors and as change agents. Training of doctors and managers in leadership, soft skills, community engagement, negotiating and creating win-win situation with local leaders and local administration in order to create a more cooperative and friendly environment to achieve results are implicated.

Second, the newly developed tool 'Questionnaire for Patient's Perspective on Performance of Primary Healthcare Centres' (Q4PHC) that can be used to measure patient perspective of PHC performance in an Indian context is quite promising. The seven scales not only provide an opportunity to assess but also to improve PHC service delivery. The PHC performance assessment from multiple perspectives offers a realistic view of the centre encompassing the local context, which is valid even though agreement on the various perspectives could not be obtained.

Third, the health system strengthening could consider balancing the providers' quality of life and engagement with those of patient's perceptions as well as the targets set. In this study, a trade-off 
between quality of care as experienced by the patients and wellbeing of the providers and productivity measured at the centre level (Chapter 6) was noted. These measures from multiple stakeholder perspectives which could be considered as innovation in the concept of PHC performance evaluation should be adopted for performance assessment of PHCs and hence policy changes are implicated to assess the centres. This uptake would be possible with the orientation of the policy makers on the utility of multiple stakeholder evaluation of the PHC depicting the complete assessment. However, further research should also be on costs involved in the adoption of this multiple stakeholder evaluation and its outcome on the quality of service and provider wellbeing along with the sustainable care at the PHC, which is beyond the scope this thesis.

\section{Knowledge dissemination taken place}

Knowledge dissemination of the research findings to various groups of public health professionals was undertaken:

- First, the main findings of the Chapter 6 were presented in $28^{\text {th }}$ International Conference on Research in Life-Sciences and Healthcare held in Kuala Lumpur, Malaysia on $30^{\text {th }}$ and $31^{\text {st }}$ of December 2019, which was attended by an international research community from mostly South Asia, South East Asia, and Africa.

- Second, the main findings of Chapter 7 (general discussion) consisting of all the main findings of the study was presented in $3^{\text {rd }}$ Global Public Health Conference conducted at Bangalore, India, on $13^{\text {th }}$ and $14^{\text {th }}$ February 2020. The conference was attended by professionals from science and health system, consultancy firms, NGOs, researchers and practice organizations from all over the world.

\section{Way forward}

It is envisaged that the this thesis will be presented to the following Health authorities in Karnataka: Additional Chief Secretary of Health and Family Welfare, Government of Karnataka; Commissioner of Health and Family Welfare Services, Government of Karnataka; Mission Director, National Health Mission, Government of India; Regional Director, Ministry of Health and Family Welfare, Government of India; State level authorities (Director and Joint Directors). This is one way forward for encouraging the Indian policy makers to initiate more research on standardizing of comprehensive performance measures for PHCs assessment and further policy changes in this direction.

Way forward beyond India 
The conclusions of this PhD-thesis are also valuable for other LMICs. The multi-stakeholder PHC evaluation addressing the nine critical areas of PHC performance should be considered with locally applicable measures, to enable holistic evaluation of PHC performance. Incorporating these perspectives in the framework of the Primary Healthcare Performance Initiative ${ }^{6}$ is also recommended.

\section{References}

1. Halbesleben J R B. The consequences of engagement: The good, the bad, and the ugly. European Journal of Work and Organizational Psychology. 2011;20(1):68-73. DOI:10.1080/1359432X.2010.514327

2. Salvador-Carulla L, Lucas R, Ayuso-Mateos J L, Miret M. Use of terms "Wellbeing" and "Quality of life" in health sciences: A conceptual framework. European Journal of Psychiatry.2014;28(1):50-65

3. Shuck B, Reio Jr T G, Employee engagement and well-being: A moderation model and implications for practice. Journal of Leadership and Organizational Studies. 2014;21(1):43-58. Doi: $10.1177 / 1548051813494240$

4. Guba E G, Lincol Y S. Fourth Generation Evaluation 1989, 21-49, Sage Publication.

5. National Health Policy 2017. Ministry of Health and Family Welfare, Government of India. https://mohfw.gov.in/sites/default/files/9147562941489753121.pdfAccessed on 25th November 2019.

6. Veillard J, Cowling K, Bitton A, Ratcliffe H, Kimball M, Barkley S, Mercereau L, Wong E, Taylor C, Hirschhorn L R, Wang H. Better measurement for performance improvement in Lowand Middle-Income countries: The primary health care performance initiative experience of conceptual framework development and indicator selection. The Milbank Quarterly.2017;95(4):836-883 
Acknowledgement 


\section{Sometimes when you're in a dark place you think you've been buried, but actually \\ you've been planted.}

\section{Christine Caine}

Completion of this thesis could only be possible with the guidance of my supervisors, help and support of my family members and friends. The journey of research has been a great learning experience for me, both professionally and personally.

Foremost, I would like to express my sincere gratitude to my supervisors Prof. Onno Van Schyack, Department of Primary Care, Prof. Anja Krumeich, Department of Health and Ethics, Prof. Angelique de Rijk, Department of Social Medicine, CAPHRI, Maastricht University and Prof. Usha Manjunath, Director, Indian Institute of Health Management and Research, Bengaluru for their continuous support, knowledgeable discourse, patience, motivation, enthusiasm, and cooperation during my $\mathrm{PhD}$. Their guidance helped me throughout my research and writing of this thesis. I could not have expected to have a better supervisors and mentors than them for my PhD. I greatly appreciate their confidence in me during the writing of the thesis, welcomed my questions readily, and cultivated the scientific viewing the issues on multiple prospects. Their vision, critical thinking and guidance abilities are unique.

A special thanks to Prof. Anja Krumeich for believing in my research topic and providing constant guidance.

I wish to express my gratitude to Prof. Onno van Schayck and Dr. H Sudarshan, Founder, Karuna Trust, Bengaluru for supporting me during the application for the NUFFIC grant.

I'm grateful to Prof. Usha Manjunath for believing in me, being my mentor and consistent support.

I thank NUFFIC grant (CF11830) for the support and funding provided that has contributed for the successful execution of this research.

I thank the Ethics Review Committee of Manipal University for providing inputs on the protocol of the study and approving the study.

I thank the evaluation committee for showing interest in my work and taking the time to review my thesis. 
Words are not enough to thank all the study participants, who form the key stakeholders of the Urban Primary Healthcare Centres in Bengaluru Urban districts, for contributing in this study, sharing their claims, concerns and beliefs thereby leading to the success of this study.

I thank Dr. Syam Vasudeva Rao, Technical Director, Maastricht Education and Research Centre, Bengaluru for introducing me to the world of research at Maastricht University.

I thank Dr. Aruna, previous Director, State Institute of Health and Family Welfare, Bengaluru for her support that motivated me in continuing this research.

My sincere thanks to Dr. Parimala S Maroor, Project Director-Reproductive and Child Health, Department of Health and Family Welfare Services, Bengaluru, for her motivation, guidance and continuous support.

I thank my friends Dr. Sowmya, Dr. Mamatha, Dr. Bharathi and many others for their continuous support and words of encouragement.

I thank my parents for their support and being with me when I needed the most. I thank my husband for his continuous encouragement and cooperation. I thank my daughter Rajasrre, for her love and being a source of inspiration. 
About the Author 
Rajeshwari Bangalore Sathyananda was born in Bengaluru, Karnataka, India on $3^{\text {rd }}$ of October 1978. After finishing her schooling and pre-university education, she graduated as a Dental Surgeon from Rajiv Gandhi University of Health Sciences, Bengaluru, Karnataka, India in 2002. She was a clinician for about 10 years and later pursued higher studies to complete Post Graduate Diploma in Health Promotion from National Institute of Health and Family Welfare, New Delhi and Master's in Philosophy in Hospital and Health Systems Management from Birla Institute of Technology and Science, Pilani, Rajasthan, India. After finishing her post-graduation, she worked on various research projects in health care and hospital management. She has independently managed multiple healthcare projects for a duration of 10 years.

She received NUFFIC Fellowship (2016-20) and started her PhD at Department of Primary Care, Care and Public Health Research Institute (CAPHRI), Faculty of Health, Medicine and Life Sciences, Maastricht University, The Netherlands in 2016. Her research was supervised by Prof. Anja Krumeich, Department of Health Ethics and Society, CAPHRI; Prof. Usha Manjunath, Hospital and Health Management, Institute of Health Management Research, Bengaluru, India; Prof. Angelique de Rijk, Department of Social Medicine, CAPHRI; and Prof. Onno Van Schayck, Department of Primary Care, CAPHRI, Faculty of Health, Medicine and Life Sciences at Maastricht University. Her research focussed on the measures and perspectives of performance of Primary Healthcare Centres (PHC) by various stakeholders of the centres. This research forms a component of Health Services Research under the area of Public Health. She compared PHCs based on the availability of infrastructure, services delivered, provider's wellbeing and patient's evaluation of the centres by developing a new questionnaire.

She works as 'State-Coordinator' at State Institute of Health and Family Welfare, Bengaluru, training wing of Health and Family Welfare Services, Government of Karnataka. Her work at the institute consists of state level management of multiple teaching and training programs; as well as planning, executing, monitoring and evaluating various research activities. Her interests include health services research, epidemiology, health promotion and health technology assessment.

She is blessed with a daughter 'Rajasrre', who is a great source of strength and motivation.

She loves swimming, cycling, travelling and being in nature. 
